UNIVERSIDAD NACIONAL DE LA PLATA FACULTAD DE CIENCIAS VETERINARIAS

Trabajo de tesis realizado como requisito para optar al título de DOCTOR EN CIENCIAS VETERINARIAS

\title{
Evaluación del comportamiento
}

\section{materno en cerdas. Componentes}

\section{genéticos y ambientales}

AUTORA: ARROYO, Paula

\author{
DIRECTORA: ANTONINI, Alicia Graciela \\ CO-DIRECTOR: FERRARI, Héctor Ricardo \\ LUGAR DE TRABAJO: Instituto de Genética Veterinaria \\ MIEMBROS DEL JURADO: GIOVAMBATISTA, Guillermo \\ REBUELTO, Marcela \\ WILLIAMS, Sara
}


Dedicatoria

A mi mamá, Adriana, a mi papá, Carlos y mis abuelos, Emilia y Juan 


\section{Agradecimientos}

A mi directora por haberme brindado el espacio y la oportunidad de transitar este camino de inicio en investigación y docencia. Gracias por haberme abierto las puertas de su equipo de trabajo.

A mi co-director por haberme guiado, aconsejado y contenido en los distintos momentos atravesados durante la realización de este trabajo.

A Marcela y Guillermo Lloveras por haberme permitido realizar el trabajo experimental con los animales pertenecientes a una de las granjas de la empresa Ceres-Núcleo genético porcino. A Omar y Norberto por haberme brindado su ayuda y paciencia durante la realización de mis tareas.

A mi familia, por acompañarme, apoyarme y alentarme en cada etapa de este trabajo.

A mis amigos, porque sin ellos no hubiera podido atravesar esta etapa, en especial a mis orejas cada día, Agus, Guille, Lau, Dani, Agus I, Caru, Co, Ro y Maru. A mi consejera objetiva y con experiencia en estas tareas Mari S. A Maxi por haber acompañado estos años a pesar de la distancia.

A Sofi, Sebas, Maca, Ruben y Miguel por haberme ayudado con el eterno pasaje de datos.

A la D.G Agustina Contreras por el diseño y realización de las distintas imágenes y esquemas utilizados en esta tesis. 
A Celes, Miguel R, y Paula R por haberme alentado y aconsejado en esta última etapa.

A Fran, Ro, Romi D, Leandro, Maca, Juli, Vivi, Azu, Lu, Romi, Gra y Silvia por tantos momentos.

A la gente de la cátedra por haberme tenido paciencia y aconsejado, gracias Ana, Juana, Sebas, Estu, Tati, Dante, Yami, Caro R, Mari y Caro C.

A todas y cada una de las personas que estuvieron acompañando, aconsejando o ayudando con alguna de las tantas partes que tuvo este trabajo. A cada una de las personas que estuvieron, están y estarán presentes siempre en cada diseño, ensayo, y página de mi vida. 


\section{Publicaciones parciales de la tesis}

Arroyo, P; Ferrari, HR; Antonini, AG "Estudio del comportamiento materno en cerdas. Componentes genéticos y ambientales" Jornada de Ciencia y Técnica de la FCV de la UNLP. Noviembre de 2014.

Arroyo, P; Ferrari, HR; Antonini, AG; "Un bienestarista perdido en producción: Una crítica ético-metodológica a técnicas descriptivas en contexto ganadero". XVI Jornadas de divulgación técnico-científica en Veterinaria. Casilda. Septiembre 2015.

Arroyo, P; Ferrari, HR; Antonini, AG. "Evaluación del comportamiento materno en cerdas: componentes genéticos y ambientales”. I Jornadas de Divulgación del IGEVET. La Plata. Diciembre. 2015

Arroyo, P; Ferrari, HR; Antonini, AG; "Asociación entre comportamiento y productividad. Primeras aproximaciones"; XIII Congreso Nacional de Producción Porcina y VIII Congreso de Producción Porcina del Mercosur, Resistencia. Agosto de 2016.

Arroyo, P; Nietto, SA; Bertini, SS; Ferrari, HR; Antonini, AG; "Estudio del comportamiento de hembras porcinas en lactancia. Primeras Aproximaciones"; XVI Jornadas de Divulgación técnico-científicas en veterinaria. Casilda. Septiembre. 2016.

Arroyo, P; Ferrari, HR; Antonini, AG; "Etograma parcial de hembras porcinas en lactancia"; IV Jornadas de difusión de la investigación y extensión. Esperanza. Noviembre. 2016

Arroyo, P, Ferrari, HR, Antonini, AG; "Evaluación del comportamiento materno en cerdas. Componentes genéticos y ambientales: Avances en el tema". Segunda Jornada de Divulgación Científica del IGEVET. La Plata. Diciembre. 2016

Arroyo, P; Nietto, SA; Ferrari, HR; Antonini, AG. "Evaluación del comportamiento en cerdas lactantes. Posibles asociaciones" XVIII Jornadas de divulgación técnica-científica 2017. Casilda 2017

Arroyo, P; Nietto, SA; Ferrari, HR; Antonini, AG. "Diferencias conductuales en dos razas de cerdas en lactancia" XLVI Congreso Argentino de Genética. Catarmarca. 2017.

Arroyo, P; Ferrari, HR; Antonini, AG. "Tesis: Comportamiento materno en cerdas. Componentes genéticos y ambientales". III Jornadas de divulgación científica del IGEVET. La Plata 2017. 
Arroyo, P; Ferrari, HR; Antonini, AG. "Diferencias conductuales en hembras porcinas en lactancia". Revista Veterinaria Argentina. Vol XXXV. $N^{\circ}$ 358. Año 2018. ISSN 1852-317X

Arroyo, P; Ferrari, HR; Antonini, AG. "Comportamiento en cerdas: Impacto de factores genéticos y ambientales". RedVet. Vol 19. №2. ISSN 16957504. 2018

Arroyo, P; Ferrari, HR; Antonini, AG; "Etologia: Análisis en Producción Porcina confinada". ANALECTA VET 2018; 38(1): 2332 Impresa ISSN 03655148 Electrónica ISSN 15142590 doi.org/10.24215/15142590e022

Arroyo, P; Ferrari, HR; Demyda-Peirás, S; Antonini, AG. "Análisis del número de partos y variaciones en la conducta de las reproductoras". IX Congreso de Producción Porcina del Mercosur. Córdoba. Agosto 2018.

Arroyo, P; Ferrari, HR; Antonini, AG. "Modificaciones en la conducta de la reproductora por una práctica frecuente en sistemas intensivos confinados". IX Congreso de Producción Porcina del Mercosur. Córdoba. Agosto 2018.

Arroyo, P; Ferrari, HR; Antonini, AG. "Maternal behavior in Sows. Differences between races" XLVII Congreso Internacional de Genética. Foz do iguazu. 2018.

Arroyo, P; Corva, S; Ferrari, HR; Antonini, AG. "Sow behavior expression: Adoptions effect". International Journal of Sciences. En prensa. Aceptado para su publicación 9/12/18. elSSN 2305-3925. 


\section{Índice}

Abreviaturas y símbolos VIII

Resumen 1

Abstract 3

Introducción

$\begin{array}{ll}\text { Filogenia: evolución de la conducta } & 16\end{array}$

Ontogenia: Historias de vida y producción 19

Fisiología: Aspectos causales del comportamiento 19

Efectos en la supervivencia y reproducción $\quad 21$

Necesidades comportamentales y comportamiento innato. Un 25 aporte de la etología al problema del bienestar animal

Una lectura etológica de las estereotipias y el enriquecimiento $\quad 32$ ambiental

$\begin{array}{ll}\text { Objetivo general } & 34\end{array}$

$\begin{array}{ll}\text { Objetivos particulares } & 34\end{array}$

$\begin{array}{ll}\text { Hipótesis } & 35\end{array}$

Capítulo 1: El comportamiento y su estudio 36

$\begin{array}{ll}\text { Introducción } & 36\end{array}$

Materiales y métodos $\quad 40$

Resultados $\quad 43$

Discusión 
Capítulo 2: Factores que afectan la expresión de las conductas 60

Capítulo 2.1: Efecto de los factores relacionados con el manejo 60 sobre el comportamiento

$\begin{array}{ll}\text { Introducción } & 60\end{array}$

Materiales y métodos $\quad 65$

$\begin{array}{ll}\text { Resultados } & 73\end{array}$

$\begin{array}{ll}\text { Discusión } & 85\end{array}$

Capítulo 2.2: Efecto de las adopciones sobre la expresión de las 91 conductas

$\begin{array}{ll}\text { Introducción } & 91\end{array}$

$\begin{array}{ll}\text { Materiales y métodos } & 93\end{array}$

$\begin{array}{ll}\text { Resultados } & 94\end{array}$

$\begin{array}{ll}\text { Discusión } & 95\end{array}$

Capítulo 3: Relación entre comportamiento y productividad 98

$\begin{array}{ll}\text { Introducción } & 98\end{array}$

$\begin{array}{ll}\text { Materiales y métodos } & 100\end{array}$

$\begin{array}{ll}\text { Resultados } & 102\end{array}$

$\begin{array}{ll}\text { Discusión } & 108\end{array}$

Capítulo 4: Aspectos genéticos del comportamiento 113

$\begin{array}{ll}\text { Introducción } & 113\end{array}$

Materiales y métodos $\quad 116$

$\begin{array}{ll}\text { Resultados } & 118\end{array}$

$\begin{array}{ll}\text { Discusión } & 121\end{array}$

$\begin{array}{ll}\text { Conclusión } & 125\end{array}$

$\begin{array}{ll}\text { Bibliografía } & 130\end{array}$ 
Abreviaturas y símbolos

NV: Nacidos vivos

NM: Nacidos muertos

mo: Nacidos momificados

PN: Peso al nacimiento

PD: Peso al destete

Dt: Lechones destetados

Mpd: Muertos pre destete

IDS: Intervalo destete-servicio

BA: Born alive (nacidos vivos)

SB: Stillbirth (nacidos muertos)

mu: mummy (momias)

WB: Birth weigth (peso al nacimiento)

WW: Weaning weigth (peso al destete)

WP: Weaned piglets (lechones destetados)

PWD: Pre-weaning deaths (muertes pre destete)

IWH: Interval weaning-heat (interval destete-celo)

CE: Comunidad Europea

Frec: Frecuencia

Desv Estan: Desvío estándar

CC: Condición Corporal

EGD: Espesor de grasa dorsal

$\mathrm{CC}_{0:}$ Condición corporal inicial

$E G D_{0}$ : Espesor de grasa dorsal

$P_{\text {PG }}$ : Prostaglandina F2 $\alpha$ 
$\mathrm{CC}_{1}$ : Variación en la condición corporal

$E G D_{1}$ : Variación en el espesor de grasa dorsal

FPc3: Frecuencia de pautas "de contacto con las instalaciones"

FPc2: Frecuencia de pautas "generales"

TPc3: Tiempo de pautas "de contacto con las instalaciones"

Fmb: Frecuencia de "morder barra o comedero"

Fh: Frecuencia de "hociquear"

Tcf: Tiempo de "arrodillada"

Tc: Tiempo de "caminar"

Tdtp: Tiempo de "descender tren posterior"

Tb: Tiempo de "beber"

Tmb: Tiempo de "morder barra o comedero"

Tp: Tiempo de "pararse"

Fdp: Frecuencia de "de pie"

Fs: Frecuencia de "sentada"

Fc: Frecuencia de "caminar"

Fco: Frecuencia de "comer"

Fo: Frecuencia de "orinar"

Tev: Tiempo de "echada ventral"

Fev: Frecuencia de "echada ventral"

Fol: Frecuencia de "olfatear lechón"

Th: Tiempo de "hociquear"

Tdp: Tiempo de "de pie"

Cant: cantidad

QTL: Quantitative trait locus (locus para un carácter cuantitativo)

$h^{2}:$ Heredabilidad 
Evaluación del comportamiento materno en cerdas.

Componentes genéticos y ambientales

\section{Palabras claves: PORCINOS-COMPORTAMIENTO- LACTANCIA-SISTEMAS CONFINADOS-PRODUCCIÓN- GENÉTICA}

\section{Resumen}

El objetivo del presente trabajo fue observar y describir diversas variables del comportamiento materno, evaluar la posible asociación entre las distintas conductas y la productividad de la hembra y determinar las componentes genéticas de la conducta para poder predecir el comportamiento de las hembras durante la lactancia. Se construyó un etograma de 35 pautas de cerdas en lactancia y luego se procedió a registrar la frecuencia y duración de cada una de las conductas descriptas. Se registraron para cada lactancia los principales parámetros productivos (NV, NM, mo, PN, PD, Dt, Mpd, IDS) de las reproductoras teniendo en cuenta las condiciones de manejo en dos generaciones. El análisis estadístico incluyó el estudio descriptivo de cada variable, los componentes genéticos y ambientales se evaluaron con un Análisis de Varianza y las asociaciones a través de Regresión Binomial Negativa y Jicuadrado. Se hallaron diferencias significativas en las conductas de las hembras según la etapa de lactancia, ubicación de la jaula paridera, si 
habían donado y/o recibido lechones y su estado corporal, entre otros. Se halló asociación entre algunos de los comportamientos y diferentes parámetros de productividad de los animales (por ej. a mayor NV menor frecuencia de pautas de contacto con las instalaciones; mayor IDS mayor tiempo en "morder barra o comedero").

El ambiente materno predestete condiciona el comportamiento de las crías como futuras reproductoras; ya que las cerdas separadas de sus madres de nacimiento presentaron comportamiento diferente respecto a aquellas criadas por su propia madre.

La variación del comportamiento respecto al número de parto, daría soporte al abordaje ontogénico del comportamiento en los animales de producción (segunda pregunta de Tinbergen).

Las diferencias en el estilo de coping realizado por las distintas razas, manifiesta la base genética de este mecanismo de disminución de los efectos nocivos del estrés mediante la conducta. 
Sow maternal behavior evaluation. Genetics and environmental components

\title{
Key words: SWINE-BEHAVIOR-NURSING- CONFINED SYSTEMS- PRODUCTION-GENETICS
}

\begin{abstract}
The aims of this work were to study different parameters involved in sow maternal behavior, evaluate the possible association between such parameters and sow productivity during lactation, and detect genetic components of behavior in order to predict sow maternal behavior during lactation. We developed a 35-item ethogram describing sow behavior during lactation and registered the frequency and length of each of the described items. We recorded the following productive parameters during each lactation period (BA, SB, mu, WB, WW, WP, PWD, IWH) considering the handling conditions of two generations. Descriptive analysis was used for the variables studied. Genetic and environmental components were assessed with variance analysis, and associations were evaluated with negative binomial regression and $X^{2}$. Differences in sow behavior according to lactation stage, location of farrowing pens, received or donated piglets and body condition were significant. We found association among some behaviors and different productivity parameters, namely, higher number of born alive piglets associated with lower frequency of
\end{abstract}


contact with installations, and higher interval weaning heat associated with greater time biting the bar or feeder.

Pre-weaning maternal environment determined piglet behavior as future breeders; for instance, female piglets removed from their mothers at birth showed a different behavior as compared with those reared with their own mothers.

The changes in behavior observed with regards to the number of sow deliveries would lend support to the ontogeny of behavior approach in production animals (Tinbergen's second questions).

Differences in coping styles among the different breeds showed the genetic basis of this mechanism aimed at reducing adverse stress-induced effects through behavior. 


\section{INTRODUCCIÓN}

La conducta de los animales es una importante variable productiva particularmente en el caso de las madres en sistemas de cría intensiva confinada, por esta razón es relevante considerarla al momento de realizar la selección de los reproductores.

Debido a que la eficiencia de una granja se mide fundamentalmente en los parámetros productivos y reproductivos de las cerdas, la selección de las mismas es de suma importancia para alcanzar los objetivos de la explotación. Este proceso de selección es llevado a cabo basándose en la conformación externa de la cerda y en registros genealógicos, siendo su temperamento uno de los criterios de descarte.

La muerte neonatal significa una importante pérdida económica para los productores porcinos, ya que reduce drásticamente los kilogramos de carne totales producidos por hembra por año. Si bien son muchas las investigaciones llevadas a cabo en el diseño de jaulas parideras para prevenir el aplastamiento de los lechones, son muy pocos los estudios realizados para determinar la base etológica (comportamental) de esta importante causa de muerte.

Dentro de las distintas etapas de producción, la de lactancia es la de mayor vulnerabilidad del lechón, de hecho, es la etapa con mayor porcentaje de mortalidad, siendo el aplastamiento por parte de la madre una de las principales causas de muerte (Garcia Gonzalez y col, 2011). Existen evidencias acerca de que el aplastamiento está significativamente 
relacionado con las diferencias individuales en el comportamiento de la cerda; algunas hembras responden a los chillidos de alarma de sus lechones y se levantan en respuesta a la vocalización de las crías atrapadas, mientras que otras no reaccionan (Wechsler y Hegglin, 1996). A esto se suma que en los sistemas intensivos, en los que alejarse de la cría no es posible, las hembras limitan el amamantamiento parándose, sentándose o echándose ventralmente (Drake y col, 2007), lo que aumenta la frecuencia de situaciones "de peligro" para los lechones.

Los psicólogos definen el comportamiento como una expresión de la interacción entre motivación, patrones innatos de comportamiento, psicología, aprendizaje basado en experiencias previas y factores de contexto o circunstancias (Rayment, 2015).

En animales muchos de los estudios realizados son los asociados con la respuesta al estrés. Este último es el conjunto de cambios fisiológicos (incluyendo la conducta) frente a estímulos adversos. Estos estudios incluyen los destinados a analizar comportamientos de coping, es decir comportamientos dirigidos a reducir el impacto deletéreo de estímulos amenazantes para la aptitud biológica (Rayment, 2015). Koolhaas (1999) define los estilos de coping como un set coherente de respuestas al estrés, comportamentales y psicológicas que son consistentes a lo largo del tiempo y son características a un cierto grupo de individuos. Broom (1991) al hablar de coping, menciona que incluye la regulación normal del estado del cuerpo y la respuesta de emergencia, y que involucre un gasto de energía. 
La historia del estudio del comportamiento ha tenido varias corrientes teóricas y métodos de estudio. El conductivismo sostenía que el ambiente explica todas las diferencias en el comportamiento. Representantes del conductivismo como Watson, Skinner o los Breland explicaron y defendieron los mecanismos estímulos-respuesta, base teórica del condicionamiento operativo.

Por otro lado, etólogos como Lorenz, Tinbergen y Withman, definieron y desarrollaron las teorías de instinto, patrones fijos de acción y la relación de los genes y como la modificación de estos y de sus combinaciones ha permitido afrontar (o no) nuevas condiciones ambientales (Grandin y Deesing, 1998) (Nisbett, 1993) David Wood-Gush fue uno de los pocos científicos en los años '50s en comenzar a aplicar la investigación del comportamiento en animales domésticos (Lawrence, 2008).

El análisis del comportamiento es un estudio complejo en el que se deben tener en cuenta una gran cantidad de factores y posibles causales, y considerar múltiples consecuencias, tanto éticas como productivas. Más allá de que las experiencias previas de cada individuo tienen un importante efecto sobre el comportamiento de los mismos, y que las particularidades de la conducta puedan ser modificadas por el ambiente, estas están fijadas genéticamente (Fajardo-Castillo, 2009). Es por esto que es relevante para la selección de los reproductores determinar su heredabilidad. Es decir, conocer el impacto de los factores genéticos en las diferencias comportamentales halladas en la progenie de las distintas reproductoras. 
Estas diferencias en los estilos de comportamiento de los animales, son lo que se define como Temperamento, el cual es el conjunto de estilos conductuales de un animal, una característica genética controlada por poligenes, altamente influenciada por el ambiente. Su expresión fenotípica es la resultante de un conjunto de comportamientos y sus diferentes estilos que se ven afectados por la organización hormonal, nerviosa y física del individuo y puede evidenciarse como la respuesta comportamental de un animal al manejo producido por el hombre (Piedrafita y Manteca, 2002). Las normas de reacción son el rango de fenotipos que pueden ser producidos por un genotipo dado (Stamps y Groothuis, 2010). El temperamento engloba las conductas de agresión, las cuales reducen el bienestar animal y en general suelen expresarse con heredabilidades que pueden ir de 0,32 (Hellbrügge, 2007) a 0,47(D’Eath y col, 2009), estas estimaciones son medias o altas. Otros componentes del temperamento son las respuestas al aislamiento y al manejo como así también la conducta materna, teniendo en cuenta que esta última es un importante componente de la productividad de la hembra (D’Eath y col, 2009).

Se interpreta como comportamiento materno al conjunto de conductas que realiza la hembra durante la expresión de celo, la gestación y la crianza de los lechones, ya que forman parte del proceso que permitirá a los reproductores dejar descendencia. Lo que otros autores denominan “cortejo", "reproducción” y "crianza”. 
Por otra parte, las experiencias previas son cruciales para entender el comportamiento de los animales (Fraser, 1999). Según Fajardo-Castillo (2009), las particularidades de la conducta del animal están fijadas genéticamente, pero pueden ser modificadas por el ambiente.

El cambio en el acervo génico de los animales domésticos es resultado de las manipulaciones de los criadores y de la selección natural, que mantiene un equilibrio de distintos rasgos (Korte y col, 2005). A su vez, los genes, el efecto materno y el ambiente intergeneracional pueden influenciar el efecto de la selección en cualquier rasgo fenotípico, incluyendo la personalidad (Stamps y Groothuis, 2010).

Hellbrügge en 2007 demostró que existe correlación entre los componentes del temperamento y los parámetros productivos de las hembras, como por ejemplo una hembra altamente agresiva será más reactiva frente a rutinas de manejo, tendrá menor cantidad de lechones nacidos totales, y a su vez mayor tasa de supervivencia de los lechones. Por otra parte Williams (2004) concluyó que la estructura social de las camadas de las que provienen las hembras influye en su performance reproductiva.

Actualmente junto a los estudios e investigaciones medioambientales y de manejo, los estudios etológicos son también importantes para mejorar la eficacia productiva del ganado porcino. El conocimiento de las pautas etológicas, es un paso relevante para la aplicación de medidas de Bienestar Animal, que permitirán mejorar el manejo y conseguir una 
mayor eficacia reproductiva, y por lo tanto una mayor rentabilidad de la explotación.

El Bienestar Animal es el estado de un animal en sus intentos para enfrentar su entorno (Broom, 1986), hace referencia a cuanto se tiene que hacer y al éxito o fracaso en cada tentativa. Es importante aclarar que el Bienestar Animal es una característica propia del animal. Esta característica varía de muy pobre a muy buena (pobre bienestar o muy buen bienestar), y este puede ser medido científicamente, de manera independiente de las consideraciones morales que conlleva. Los animales utilizarán una variabilidad de métodos al intentar acoplar con el medio, y habrá varias consecuencias de la falla en este intento de hacer frente al entorno. De esta manera ninguna de las variables medidas, aisladas, ya sea el conocimiento de las preferencias de un animal o una variable productiva, podrán indicar que el bienestar animal es pobre, y el hecho que una medida se encuentre dentro de los parámetros esperados no significará, por si sola, que haya un buen bienestar (Broom, 1991).

El Bienestar Animal surge como una inquietud del público europeo a partir de la publicación del libro "The Animal Machine" de Ruth Harrison en 1964, respecto a la vida de los animales de producción. Este fue seguido por el informe Brambell, y años más tarde por documentos como "Welfare Quality", proyecto financiado por la Unión Europea acerca de la integración del Bienestar Animal en la cadena alimentaria. Acompañado de una serie de legislaciones al respecto: las directivas del consejo de la Comunidad Europea del 23 de octubre de 2001 (2001/88/CE) y del 9 de 
noviembre de 2001 (2001/93/CE) que modifican la directiva del 19 de noviembre de 1991 relativa a las normas mínimas para la protección de cerdos (91/630/CEE). Dichas normativas se agruparon en la Directiva del 18 de diciembre del 2008 (2008/120/CE).

En la actualidad el bienestar animal como disciplina se ha ido extendiendo y se conocen mejoras en la ganancia diaria de peso, la conversión alimenticia, el rendimiento de la canal y la calidad de la carne, asociadas a animales con buen bienestar animal. Si bien comienza como una inquietud ética y moral, se conoce su importancia económica. Ha avanzado tanto que a partir de enero de 2013 , no está permitido el uso de jaulas individuales de gestación en Europa, debido a que en las condiciones de alojamiento que estas instalaciones brindaban las hembras se encontraban muy restringidas en movimientos.

El bienestar animal es una mezcla de ciencia y valores (Marie, 2006). Ha crecido el concepto de que los animales deben ser tratados en forma moral. El estudio del comportamiento y de cómo el cerebro lo controla, y las grandes similitudes con otras especies ha tenido un impacto revolucionario en las actitudes humanas. Para los consumidores y productores, el concepto de calidad incluye sustentabilidad y que sea aceptable en relación al bienestar animal y el impacto en el ambiente (Broom, 2011).

Una compresión completa del Bienestar Animal requiere conocer 1-Los aspectos científico de los factores que lo afectan. 
2-Las razones éticas y morales de porque se debe respetar el bienestar de los animales.

3-Las fuerzas económicas que llevan a tratar a los animales como se lo hace (Rushen y col, 2008).

El problema con el sufrimiento es que es un estado subjetivo, inaccesible para un observador externo (Bernard, 2007). El comportamiento animal es uno de los mejores indicadores de bienestar animal (Smulders, 2006). El conocimiento de las preferencias a menudo brinda información valiosa acerca de qué condiciones resultarán en un buen bienestar. Por otro lado, los animales que han permanecido mucho tiempo en alojamientos con deficiencia de estímulos, puede que tengan modificaciones psicológicas ${ }^{1}$. Por esta circunstancia, las pruebas de preferencia pueden arrojar resultados que respondan más a esta alteración, que a las mencionadas preferencias. Deben usarse en conjunto con medidas directas de bienestar animal (Broom, 1991).

El aumento del interés en este tema crea oportunidades para que los veterinarios tomen una nueva posición frente a aspectos científicos y tecnológicos, un nuevo rol de líder social y educativo para mejorar la vida de los animales (Fraser, 2010). El personal encargado del cuidado animal debe estar familiarizado con el comportamiento específico de especie para poder intervenir a tiempo, en caso de individuos con pobre bienestar (Salak-Johnson y col, 2010).

Expresión en texto original. 
La percepción del bienestar animal varía dependiendo del contexto. En un estudio realizado al respecto con cerdos en Dinamarca, los resultados arrojaron diferentes percepciones en el público en general y en el sector agrícola (Lassen, 2006). Los científicos que trabajan en este último, por ejemplo, persiguen la eficiencia y la productividad con el objetivo de alimentos más económicos y más saludables, por lo que sus valores están más asociados con dichos objetivos (Hodges, 2006). Entendiendo esto, la Unión Europea, desde el año 2007, implementó pagos diferenciales a los productores que cumplen con los requerimientos de bienestar animal (Vassier, 2008).

Aplicados estos conceptos a los animales que se emplean en investigación, han surgido situaciones específicas del campo. Por ejemplo la implementación de las 3R (Refinamiento, Reemplazo y Reducción) como forma de propiciar el bienestar de los sujetos de investigación. Y para lograr el primero de estos criterios, el refinamiento, es necesario el estudio del comportamiento animal (Cuthill, 2007).

El conocimiento del comportamiento permite mejorar el manejo de los animales utilizados en producción y optimizar su bienestar. La disciplina de las ciencias biológicas que aborda este tema es la etología. Basada en la teoría de la evolución, hace énfasis en cuatro tipos de explicaciones, conocidas como las "cuatro preguntas de Tinbergen", las que se refieren a la filogenia, la ontogenia, la fisiología y el efecto del comportamiento en la supervivencia y la reproducción. Originadas a mediados del siglo pasado 
(Tinbergen, 1963), si bien se han sometido a periódicos análisis y revisiones, (Alcock, 2001;Curio, 1994; Dewsbury, 1999; Duncan, 1995; Hogan, 2015; Stamps, 2003) se siguen empleando con su formulación inicial.

Por filogenia entendemos la historia evolutiva de las características comportamentales en estudio. Esto no es una mera relación histórica, sino que se refiere a los cambios que fueron llevando de una conducta a otra hasta llegar al síndrome de rasgos actuales; en términos de producción esto significa que lo que estamos viendo es el producto de una larga historia de interacciones entre una población y un ambiente ancestral de selección que ya no está presente. Muchas de las problemáticas de bienestar animal se deben a ese desajuste entre las características y el ambiente, las cuales son más fáciles de entender si conocemos esa historia evolutiva.

La ontogenia estudia los cambios de desarrollo en la vida de un individuo de ese síndrome de rasgos. En la etología clínica de los animales domésticos los periodos sensibles en el desarrollo son los momentos cruciales de la ontogenia que determinarán la futura relación individuo entorno. En momentos cruciales de la vida del individuo, ciertos estímulos o circunstancias moldearán las conductas futuras.

Los aspectos fisiológicos de regulación del comportamiento están ampliamente estudiados y son utilizados en la práctica profesional, estos mecanismos constituyen el funcionamiento de los sistemas del cuerpo que llevarán adelante los procesos que se evidenciarán en la conducta. 
Por último se hace referencia a los efectos, en los cambios en la supervivencia y en la reproducción generados por un rasgo conductual. En el caso de los animales de producción, estos dos aspectos están regulados por los criadores en función de los objetivos productivos, pero las conductas de los animales siguen respondiendo a los efectos que tenían en el ambiente ancestral de selección.

¿Son estos cuatro abordajes útiles para la etología aplicada a la producción en porcinos? ¿Las investigaciones en etología pueden aportar a la mejora en las condiciones de crianza? $\mathrm{Y}$, fundamentalmente ¿son relevantes para el bienestar animal?

Tomando la definición de Broom (1991), y entendiendo que la relación con el medio ambiente es mediante el comportamiento, queda establecida la relevancia de la etología con respecto a la importancia de este problema.

Las cuatro preguntas de Tinbergen, en este contexto, son las explicaciones que el etólogo da a la forma en que un animal afronta su ambiente. Si bien algunos estudios focalizan en forma particular sobre alguna de ellas, un estudio exhaustivo, idealmente, podría contestar las cuatro, para un comportamiento.

A mediados del siglo pasado comenzó el interés social por el bienestar de los animales, con el consecuente desarrollo de investigaciones que tenían esta inquietud como eje. Respondiendo inicialmente a un imperativo ético que emergía del público, al conocer este las condiciones de producción, 
fue derivando en la formación de un campo transdisciplinar. En la actualidad incluye estudios de etología, psicología comparada, antropología, sociología y medicina veterinaria, todos contextualizados en desarrollos de filosofía y, en algunos casos, de religión.

Actualmente, los profesionales dedicados a la producción animal han comenzado a identificar la importancia de reconocer la etología como una herramienta útil en la definición de estrategias de manejo en los diferentes sistemas de producción.

Algunas prácticas realizadas de manera "intuitiva" o "empírica" hoy pueden ser identificadas como "la ayuda silenciosa" que la etología ha aportado a cada etapa productiva desde el inicio de la utilización de la cría de animales domésticos, particularmente cuando ésta comienza a hacerse de manera intensiva. Esta ayuda silenciosa generó un conjunto de saberes específicos que, paradójicamente, no se relacionan con esta disciplina. A continuación se propone enumerar los diversos abordajes posibles identificando los distintos desarrollos etológicos implicados en la producción porcina.

\section{Filogenia: evolución de la conducta}

Toda especie doméstica puede reconocerse como producto de tres procesos evolutivos. En un principio, los ancestros silvestres fueron moldeados mediante los procesos de selección natural, como resultado de lo cual las poblaciones desarrollaron y conservaron potencialidades genéticas orientadas a su supervivencia y reproducción. En algunos 
casos, en ciertas poblaciones ocurrió un proceso denominado "autodomesticación": las condiciones ambientales favorecieron una baja en las conductas de agresión llevando a una mayor tolerancia entre los individuos; se cree que fue con individuos de estas poblaciones que se generaron los actuales animales domésticos.

La domesticación es entendida como el proceso de selección, por parte de los humanos, de los individuos mejor adaptados a las necesidades de los productores. Esto llevó a cambios genéticos en las poblaciones, expresados en cambios en las frecuencias de alelos $y$, consecuentemente, de los genotipos que ellos determinan. A diferencia de lo que ocurrió con la selección natural, en la domesticación los cambios se orientaron principalmente a beneficiar a las personas, poniendo a la supervivencia y a la reproducción de los animales a cargo del productor.

Mientras que para un animal silvestre el ser humano, por lo general, es o presa o predador, los cambios ocurridos durante la domesticación hacen que las poblaciones que los sufren sean a veces totalmente dependientes de la conducta humana. Los animales domésticos son más gregarios, menos cautelosos, más juguetones, presentan precocidad sexual, son más receptivos y el ambiente de estos es más estable y predecible. La complejidad cognitiva no ha pasado por cambios especiales relacionados con la domesticación. 
En el cerdo este proceso comenzó hace aproximadamente 9.000 años en el sudoeste asiático. De allí se expandió hacia India, luego al este de Asia y finalmente a Europa.

Gracias al estudio de ADN mitocondrial, Larson y col, en 2005, lograron identificar los principales centros de domesticación del ganado porcino, uno en Asia y dos en Europa (uno en la Península Ibérica, -sur de España y Portugal- y otro en la región del Mediterráneo -sur de Francia, Italia, Grecia, Malta, Austria, Hungría y Bulgaria-).

Debido a una alta proximidad con las personas y a su consecuente selección, se evidencian diferencias en el comportamiento entre las razas, como por ejemplo que la raza Meishan china y la Large White europea presentan distinto comportamiento al amamantar (Manier-Salaün y col, 1991). Hohenshell y col, (1996), concluyeron que la Meishan y las híbridas de 2 razas europeas, Large White y Landrace, lo hacen en las frecuencias de las pautas "arrodillada" y "sentada".

Por su parte, los porcinos que llegaron a América fueron de origen europeo, principalmente de la Península Ibérica, pero también del tronco mediterráneo, y se aparearon de manera no controlada por el ser humano, hasta mediados del siglo XIX. Durante los siguientes 100 años se introdujeron otras razas para absorber al llamado ganado porcino criollo, resultado de los cruzamientos de las primeras líneas genéticas que llegaron.

A la Argentina los cerdos ingresaron por 3 vías: por el Río de La Plata en 1557, desde Paraguay en 1573 y finalmente desde el alto Perú. Estos 
animales se criaron como ganado cimarrón, y se explotaron estas líneas. Los primeros reproductores Landrace se importaron desde Alemania e Inglaterra en 1960 (Revidatti, 2009). Anteriormente, en el siglo XIX, se introdujeron animales provenientes del continente americano y perteneciente a otras razas (Dra Williams, S. Comunicación personal).

\section{Ontogenia: historias de vida y producción}

Un estudio comparativo entre cerdos silvestres y domésticos concluyó que las diferencias en sus capacidades cognitivas se deben a la ontogenia (AlbiachSerrano y col, 2012). Los cerdos frecuentemente se escapaban de los humanos volviéndose ferales y se mezclaban con las poblaciones locales. Esta falta de aislamiento genético completo puede haber mantenido la homogeneidad cognitiva en ambas poblaciones. Es posible considerar que la domesticación haya empobrecido su habilidad para acoplar con el ambiente físico y, por lo tanto, las diferencias observadas no pueden ser atribuibles a procesos de cambios evolutivos. Por lo tanto, estas diferencias no responden al pasado evolutivo de la especie, sino al desarrollo actual de los individuos. En casos como este, la manipulación del ambiente y de la relación humano animal puede llevar a expresiones comportamentales que faciliten el proceso evolutivo, por ejemplo, el acostumbramiento de los animales al contacto con humanos.

\section{Fisiología: Aspectos causales del comportamiento}


Entre la multiplicidad de factores que determinan una conducta existen efectos indirectos que suelen no ser tenidos en cuenta. Por ejemplo, la manera de percibir los colores o las formas determina, en parte, el comportamiento, es decir las variaciones filogenéticas tienen impacto en la manera de expresar un evento observable. De esta manera decimos que los compartimientos típicos de cada especie han evolucionado. En el trabajo de Finlay y col, (2011) se menciona la diferencia en el tamaño del cerebro entre las especies de mamíferos, en sus maneras de percibir formas y, como consecuencia, los distintos comportamientos. Estas percepciones responden a mecanismos y estructuras específicos de cada especie; hablamos entonces de mundo perceptivo o Umwelt.

Se presta aquí atención a un aspecto de esta regulación: la percepción. Los órganos de los sentidos no son ventanas, sino elementos sensibles a determinadas cualidades del entorno. Cada especie tiene los suyos propios, que le son específicos, y que han evolucionado en el ambiente ancestral de selección: son, en cierta forma, el producto de la historia ecológica de la especie, adaptados a maximizar la eficiencia para ese tipo de vida, en un ambiente determinado (Lorenz, 1995).

La percepción, a su vez, es producida por el cerebro (Lorenz, 1995). La dinámica neuronal es el resultado de la suma espaciotemporal de estímulos. Percibir es computar, y ese cómputo es específico de especie, porque el cerebro que procesa los estímulos, y los órganos de los sentidos que los generan, son específicos de especie. A esto lo denominamos Umwelt: mundo sensorial y perceptual propio, característico 
de una especie (Thorpe, 1982). Así, cada individuo percibe el mundo de una manera que le es propia, y como la conducta la dirige hacia lo que percibe, vive en un mundo propio. En el caso que nos ocupa, en los cerdos se distingue el olfato. Probablemente existan feromonas con mensajes muy específicos. Podría haber una relacionada con la sumisión. Si se colocan gotas opacas en los ojos de los animales no cambia la conducta social, pero se observan cambios cuando se produce anosmia (Jensen, 2004). Sin embargo, existen señales visuales específicas en jabalíes y cerdos domésticos, como por ejemplo posturas de las orejas, cola o cuerpo. Orejas hacia atrás sobre el cuerpo comunican temor, cola rígida y hacia arriba, peligro y cola caída, sumisión. También emplean posturas corporales: inclinar la cabeza a un lado es sumisión y arquear el lomo es amenaza. La visión es también modulada por su anatomía, ya que detrás de la cabeza tienen una zona ciega, que abarca un ángulo de 15 grados a cada lado del eje del cuerpo y, por delante, una de visión binocular, de 25 grados a cada lado del eje del cuerpo (Grandin, 1980). El oído cumple un papel en la estructura regulatoria. Tienen un repertorio de llamados vocales. Uno de alarma, cuando el individuo está en peligro, por ejemplo, al oír a un perro. Responden repitiendo la llamada, permaneciendo muy quietos o huyendo. Emiten gruñidos de contacto, chillidos de sumisión, llamadas a la madre y gemidos de lactación (Jensen, 2004). Entonces, el mundo del cerdo no es el nuestro ni el de un perro: es el que sus sentidos pueden registrar y su cerebro procesar. 


\section{Efectos en la supervivencia y la reproducción}

En la fase de lactancia, o etapa de maternidad, en las granjas, en las primeras 24 horas posparto, luego de haber calostrado, se realiza una práctica denominada adopción cruzada, en la cual se equiparan en cantidad y peso los lechones de las camadas de las distintas hembras que parieron.

Debe ser en este periodo, debido al troquelado o impronta madre cría, periodo ventana en el cual se realiza el reconocimiento de uno por parte del otro en ambos sentidos, el cual será permanente. Constituye el proceso por el cual ciertos estímulos se asocian para provocar determinadas conductas (Lorenz, 1937).

Durante esta etapa se observa la comunicación entre la madre y la cría (entendiendo a la comunicación como el proceso por el cual un actor influencia a un reactor, según Tinbergen 1939, mediante señales). Dicho proceso se pone en evidencia mediante el cambio de frecuencia del sonido emitido por la hembra, obteniendo como resultado que la cría adopte el comportamiento de mamar (Jensen, 2004).

La competencia de los lechones por las tetas craneales para mamar puede recibir una lectura desde la etología. ¿Cuáles son los efectos en la supervivencia y la reproducción de esta conducta? (cuarta pregunta de Tinbergen). Básicamente, lo que se analiza es que cada lechón se “apega” a una teta, y se disputan las craneales, observándose lechones más grandes en las mamas torácicas, y algunos en 2 mamas (Hartsock y Graves, 1976). Esto se hace en el contexto de una así llamada "carrera 
armamentista": nacen con 8 dientes agudos orientados hacia lateral ya en condición de infringir cortes durante las interacciones agonísticas con otras crías (Fraser y col., 1995).

Existen diversos argumentos que intentan explicar estas observaciones. En primer lugar, desde el punto de vista nutricional, las tetas craneales proveerían más leche, en especial, más calostro. Esto resulta no ser así (Fraser Rushen,1992; Orihuela-Solano, 1995). En segundo lugar, las posibilidades de supervivencia, ya que, en las tetas caudales, las crías pueden ser aplastadas al sentarse la madre (Fraser, 1990; Fraser y col., 1995).

A su vez, la defensa de las tetas de los "ladrones de leche", permite expulsar a los individuos de otra camada que tratan de mamar de una hembra que no es su madre (Fraser, 1991). Un estudio muestra que los desplazados no pierden peso y los desplazadores no lo ganan (IIIman y col., 2007). Esta es, entonces, un área pendiente de investigación.

Otra teoría respecto a las peleas de los lechones sostiene que las hembras paren, en promedio, un $20 \%$ más de crías de las que sobrevivirán, entendiéndose la competencia como una estrategia para disminuir la cantidad de lechones con el fin de no comprometer el ciclo reproductivo siguiente. Esto, en el contexto de la producción porcina actual, se ve compensado en la mayor cantidad de mamas que poseen las cerdas y en el manejo en el parto y periparto que aumenta la supervivencia de los lechones (Fraser, 1991). Por último, otra teoría respecto a la funcionalidad de la presencia de los dientes filosos en los 
neonatos es que estos sirven para romper la placenta, aspecto irrelevante si consideramos que otras especies no los poseen y son capaces de liberarse de las membranas placentarias (Fraser y Thompson, 1991).

Continuando con el acto de amamantamiento, se puede analizar el masaje de las mamas por parte de los lechones. Dostalkova y col., (2002) desarrollaron un modelo matemático con el fin de entender la coevolución o evolución conjunta del masaje de tetas y la provisión de leche. En este trabajo plantearon cómo el aumento en la performance relativa de un individuo tiene una relación inversa con la performance grupal, por lo que la selección basada en el grupo disminuye los comportamientos competitivos. De esta manera, y debido a los objetivos de los programas de selección, la evolución podría conducir a disminuir el comportamiento de "súplica" (masaje de mamas por parte de los lechones).

Son dos protagonistas de esta interacción, la madre y las crías. En el caso de la madre, la respuesta a la conducta de las crías tiene efectos en la reproducción y, en el caso de las crías, en la supervivencia; es decir, todos, madre e hijos tienen el mismo objetivo: que estos últimos sobrevivan. Más tarde, se observa el llamado "conflicto madre-cría", en el que los requerimientos de los lechones comienzan a dejar de ser prioridad para los progenitores, para quienes resulta más eficiente producir nuevas crías. Para ejemplificar esto mencionaremos el hecho que cuanta más cantidad de leche produce una hembra, más se compromete su futuro reproductivo, ya que se prolongará el intervalo destete celo. Es por esto 
que el acto de amamantamiento es finalizado por la hembra en el 30-50 \% de los casos en la primera semana (Spinka y Algers, 1995).

\section{Necesidades comportamentales y comportamiento innato. Un aporte de la etología al problema del bienestar animal}

Respecto del comportamiento, una herramienta de análisis pertinente y sumamente útil es el concepto de necesidad comportamental, ya mencionado por Thorpe en el informe Brambell (1965).

Veamos, por ejemplo, el análisis de Jensen y Toates (1993). Según estos autores, los animales tienen necesidades comportamentales, además de las más obvias necesidades fisiológicas a las que el comportamiento atiende. Este concepto se basa en las teorías de Lorenz (1974) que plantea que la energía específica de acción puede crecer dentro del animal si este es privado de los estímulos liberadores (llave) relevantes.

En el modelo psicohidráulico de Lorenz, el cual explica el "comportamiento instintivo", el autor menciona cómo ciertos estímulos, llamados estímulos llave, actúan sobre los mecanismos desencadenantes innatos, los cuales dispararán las pautas fijas de acción, que son aquellas que se dan siempre de la misma manera. Mediante este proceso explica cómo, al transcurrir cierto tiempo sin que se desarrolle una pauta, aumenta la posibilidad para que esta pauta ocurra sin su estímulo llave. De esta manera, la energía específica para esta acción se va acumulando hasta "rebalsar", es decir, se ejecutará la pauta aún en ausencia del estímulo y ocurrirán los llamados "disparos al vacío". En otras palabras, se 
observará la pauta carente de contexto. Un ejemplo de esto puede observarse en la etapa de engorde de la producción porcina actual, durante la cual se observa la succión de las colas por parte de sus congéneres. En este fenómeno, la pauta de succión se "dispara" aún en ausencia del estímulo "pezón”. De tal manera, la separación de la madre constituye una situación estresante para los lechones, y la ausencia de las tetas maternas se establece como el estímulo principal que provoca el acrecentamiento de la probabilidad de ocurrencia de la succión, y uno de los factores más importantes en el origen de la caudofagia y la succión de parte de las instalaciones.

Si bien el modelo "psicohidráulico" es simple e intuitivo, varias de las interpretaciones realizadas con este método se pierden con mucha frecuencia en los modernos modelos motivacionales que solamente tienen en cuenta la necesidad fisiológica como única fuente del estímulo. Hughes y Duncan (1998) afirman, en forma explícita, que el concepto de "necesidad" etológica puede ser clarificado solamente si se lo puede integrar satisfactoriamente en el contexto de un modelo motivacional.

Estos autores identifican una necesidad como un estado que, si no es atendido, causa sufrimiento a un animal que se evidencia como disturbios comportamentales, con un incremento en el riesgo de enfermedades y/o un perfil hormonal compatible con estrés. El estado motivacional es un estado del sistema nervioso. Algo que tiende a perderse en los modelos es la incorporación expresa de retroalimentación positiva, lo que lleva a cierta persistencia en la liberación del comportamiento. 
Si se deja de lado los modelos basados en energía, se puede hacer una serie de sugerencias sobre las causas, basadas en ellos:

1. un comportamiento es liberado por una combinación de factores internos y externos,

2. cuando un comportamiento se realiza, después de un período inicial de retroalimentación positiva, la motivación se va debilitando progresivamente y el comportamiento se detiene, con independencia de sus consecuencias,

3. durante la no realización de un acto específico la motivación para ese acto se incrementa gradualmente.

Algunos autores han dividido las motivaciones en aquellas que contribuyen a la homeostasis, por ejemplo alimentarse, y aquellas que no, por ejemplo el apareamiento. Se ha argumentado que la primera clase está internamente motivada, mientras que la última lo está externamente; otros proponen que la teoría de la motivación por incentivos puede explicar una gran cantidad de resultados y permite que el sexo y la agresión sean discutidos en el mismo contexto que el comer y beber (Hughes y Duncan, 1998).

En las ramas aplicadas de la etología que se ocupan del bienestar animal, el modelo de Wiepkema (1987) ha ganado influencia. De acuerdo con éste, los animales monitorean continuamente el estado del mundo externo (Istwert) y lo comparan con una representación interna del estado deseado (Sollwert). Cuando hay una discrepancia, se realiza una acción 
para disminuirla. Cuando la discrepancia disminuye, el animal experimenta un sentimiento de placer.

Como en el modelo de Lorenz, se pueden deducir algunas características de los modelos homeostáticos, incluyendo el de Wiepkema (1987):

1. el comportamiento es liberado cuando el valor de una variable de control se aparta de un punto fijo, un óptimo de equilibrio,

2. el comportamiento apaga su motivación reduciendo la discrepancia entre los valores comparados,

3. cuando no se aparta la variable medida de su valor de referencia, el comportamiento no se libera.

En las versiones posteriores, Lorenz cambió levemente su idea de la motivación como un estado interno. Generalmente se utiliza la expresión "necesidades comportamentales" para describir la necesidad de realizar un patrón de comportamiento específico, cualquiera sea el ambiente, incluso si la necesidad fisiológica a la que el comportamiento atiende está satisfecha.

Esto significa que la realización del comportamiento que constituye una necesidad es motivacionalmente diferente de otros comportamientos en el repertorio del animal. Se separan "necesidades" de "lujos". Esto lleva a que el objetivo de la investigación es producir una lista de expresiones comportamentales especie-específicas que deben permitirse cuando el animal está en cautiverio.

Esta definición no aporta al conocimiento de las motivaciones en el comportamiento y hace poco por el bienestar de los animales. Por un 
lado, empezando por Thorpe, están los que opinan que la aproximación de Lorenz es la manera más fructífera de contemplar la motivación. Por otro, hay autores que rechazan la existencia de un crecimiento interno de la motivación, apoyándose en modelos como el de Wiepkema (1987). Por ejemplo, Baxter (1983) propone el concepto de "necesidad psicológica" como una alternativa, significando que los animales tienen objetivos para sus actividades y, si estos pueden ser alcanzados sin que el animal actúe, el comportamiento nunca es liberado (disparos al vacío). Son dos posiciones extremas, en un continuo.

Hay ciertas actividades que son casi enteramente dependientes de fluctuaciones de estados internos para su desarrollo, como alimentarse, anidar y picotearse las plumas, mientras que otras dependen exclusivamente de variaciones de estados externos, por ejemplo, comportamiento agonístico y respuestas antipredador. Hughes y Duncan (1998) expresan: "Cuando el comportamiento es normalmente incitado por la presencia de factores externos, entonces la cuestión de la necesidad comportamental, obviamente, no aparece; si un fenómeno tal como una necesidad existe, entonces debe aparecer bajo la forma de patrones de comportamiento motivados principalmente por actores internos".

Entonces, una necesidad comportamental debe:

1. ser causada principalmente por factores internos,

2. tender a crecer gradualmente, en la medida que no es realizada, 
3. originar recompensa la sola realización del comportamiento; el animal tratará de realizar el patrón motor con independencia del estado del ambiente y de las consecuencias funcionales de la actividad.

La necesidad de realizar el comportamiento debe también ser independiente del tipo de ambiente en el que el animal vive. Impedir su realización se asociará con bienestar pobre. Sin embargo, obstaculizar otros comportamientos, que no cumplen estos criterios, puede ser seguro desde el punto de vista del bienestar.

Cuando se comienza a mirar en detalle lo que parecen ser sistemas de comportamiento simples, encontramos que emerge una compleja imagen que sería errado categorizar en clases dependientes de, por ejemplo, una supuesta dicotomía entre factores internos y externos. Como se verá, esto lleva a los autores a la conclusión que no es posible clasificar algunos de los comportamientos como necesidades por comparación con otros. Se examinarán tres criterios para mostrar que son demasiado simplificados para aportar a una teoría general de las necesidades comportamentales. Uno de los casos investigados tiene que ver con producción en porcinos: la construcción del nido en cerdas. En un intento por distinguir los efectos de los dos tipos de factores, Jensen $(1986,1993)$ estudió la realización de las actividades de construcción del nido en cerdas en corrales libres de estímulos relevantes (corrales de concreto), comparando con cerdas en corrales similares pero enriquecidos, con cama que les permite hocicar y con paja en una canasta, para usar como material de nido. 
No hubo diferencia en la cantidad de la actividad de nidificación vista en ambos grupos. Sin embargo, las cerdas en ambientes con pocos estímulos desarrollaron sólo los comportamientos correspondientes a la primera parte de la actividad (husmear, hociquear, patear) y no hicieron ningún intento de realizar en vacío las conductas de colocar u ordenar el material.

Así, no habría un "impulso nidificador" unitario. Por supuesto, esto puede significar que la nidificación constituye un complejo de dos procesos motivacionales diferentes: unos internos y otros externos. Tal vez la primera parte del patrón pueda calificar como necesidad (Hughes y Duncan, 1998).

Una interpretación probable es que el incremento en la prolactina dispara un estado motivacional en el que dominan las tendencias a nidificar. Este estado luego se asocia con una representación de logro y, al mismo tiempo, dispara la primera parte del programa motor. Si la cerda no alcanza algo que sea satisfactorio, que disminuya la diferencia IstvertSollwert, como dice Wiepkema, la siguiente parte del patrón no comienza. El anidamiento en las cerdas claramente refleja una necesidad, pero sería un error considerar que eso constituye solamente realizar un cierto patrón motor en cualquier ambiente.

El hecho de que a las cerdas a las que se les impide nidificar esto les provoca el desarrollo de comportamientos anormales, como estereotipias, indicaría que el comportamiento está asociado a una necesidad. 
Una conducta necesaria en el momento de la inseminación de hembras es su inmovilidad, que es simplemente un reflejo como respuesta a la monta del verraco. Reproducir esta conducta en ausencia del macho requiere establecer estrategias adecuadas, como por ejemplo la utilización de "mochilas" (dispositivo similar a un arnés con peso en los laterales, que se coloca sobre el dorso-lomo de la reproductora) que simulan el peso del macho sobre la hembra. También es necesaria la presencia de un macho "celador" que al segregar feromonas y emitir sonidos contribuye a la expresión de la conducta deseada.

En el caso de los padrillos, para realizar las extracciones seminales, se hace uso de un caballete o súcubo, que actuará como estímulo desencadenante de la conducta de monta, y esta pauta es, a su vez, reforzada de manera positiva, es decir, se los "premia". Skinner (1974) propone que "una conducta al obtener una consecuencia reforzante tiene más probabilidades de ocurrir nuevamente en circunstancias similares".

\section{Una lectura etológica de las estereotipias y el enriquecimiento ambiental}

Bajo ciertas circunstancias los animales confinados desarrollarán estereotipias, las cuales constituyen comportamientos repetitivos, constantes en la forma y sin propósito obvio en el contexto, como por ejemplo el mordido de barrotes y el masticar al vacío (en algunos casos denominados animales "tragadores de aire"). Dentro de las alteraciones más notorias del comportamiento se encuentra el mordido de las colas de 
los congéneres. Todo esto puede ser entendido como necesidades comportamentales que el ambiente canaliza transformándolas en conductas dañinas para los individuos y su entorno. El hecho de que sean motivaciones intrínsecas las hace particularmente difíciles de manejar, siendo una de las formas más utilizadas para tratarlas el enriquecimiento ambiental.

El enriquecimiento ambiental consiste en el proceso por el cual se modifica el ambiente de los animales con el objetivo de que aparezcan conductas nuevas y poder de esta manera mejorar el bienestar animal (Hoy y col., 2010) 


\section{Objetivo general}

Determinar las componentes heredables del comportamiento materno y los aspectos provenientes del aprendizaje en la paridera, para poder predecir el comportamiento de las hembras durante la lactancia.

Objetivos particulares

- Observar y describir diversas variables del comportamiento materno

- Registrar información de madre-hija para cada una de las variables

- Evaluar las componentes de la varianza para cada una de las variables comportamentales y para cada uno de los caracteres productivos

- Estimar la heredabilidad de las variables estudiadas

- Evaluar la posible asociación entre las distintas conductas y la productividad de la hembra 


\section{HIPÓTESIS}

La conducta materna está influenciada por características genéticas, ambientales y por la interacción entre ambos, por este motivo las hembras hermanas enteras criadas al pie de su propia madre tendrán un comportamiento más parecido entre ellas que las hembras hermanas enteras separadas al nacimiento y criadas por madres adoptivas diferentes. 


\section{CAPÍTULO I: EI COMPORTAMIENTO Y SU ESTUDIO}

\section{Introducción}

La Etología es la rama de la biología que correlaciona los cambios de postura y posición de las partes del cuerpo con las variaciones del ambiente. La teoría de la evolución delimita el marco conceptual que permite realizar análisis utilizando una metodología descriptiva como forma de construir el objeto de estudio, en el que se aplicarán diseños experimentales con el fin de abordar las diferentes conductas observadas en su ambiente.

Según Lorenz (1959) La metodología tiene 3 etapas:

- Ideográfica: es la descripción sistemática del comportamiento de un grupo reducido de formas.

- Sistemática: es todo lo observado que se organiza bajo un sistema clasificatorio.

- Nomotética: es la elaboración de las explicaciones interpretativas. El etólogo Thorpe, integrante del comité Brambell en 1965 resaltó la importancia del entendimiento de la biología del animal y explicó que los animales tienen necesidades con una base biológica, incluyendo la necesidad de realizar comportamientos particulares (Broom, 2011).

En el caso de los porcinos, existen diferentes estudios sobre el comportamiento. Las cerdas que pueden alejarse de sus crías cuando estos crecen lo hacen, mientras que las que se encuentran confinadas en 
jaulas no pueden. Estas deben alejarse, por el ya mencionado conflicto madre-cría.

Existen distintas técnicas para acceder al estudio de la conducta de estos animales, y para evaluar su posible asociación con la productividad.

Dentro de los métodos hay diferentes abordajes. Un método cualitativo es el método desarrollado por Wemelsfelder (1997). La autora define al "sujeto" como un ser con su propia perspectiva individual del mundo, sus propias necesidades y deseos. El concepto de "agencia" que desarrolla esta autora sugiere que hay una relación intrínseca e inmediata dada entre la perspectiva subjetiva del animal y la forma dinámica en la cual interactúa con el ambiente. El estilo de interacción dinámica del animal permite describir el comportamiento como un proceso "expresivo" (Wemelsfelder, 2000). La técnica consiste en la descripción por observadores inexpertos, mediante la utilización de términos propios para definir la conducta global del animal, y posteriormente cuantificarla mediante una escala respecto a cada término utilizado. Esto da acceso cualitativamente a la experiencia del animal.

Algunas técnicas miden el miedo al humano. Se colocan hembras en un recinto de $3 \times 3$, estas tienen 2 minutos para acostumbrarse al entorno, luego entra un operario y miden cuánto tarda la cerda en acercarse al mismo (Hellbrügge, 2007). En otra experiencia separaron a las cerdas y midieron su comportamiento exploratorio. Concluyeron que debían utilizar pruebas en las que las hembras permanezcan en su ambiente. 
Algunos autores (Hellbrügge, 2007; Champagne, 2011) desarrollaron el uso de diferentes técnicas con el fin de clasificar a las madres según comportamiento materno.

En la "prueba a campo" luego de separar a las cerdas, el día del parto se clasificaron en hembras que se acercaban al operario, las que no se movían y aquellas que se alejaban del operario. En la "prueba de separación" se separó a los lechones de la madre al día 1 y al 21 posparto y clasificó a las cerdas de acuerdo a las posturas adoptadas luego de apartar a las crías (echada lateral, ventral, sentarse o pararse) y se les reprodujo el chillido de un lechón siendo manipulado por un operario, y música como sonido neutro. Luego de esto se las ordenó de acuerdo a las respuestas a estos estímulos y parámetros productivos. Este autor halló correlaciones entre las "pruebas de separación" y de reacción al sonido con distintos parámetros productivos de las reproductoras (Hellbrügge, 2007).

Champagne (2011) clasificó a las ratas, según su comportamiento materno de acuerdo a la conducta de lamido/acicalamiento de las crías, ya que es un parámetro que se distribuye normalmente y puede ser usada para selección.

El etograma es un método descriptivo con el cual se realiza un inventario de pautas de una especie (Lahitte y col., 2005). 
A partir de la descripción del comportamiento realizado a través del etograma pueden medirse la frecuencia y la duración de las distintas pautas.

Las categorías de comportamiento deben ser independientes entre sí; ser distinguibles; homogéneas y claras para ser comprensibles y utilizadas por otros (Fajardo-Castillo, 2009).

Esta técnica ha sido ampliamente utilizada, en el análisis de la conducta materna. Hernández-González (2014) construyó y utilizó un etograma en el día 1 y 7 posparto en hembras híbridas de Yorkshire y Landrace. Fajardo-Castillo (2009) utilizó está técnica para comparar la conducta de hembras alojadas en sistemas confinados y en pastoreo. Wechler y Hegglin (1997) la utilizaron para analizar la conducta los primeros 10 días posparto y cómo variaba la misma luego de la reproducción de diferentes sonidos. Arey y Sancha (1996) hicieron uso de un etograma para estudiar las diferencias en dos tipos de instalaciones parideras, y luego sometiendo a esos animales a la grabación de un lechón siendo manipulado por un operario. Chidgey y col (2016) elaboraron y utilizaron un etograma segmentado en varias categorías comportamentales, para medir la duración de las pautas en los primeros 3 días posparto en hembras nacidas en corrales o en jaulas y que parieron y criaron a sus lechones en corrales o en jaulas, es decir cuatro grupos: hembras nacidas en corral que criaron en corral, hembras nacidas en corral que parieron y amamantaron en jaulas, nacidas en jaulas que parieron y criaron en jaulas y por último aquellas que nacieron en jaulas y amamantaron en corrales. 
La descripción de las pautas es en términos de los cambios de postura y posición de las partes del cuerpo, no incluye intenciones ni interpretaciones funcionales y requiere una segmentación del cuerpo del animal y del ambiente para poder comparar dichas descripciones.

Junto a los estudios e investigaciones medioambientales y de manejo, los estudios etológicos son también importantes para mejorar la eficacia productiva del ganado porcino. El mejor conocimiento de las pautas comportamentales, es un paso importante para la aplicación de medidas de Bienestar Animal, que permitirá mejorar el manejo y conseguir una mayor eficacia reproductiva, y por lo tanto una mayor rentabilidad de la explotación.

\section{Materiales y métodos}

Los datos se obtuvieron bajo condiciones de producción y la influencia del observador se estandarizó colectándolos por una sola persona (Hellbrügge, 2007; Chidgey y col, 2016). El protocolo de trabajo fue aprobado por el Comité Institucional para el Cuidado y Uso de Animales de Laboratorio de la Facultad de Ciencias Veterinarias de la Universidad Nacional de La Plata.

Se realizaron observaciones de comportamiento de hembras porcinas en lactancia de dos razas de aptitud mixta utilizadas en la formación de líneas maternas, 39 cerdas Landrace y 64 reproductoras Yorkshire. Los animales, (Esquema $n^{\circ} 1$ ) pertenecientes a una granja comercial de 300 madres, con una reposición anual del $30 \%$, ubicada en la zona norte de la 
provincia de Buenos Aires (-33.933833, -60.778806) (Fotografía $n^{\circ} 1$ ), se alojaron en jaulas parideras de $60 \mathrm{~cm}$ de ancho por $210 \mathrm{~cm}$ de largo, (Esquema $\mathrm{n}^{\circ} 2$ ) en salas de 14 parideras cada una. Las hembras se llevaron a los galpones de maternidad una semana previa al parto y permanecieron allí hasta el momento del destete, el cual se realizó a los 28 días de lactancia, fueron alimentadas 4 veces por día y poseían agua ad libitum.

Fotografía $\mathrm{n}^{\circ}$ : : Imagen satelital del establecimiento

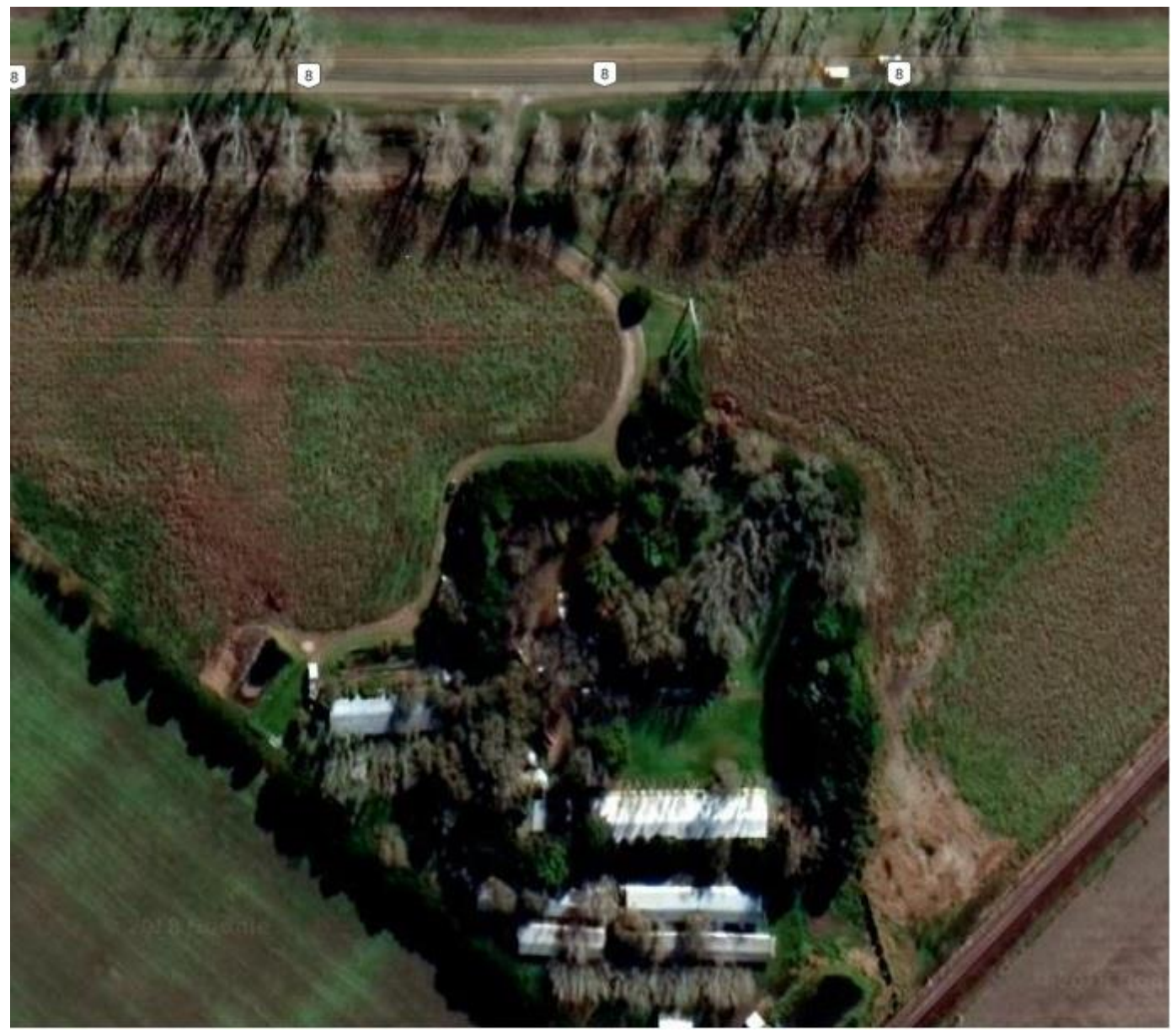

En la etapa de construcción del etograma, se realizaron 3 sesiones de observación diarias $(7: 30-8: 30,10: 30-11: 30$ y 14:00-15:00) como en el 
trabajo realizado por Hernández-Gonzalez (2014) de lunes a sábado las 4 semanas que las cerdas permanecíeron con sus crías, y la técnica de observación fue "ad libitum" (Observaciones sin estructura de ningún tipo) (Altman, 1974). El criterio de corte del etograma utilizado fue el método de la asíntota, curva en la que se van confrontando pautas nuevas por sesión de observación, y pautas acumuladas totales. Cuando estas últimas se mantienen constantes, se da por finalizada la elaboración del listado de pautas. El corte se produjo luego de 4 meses de observación, luego de 3 sesiones en las que no apareció ninguna pauta nueva (Esquema $n^{\circ} 3$ ) (Lahitte y col, 2002).

Durante la etapa de medición de frecuencia y duración de las pautas comportamentales las sesiones de observación se registraron en filmaciones continuas de 5 minutos por día por hembra. El método de observación fue Animal Focal (observaciones individuales por animal), (Altman op. Cit). No se realizaron observaciones en los momentos en los que había operarios trabajando en las salas de maternidad, como se hace rutinariamente en estudios en ambientes en producción (Chidgey y col, 2016)

Para el análisis se fragmentó la lactancia, de 28 días, en 4 bloques de análisis:

1) Del día 1 al 5 postparto, momento en que se estabiliza la mortalidad de las camadas, (Dra Lloveras, INTA Pergamino. Comunicación personal) ya que el $80 \%$ de la mortalidad pre destete ocurre en los primeros 4 días posparto (Drake, 2008). 
2) Del día 6 al 10, edad de los lechones en los que la hembra de Sus scrofa en estado de silvestría se reúne con el grupo nuevamente y tolera amamantamientos de crías ajenas (Drake, 2008) (Goenaga, 2010).

3) Del día 11 al 21, día de destete en algunas granjas comerciales intensivas confinadas, y finalmente

4) del día 22 al momento del destete

Para la medición de la frecuencia de las pautas se consideró en cuantas de las sesiones de observación aparecía la pauta medida, método 1-0 (Altman op cit.). Para la duración se registró el tiempo total de duración de la pauta respecto al tiempo total de observación. El análisis se realizó para el tiempo total de lactancia y para cada bloque por separado.

Se procedió a la descripción estadística de las pautas definidas en el etograma, mediante el análisis de una variable, utilizando el programa Statgraphic Centurión ${ }^{\mathrm{R}}$ en general y por cada categoría en las que se clasificaron las pautas conductuales.

\section{Resultados}

Esquema $\mathrm{n}^{\circ} 1$ : Criterio de fragmentación del cuerpo de la cerda (utilizada en la descripción de los comportamientos) 


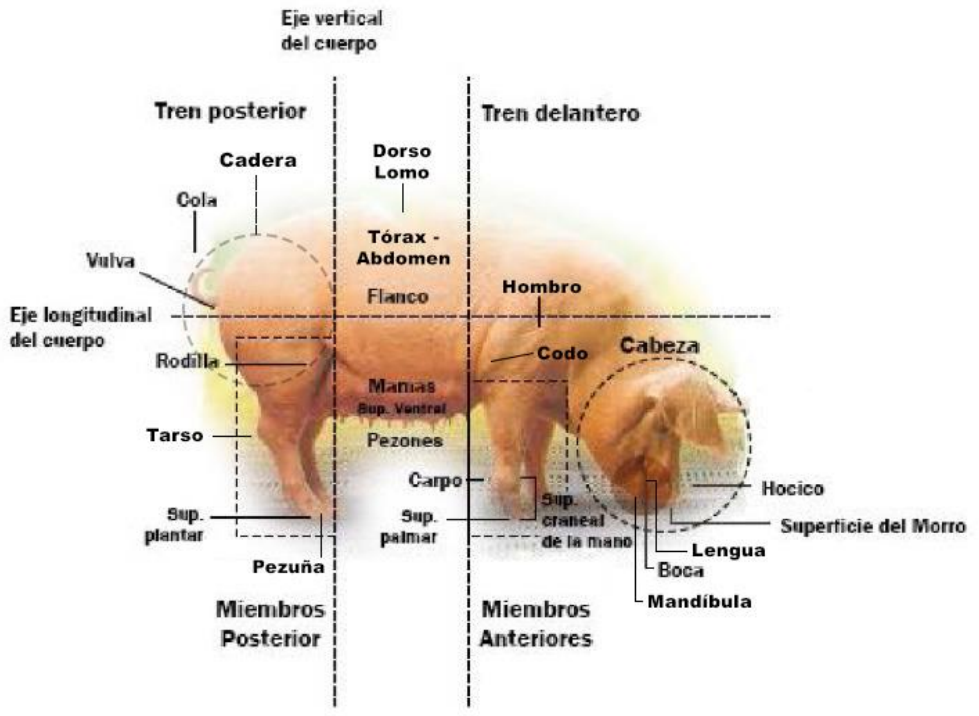

Vista lateral

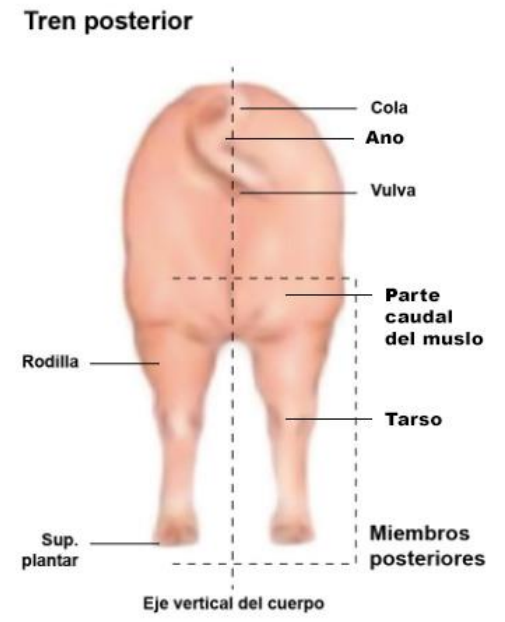

Vista caudal

Esquema $\mathrm{n}^{\circ} 2$ : Planos de las plazas parideras (vista desde arriba y lateral)
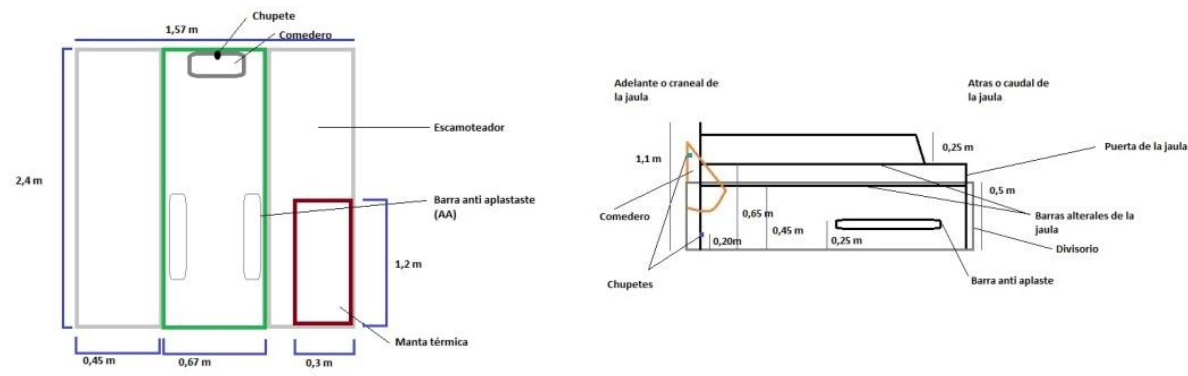
Etograma parcial de hembras porcinas en lactancia, constituido por 35 pautas, agrupadas en las siguientes categorías:

\section{Posturas}

1. De pie: los 4 miembros extendidos y en dirección perpendicular al suelo. En contacto simultáneo con este.

2. Echada lateral: una de las superficies laterales del cuerpo (en su totalidad) en contacto con el suelo. Pueden observarse una línea mamaria completa.

3. Echada ventral: ambas líneas mamarias en contacto con el suelo. No se visualizan los pezones. Miembros anteriores flexionados o extendidos, miembros posteriores uno o ambos flexionados.

4. Sentada: tren posterior flexionado en contacto con el piso, miembros posteriores flexionados o extendidos y miembros anteriores extendidos en sentido perpendicular al suelo en contacto con este. Con el eje longitudinal del cuerpo en $45^{\circ}$ respecto del suelo.

5. Arrodillada: hembra con superficie craneal de los miembros anteriores en contacto con el suelo y los miembros posteriores extendidos en forma perpendicular al suelo. El eje longitudinal del cuerpo forma un ángulo de $45^{\circ}$ respecto al suelo.

Pautas generales (pueden ser realizadas por la hembra fuera de la crianza) 
6. Arrodillarse: flexiona las articulaciones del carpo y pone en contacto con el suelo las superficies craneales de las manos, y desciende el tren delantero. Miembros posteriores extendidos perpendiculares al suelo.

7. Beber: bebedero tipo "chupete" introducido en la boca. Puede ser de pie o sentada.

8. Caminar: los miembros perpendiculares al suelo, eleva 1 miembro, lo dirige hacia adelante, o atrás, y lo apoya en el suelo; repite con otro miembro. Se considera caminar cuando realiza como mínimo 2 pasos.

9. Comer: la cabeza introducida en el comedero, al retirarla hay menos cantidad de alimento. Puede ser de pie o sentada.

10. Defecar: de pie, cabeza hacia adelante, sale materia fecal por ano.

11. Descender tren posterior: en posición "arrodillada" flexiona la cadera, rodillas y tarso hasta contactar la parte caudal de los muslos con el suelo. Queda en posición "echada ventral"

12. Elevar tren posterior: estando "echada", extiende los miembros posteriores con su superficie plantar apoyada en el suelo, Dejándolos perpendiculares al piso. Queda en "arrodillada".

13. Masticar: abre y cierra la boca varias veces. La mandíbula se desplaza en diagonal y verticalmente.

14. Mirar lateral: en posición "sentada" o "de pie" dirige la cabeza hacia alguno de los laterales de la jaula. Puede ser con el hocico dirigido hacia el suelo o no.

15. Orinar: cabeza hacia adelante, miembros anteriores extendidos perpendiculares al suelo, cadera flexionada, sale orina por vulva. 
16. Pararse (estando sentada): inclina la cabeza y los hombros hacia adelante y con la superficie plantar de las pezuñas de los miembros pelvianos en contacto con el suelo, extiende las rodillas. Queda de pie.

17. Rotar: hembra echada ventral gira sobre su eje longitudinal quedando echada lateral. O viceversa.

18. Sentarse (estando de pie): la hembra en posición "de pie" flexiona la cadera, rodillas y por último los tarsos, hasta contactar el tren posterior con el suelo.

19. Sentarse (estando echada): extiende los miembros anteriores, apoya la superficie palmar en el suelo.

20. Toser: exhala (expulsa) aire por boca, expande el tórax-abdomen.

\section{De contacto con las instalaciones}

21. Hociquear: apoya el hocico contra el sustrato, y sin perder el contacto, lo aleja de su pecho. Repetidas veces. Sustrato: suelo, jaula, comedero.

22. Lamer: hembra exterioriza la lengua, la pone en contacto con el sustrato, y recorre parte de la superficie del mismo con ella. Sustrato: barras de la jaula, o comedero.

23. Levantar barra anti aplaste: coloca el hocico, o cualquier parte de la cabeza, debajo de la barra anti-aplaste, eleva la cabeza (con la barra encima) y retira lateralmente el hocico.

24. Meter pata en comedero: hembra flexiona un codo, coloca la superficie palmar de un miembro anterior sobre el comedero. Luego 
flexiona hombro y codo y retira ese miembro anterior hacía atrás, sacándolo del comedero.

25. Morder barra o comedero: introduce parte de alguna de las barras de la jaula, o del comedero, en la boca y desliza la boca de un lado a otro de la barra o del comedero.

26. Rascarse con objeto: en posición "de pie" rota sobre el eje vertical del cuerpo, quedando a $45^{\circ}-60^{\circ}$, coloca el flanco, dorso-lomo, o cabeza, en contacto con una superficie fija (barrote de jaula) y sube y baja, sin perder el contacto.

27. Rascar suelo: flexiona el codo y lleva el miembro anterior hacia craneal de la jaula, extiende el codo y la superficie palmar contacta con el suelo, y lo lleva hacia caudal.

28. Vulva contra jaula: la hembra de pié, contacta la vulva con la puerta trasera de la jaula.

\section{Dirigidas hacia el lechón}

29. Amamantando: echada lateral con lechones en los pezones, gruñe a una frecuencia de 2-3 sonidos por segundo.

30. Llamar a mamar: echada lateral gruñe 1 vez por segundo.

31. Aplastar lechón: hembra en posición "sentada", "de pie", "echada" o "arrodillada", cambia de posición y parte o la totalidad del cuerpo de un lechón queda bajo alguna parte de su cuerpo.

32. Empujar lechón: hembra en posición "sentada", "de pie", "echada" o "arrodillada" coloca parte de su cuerpo (miembro anterior, posterior, 
cabeza) en contacto con el lechón, mueve esa parte en dirección opuesta a su cuerpo, alejando el lechón.

33. Morder lechón: la hembra introduce parte del cuerpo de un lechón en su boca y la cierra.

34. Olfatear lechón/es: la hembra dirige el hocico hacia uno/s lechón/es y realiza movimientos hacia adelante y atrás con la superficie del morro.

35. Tarascón a lechón: golpea con la boca, abierta, un lechón. Lo realiza en cualquier posición.

Esquema $n^{\circ} 3$ : Pautas acumuladas por sesión de observación

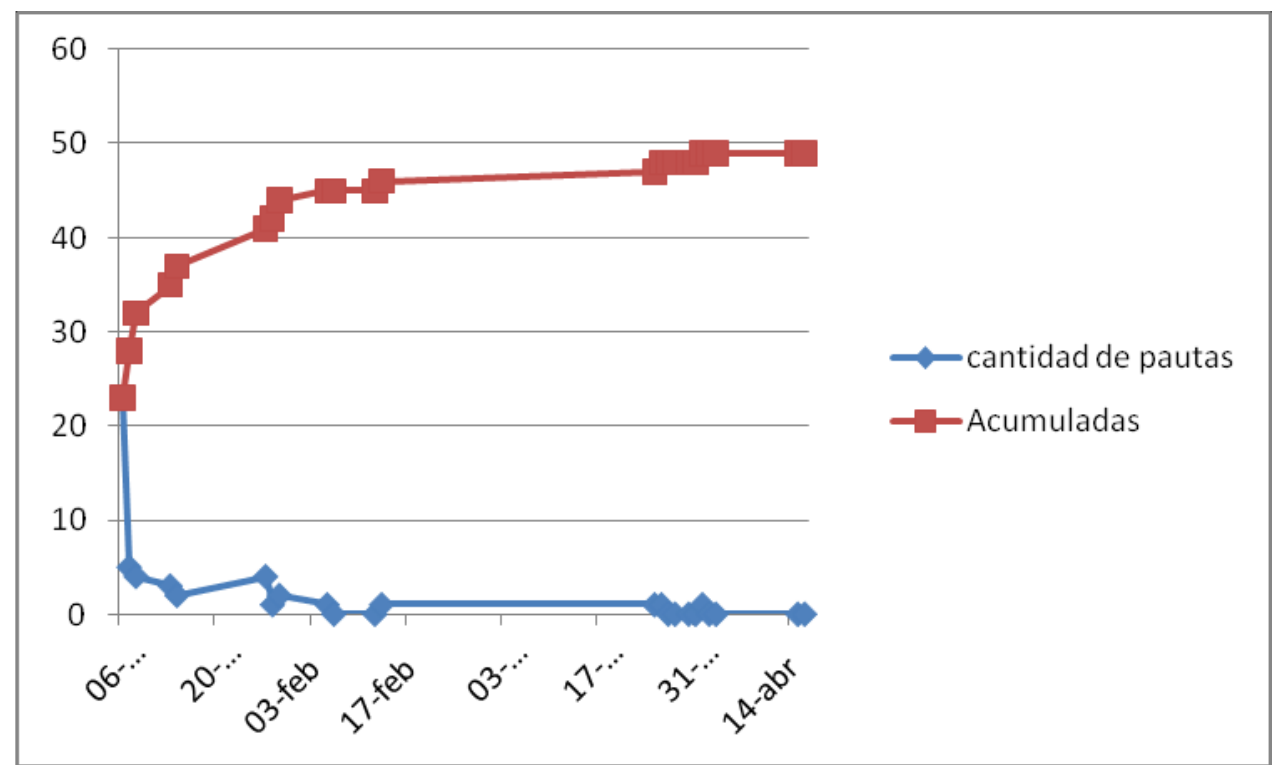

Tabla $\mathrm{n}^{\circ}$ 1: Promedio de frecuencia de aparición y duración relativa en segundos de las pautas en la lactancia para 2 generaciones de hembras porcinas en un total de 166 lactancias de 4 semanas cada una.

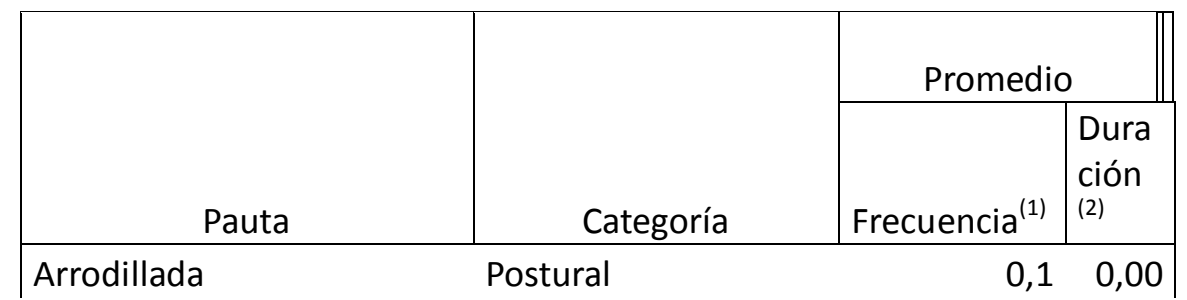




\begin{tabular}{|c|c|c|c|}
\hline & & & 4 \\
\hline De pie & Postural & 0,23 & 0,12 \\
\hline Echada lateral & Postural & 0,53 & 0,37 \\
\hline Echada ventral & Postural & 0,43 & 0,27 \\
\hline Sentada & Postural & 0,22 & $\begin{array}{l}0,07 \\
0,00\end{array}$ \\
\hline Arrodillarse & General & 0,18 & 1 \\
\hline Beber & General & 0,19 & 0,02 \\
\hline Caminar & General & 0,19 & 0,01 \\
\hline Comer & General & 0,22 & $\begin{array}{r}0,1 \\
0,00\end{array}$ \\
\hline Defecar & General & 0,03 & $\begin{array}{r}3 \\
0,00\end{array}$ \\
\hline Descender tren posterior & General & 0,09 & 1 \\
\hline Elevar tren posterior & General & 0,005 & $\begin{array}{r}0 \\
0,00\end{array}$ \\
\hline Masticar & General & 0,01 & $\begin{array}{r}1 \\
0,00\end{array}$ \\
\hline Mirar lateral & General & 0,03 & $\begin{array}{r}4 \\
0,00\end{array}$ \\
\hline Orinar & General & 0,02 & 2 \\
\hline Pararse & General & 0,1 & $\begin{array}{r}0 \\
0,00\end{array}$ \\
\hline Rotar & General & 0,17 & 1 \\
\hline Sentarse (estando de pie) & General & 0,001 & $\begin{array}{r}0 \\
0,00\end{array}$ \\
\hline Sentarse (estando echada) & General & 0,17 & 1 \\
\hline Toser & $\begin{array}{l}\text { General } \\
\text { Contacto con } \\
\text { instalaciones }\end{array}$ & 0 & 0 \\
\hline Hociquear & $\begin{array}{l}\text { Contacto con } \\
\text { instalaciones }\end{array}$ & 0,1 & $\begin{array}{l}0,01 \\
0,00\end{array}$ \\
\hline Lamer & $\begin{array}{l}\text { Contacto con } \\
\text { instalaciones }\end{array}$ & 0,008 & $\begin{array}{r}1 \\
0,00\end{array}$ \\
\hline Levantar barra anti aplaste & Contacto con & 0,03 & 2 \\
\hline & instalaciones & & 0,00 \\
\hline Meter pata en comedero & $\begin{array}{l}\text { Contacto con } \\
\text { instalaciones }\end{array}$ & 0,01 & $\begin{array}{r}1 \\
0,00\end{array}$ \\
\hline Morder barra o comedero & $\begin{array}{l}\text { Contacto con } \\
\text { instalaciones }\end{array}$ & 0,09 & 6 \\
\hline Rascar suelo & & 0,009 & 1 \\
\hline Rascarse & Contacto con & 0,01 & 0 \\
\hline
\end{tabular}




\begin{tabular}{|llrr|} 
& instalaciones & & \\
& $\begin{array}{l}\text { Contacto con } \\
\text { instalaciones }\end{array}$ & & \\
Vulva contra jaula & Hacia el lechón & 0,07 & 7 \\
\hline Amamantando & Hacia el lechón & 0,16 & 0,04 \\
& & 0,03 \\
Llamar a mamar & Hacia el lechón & 0,17 & 5 \\
Aplastar lechón & Hacia el lechón & 0,002 & 0 \\
& & 0,03 & 1 \\
Empujar lechón & Hacia el lechón & 0,02 & 0,00 \\
Hociquear lechón & Hacia el lechón & 0,007 & 0 \\
Morder lechón & Hacia el lechón & 0,003 & 0 \\
Tarascón a lechón & Hach & & \\
\hline
\end{tabular}

(1): cociente entre las sesiones de observación en las que apareció la pauta y las sesiones totales de observación (una vez por cada día). (2): cociente entre los segundos totales que la hembra dedicó a la pauta y los segundos totales de observación (300 segundos diarios).

Tabla $n^{\circ}$ 2: Parámetro descriptivos para Frecuencia de aparición y tiempo relativo por categoría de pautas

\begin{tabular}{|c|ccc|c|cc|}
\hline \multirow{2}{*}{ Categoría } & \multicolumn{3}{|c|}{ Frecuencia $^{(5)}$} & \multicolumn{3}{c|}{ Duración $^{(6)}$} \\
\cline { 2 - 7 } & Media & Mediana & Desv Estan & Media & Mediana & Desv Estan \\
\hline 1 & 0,298 & 0,267 & 0,125 & 0,165 & 0,176 & 0,05 \\
\hline 2 & 0,078 & 0,069 & 0,073 & 0,008 & 0,003 & 0,011 \\
\cline { 1 - 4 } & 0,04 & 0 & 0,067 & 0,003 & 0 & 0,007 \\
\hline 4 & 0,068 & 0,062 & 0,069 & 0,011 & 0,004 & 0,017 \\
\hline
\end{tabular}

Referencias: Categoría 1: Conductas posturales. Categoría 2: Conductas generales. Categoría 3: Conductas de contacto con las instalaciones. Categoría 4: Conductas hacía los lechones. (5): cociente entre las sesiones de observación en las que apareció la pauta y las sesiones totales de observación (una vez por cada día). (6): cociente entre los segundos totales que la hembra dedicó a la pauta y los segundos totales de observación (300 segundos diarios).

A continuación se realiza el mismo análisis descriptivo, pero para cada uno de los bloques de lactancia. 
Tabla $\mathrm{n}^{\circ}$ 3: Frecuencia (Frec) y Tiempo de duración de conductas de Posturas para cada bloque de lactancia

\begin{tabular}{|c|c|c|c|c|c|c|c|c|}
\hline & Bloque & 1 & Bloque & 2 & Bloque & 3 & Bloque & 4 \\
\hline Pauta & Frec & Tiempo & Frec & Tiempo & Frec & Tiempo & Frec & Tiempo \\
\hline Arrodillada & 0,05 & 0,002 & 0,05 & 0,002 & 0,11 & 0,004 & 0,1 & 0,004 \\
\hline $\begin{array}{l}\text { De pie } \\
\text { Echada }\end{array}$ & 0,08 & 0,02 & 0,08 & 0,02 & 0,21 & 0,1 & 0,34 & 0,19 \\
\hline $\begin{array}{l}\text { lateral } \\
\text { Echada }\end{array}$ & 0,72 & 0,52 & 0,72 & 0,52 & 0,51 & 0,38 & 0,37 & 0,22 \\
\hline ventral & 0,3 & 0,2 & 0,3 & 0,2 & 0,46 & 0,28 & 0,52 & 0,34 \\
\hline Sentada & 0,12 & 0,04 & 0,16 & 0,04 & 0,22 & 0,07 & 0,33 & 0,09 \\
\hline
\end{tabular}

Referencias: Frec: Frecuencia de aparición. Bloque: Bloque de lactancia

Tabla $n^{\circ} 4$ : Frecuencia (Frec) y Tiempo de duración de conductas Generales para cada bloque de lactancia

\begin{tabular}{|c|c|c|c|c|c|c|c|c|}
\hline & Bloque & 1 & Bloque & 2 & Bloque & 3 & Bloque & 4 \\
\hline Pauta & Frec & Tiempo & Frec & Tiempo & Frec & Tiempo & Frec & Tiempo \\
\hline Arrodillarse & 0,09 & 0,001 & 0,9 & 0,001 & 0,18 & 0,001 & 0,23 & 0,002 \\
\hline Beber & 0,08 & 0,01 & 0,08 & 0,01 & 0,18 & 0,03 & 0,26 & 0,03 \\
\hline Caminar & 0,07 & 0,004 & 0,07 & 0,004 & 0,18 & 0,007 & 0,28 & 0,02 \\
\hline Comer & 0,07 & 0,04 & 0,07 & 0,04 & 0,21 & 0,08 & 0,31 & 0,15 \\
\hline $\begin{array}{l}\text { Defecar } \\
\text { Descender } \\
\text { tren }\end{array}$ & & & & & 0,02 & 0,003 & 0,05 & 0,005 \\
\hline $\begin{array}{l}\text { posterior } \\
\text { Elevar tren }\end{array}$ & 0,05 & 0 & 0,17 & 0 & 0,1 & 0,01 & 0,1 & 0,001 \\
\hline posterior & & & & & 0,006 & 0 & 0,008 & 0 \\
\hline $\begin{array}{l}\text { Masticar } \\
\text { Mirar }\end{array}$ & 0,01 & 0,001 & 0,02 & 0,002 & 0,01 & 0,003 & 0,001 & 0 \\
\hline lateral & 0,04 & 0,006 & 0,03 & 0,005 & 0,04 & 0,006 & 0,02 & 0,002 \\
\hline Orinar & 0,01 & 0,001 & 0,03 & 0,003 & 0,03 & 0,002 & 0,02 & 0,002 \\
\hline Pararse & 0,04 & 0 & 0,1 & 0,001 & 0,09 & 0 & 0,15 & 0,001 \\
\hline $\begin{array}{l}\text { Rotar } \\
\text { Sentarse } \\
\text { (estando }\end{array}$ & 0,1 & 0,001 & 0,2 & 0,001 & 0,16 & 0,001 & 0,19 & 0,001 \\
\hline $\begin{array}{l}\text { de pie) } \\
\text { Sentarse } \\
\text { (estando }\end{array}$ & & & 0,004 & 0 & & 0 & 0,006 & 0 \\
\hline echada) & 0,09 & 0 & 0,12 & 0 & 0,16 & 0,001 & 0,25 & 0,002 \\
\hline Toser & & & & & & & 0,003 & 0 \\
\hline
\end{tabular}

Referencias: Frec: Frecuencia de aparición. Bloque: Bloque de lactancia 
Tabla $n^{\circ} 5$ : Frecuencia (Frec) y tiempo de duración de conductas de contacto con las instalaciones para cada bloque de lactancia

\begin{tabular}{|c|c|c|c|c|c|c|c|c|}
\hline & Bloque & 1 & Bloque & 2 & Bloque & 3 & Bloque & 4 \\
\hline Pauta & Frec & Tiempo & Frec & Tiempo & Frec & Tiempo & Frec & Tiempo \\
\hline Hociquear & 0,04 & 0,005 & 0,11 & 0,009 & 0,09 & 0,009 & 0,13 & 0,009 \\
\hline $\begin{array}{l}\text { Lamer } \\
\text { Levantar } \\
\text { barra anti }\end{array}$ & 0,007 & 0,001 & 0,01 & 0,001 & 0,007 & 0,001 & 0,008 & 0 \\
\hline $\begin{array}{l}\text { aplaste } \\
\text { Meter pata } \\
\text { en }\end{array}$ & 0,02 & 0,03 & 0,03 & 0,001 & 0,03 & 0,002 & 0,04 & 0,001 \\
\hline $\begin{array}{l}\text { comedero } \\
\text { Morder } \\
\text { barra o }\end{array}$ & 0,003 & 0 & 0,02 & 0,001 & 0,007 & 0,001 & 0,02 & 0,001 \\
\hline $\begin{array}{l}\text { comedero } \\
\text { Rascar }\end{array}$ & 0,02 & 0 & 0,07 & 0,004 & 0,09 & 0,004 & 0,14 & 0,01 \\
\hline suelo & 0,02 & 0,001 & 0,01 & 0,002 & 0,007 & 0 & 0,003 & 0 \\
\hline $\begin{array}{l}\text { Rascarse } \\
\text { Vulva } \\
\text { contra }\end{array}$ & 0,01 & 0 & 0,004 & 0,001 & 0,02 & 0,001 & 0,01 & 0 \\
\hline jaula & 0,04 & 0,002 & 0,06 & 0,002 & 0,06 & 0,006 & 0,1 & 0,01 \\
\hline
\end{tabular}

Referencias: Frec: Frecuencia de aparición. Bloque: Bloque de lactancia

Tabla $n^{\circ} 6$ : Frecuencia (Frec) y tiempo de duración de conductas hacia el lechón para cada bloque de lactancia

\begin{tabular}{|c|c|c|c|c|c|c|c|c|}
\hline & Bloque & 1 & Bloque & 2 & Bloque & 3 & Bloque & 4 \\
\hline Pauta & Frec & Tiempo & Frec & Tiempo & Frec & Tiempo & Frec & Tiempo \\
\hline $\begin{array}{l}\text { Amamantando } \\
\text { Llamar a }\end{array}$ & 0,25 & 0,09 & 0,25 & 0,09 & 0,13 & 0,03 & 0,14 & 0,03 \\
\hline mamar & 0,24 & 0,04 & 0,24 & 0,04 & 0,16 & 0,03 & 0,13 & 0,03 \\
\hline Aplastar lechón & 0,003 & 0 & 0,003 & 0 & 0,002 & 0 & 0,001 & 0 \\
\hline Empujar lechón & 0,008 & 0 & 0,008 & 0 & 0,03 & 0 & 0,06 & 0,003 \\
\hline $\begin{array}{l}\text { Hociquear } \\
\text { lechón }\end{array}$ & 0,006 & 0 & 0 & 0,012 & 0,02 & 0,002 & 0,06 & 0,003 \\
\hline Morder lechón & 0,002 & 0 & 0,006 & 0 & 0,003 & 0 & 0,02 & 0,001 \\
\hline $\begin{array}{l}\text { Tarascón a } \\
\text { lechón }\end{array}$ & & & 0,002 & 0 & & & 0,008 & 0 \\
\hline
\end{tabular}

Referencias: Frec: Frecuencia de aparición. Bloque: Bloque de lactancia 
Se analizan a continuación las categorías de acuerdo a frecuencia y duración en la lactancia globalmente, y en cada uno de los 4 bloques

Tabla $n^{\circ} 7$ : Categorías comportamentales según frecuencia y duración relativa.

\begin{tabular}{|l|l|l|}
\hline Categoría & Frecuencia relativa & Tiempo relativo \\
\hline Posturas & 0,3 & 0,17 \\
Generales & 0,08 & 0,01 \\
$\begin{array}{l}\text { Contacto con } \\
\text { instalaciones } \\
\text { Hacia el lechón }\end{array}$ & 0,04 & 0,001 \\
& 0,07 & 0,01 \\
\hline
\end{tabular}

Tabla n8: Categorías de conducta según frecuencia y duración relativa para cada uno de los bloques de lactancia

\begin{tabular}{|c|c|c|c|c|c|c|c|c|}
\hline & Bloque & 1 & Bloque & 2 & Bloque & 3 & Bloque & 4 \\
\hline Categoría & Frec & Tiempo & Frec & Tiempo & Frec & Tiempo & Frec & Tiempo \\
\hline Posturas & 0,25 & 0,16 & 0,30 & 0,17 & 0,30 & 0,17 & 0,33 & 0,17 \\
\hline Generales & 0,04 & 0,004 & 0,08 & 0,008 & 0,006 & 0,008 & 0,11 & 0,01 \\
\hline $\begin{array}{l}\text { Contacto } \\
\text { con } \\
\text { instalaciones }\end{array}$ & 0,02 & 0,002 & 0,04 & 0,003 & 0,006 & 0,003 & 0,06 & 0,004 \\
\hline $\begin{array}{l}\text { Hacia el } \\
\text { lechón }\end{array}$ & 0,07 & 0,02 & 0,07 & 0,11 & 0,006 & 0,009 & 0,07 & 0,01 \\
\hline
\end{tabular}

Referencias: Frec: Frecuencia de aparición. Bloque: Bloque de lactancia 


\section{Discusión}

La gran cantidad de conductas descriptas en el etograma y la agrupación de las mismas utilizando la metodología de observación de Lorenz (1959), contempla el análisis de Jensen y Toates (1993) en el cual los autores plantean que el comportamiento atiende a necesidades fisiológicas, y de esta manera un amplio rango de conductas serán necesarias para cubrir los requerimientos de los individuos. La utilización de este método, el etograma, permite al considerar distintas categorías de conductas, conocer el estilo comportamental desde un abordaje cuantitativo, a diferencia de la metodología propuesta por Wemesfelder (1997). Si bien, en este estudio se ha utilizado la categorización de las pautas en "posturas", "pautas generales", "de contacto con las instalaciones" y "dirigidas hacia el lechón", otro tipo de clasificación permitiría realizar otros análisis.

Respecto a la fase de elaboración del etograma y medición de frecuencia de las pautas fueron necesarios 5 minutos de habituación, (tiempo máximo en que la hembra dejaba de estar inmóvil "mirar lateral" desde que el observador se posicionaba para comenzar) previos a cada sesión de observación por cada hembra, a diferencia de Chidgey y col., (2016), que utilizaron 10 minutos de habituación. En este trabajo se coincide con los criterios de agrupación de pautas de estos autores, a excepción del grupo "dirigidas hacia otra hembra", categoría que comprende pautas no consideradas aquí. Chidgey y col. enuncian 30 pautas de conducta clasificadas en las categorías mencionadas en esta tesis, pero el método 
de muestreo para medir las frecuencias y duraciones fue diferente al utilizado por los autores, que realizaban observaciones de 30 segundos cada 4 hembras. En los primeros tres días posparto las pautas más observadas por ellos fueron "echadas", "investigando a lechones" y "vocalización hacía lechones". Esta última es la única que no posee un equivalente en esta tesis, debido a que en esta no se consideran sonidos, con excepción de la frecuencia en dos pautas. Pero en el primer bloque en el cual se ubican los tres primeros días, las pautas más observadas en esta investigación fueron "echada lateral", "echada ventral" y "amamantando".

Hernández-Gonzalez (2014), utilizó seis pautas comportamentales y halló tiempos relativos de duración de las pautas similares en las primeras 24 hs y el séptimo día posparto. En esta tesis se describieron 36 pautas de comportamiento. En el día 1 y 7 posparto las pautas más observadas fueron las mismas: "acostada", "amamantar" y "parada", en los bloques 1 y 2 en los que se encuentran el primer y séptimo día de lactancia, respectivamente. Tampoco hubo diferencias en las pautas más frecuentes, las cuales fueron "echada lateral", "echada ventral" y "amamantando". A diferencia de Hernandez-Gonzalez (2014) se describen en esta tesis dos pautas para el equivalente a "acostada" del autor. Se consideró fundamental diferenciar si la hembra estaba "echada lateral" o "echada ventral" ya que la exposición o no de los pezones es una situación muy importante en lo que respecta a conducta materna, por ser las partes del cuerpo de la hembra que los lechones utilizarán para 
alimentarse, y nutrir a las crías es una característica a evaluar en la conducta materna de las hembras.

Fajardo-Castillo (2009) midió nueve conductas, y las duraciones relativas y promedios en sistemas confinados no coinciden en su mayoría con las presentadas en esta tesis, diferencias que se explican en las distintas pautas utilizadas y analizadas aquí. En las hembras en confinamiento las pautas más registradas por Fajardo-Castillo en la lactancia fueron "amamantando" "reposo" y "tomar agua", en cambio en esta tesis, las pautas de mayor aparición en la lactancia en general fueron "echada lateral", "echada ventral" y "de pie". A diferencia de este autor, en este trabajo la secuencia de alimentación de las crías está compuesta por dos pautas, "Ilamar a mamar" y "amamantando", ya que es en "amamantando" cuando se produce la eyección de leche. Resultó relevante discriminar en estos dos momentos en particular.

Wechler y Hegglin (1997) definieron cinco pautas y utilizaron dos para comparar las cerdas luego de exponerlas a sonidos de alarma de lechones, u otros sonidos, como el llamado de un ave. En comparación, aquí se describe un mayor número de pautas que se analizaron respecto a distintas características de las hembras. Se difiere de estos autores en que ellos presentan y describen dos formas de echarse, de acuerdo a como cae el tren posterior de la hembra, hecho visto en este trabajo. Esto no se consideró relevante para el análisis, por lo que se unificó en la pauta "descender tren posterior". Estos autores puntuaron a las cerdas de acuerdo al porcentaje de tiempo del día que pasaban realizando cada 
pauta, y las ordenaron de acuerdo a este puntaje asociándolo a los lechones aplastados.

La diferencia con el trabajo de Arey y Sancha (1996) cuyas pautas más observadas en las hembras alojadas en jaulas parideras fueron "echada", "parada" y "amamantando", puede deberse al método utilizado para medir la duración y la frecuencia de las pautas, que en dicho trabajo fue la observación de un lugar (método "lugar focal") cada 10 minutos a las 9 y $12: 30$ hs 4 veces la primer semana, y una vez por semana las siguientes 3 semanas de lactancia. A su vez las hembras alojadas en jaulas la categoría de pautas que más realizaron fueron las dirigidas a la jaula. En este trabajo en cambio, en la lactancia en general, fueron las pautas generales, y en duración las dirigidas hacia el lechón.

Más allá de las diferencias con estos autores, en las tablas 7 y 8 puede verse cómo las pautas de comportamiento posturales fueron las más frecuentemente observadas y de mayor duración, y luego, en cuanto a actos los más frecuentes fueron aquellos que la hembra realiza hacia el lechón, hecho coincidente con que en esta categoría se encuentran las conductas que realiza la cerda en la etapa de maternidad o lactancia. puede también observarse, como en la lactancia en general, y los primeros 21 días de la misma, que la hembra dedica mayor tiempo a comportamientos dirigidos hacia el lechón, pero en los días restantes de lactancia dedica mayor tiempo a conductas generales. Respecto a que actos conductuales son más frecuentes podemos observar como en los primeros 5 días son aquellos dirigidos hacía el lechón coincidente con los 
días en que los lechones son más dependientes de la madre. Entre los días 6 y 10 posparto las conductas más frecuentes son las generales por lo que se entiende que la hembra comienza a priorizar la ingesta de alimentos y otras funciones fisiológicas. Entre los días 11 y 21 de lactancia las pautas más frecuentemente observadas son las que la cerda realiza de contacto con las instalaciones, quizás debido a que en silvestría permanece aislada en el nido durante los primeros 10 días, como se mencionó anteriormente. Y luego puede intentar alejarse de las crías, hecho imposibilitado en este tipo de producción. Y en los últimos días de lactancia las pautas mayormente vistas son las generales, hecho consistente con que es en esta categoría donde se encuentran las pautas que la hembra realiza independientemente de su estado fisiológico. 


\section{CAPÍTULO 2: FACTORES QUE AFECTAN LA EXPRESIÓN DE LAS CONDUCTAS}

\subsection{EFECTO DE LOS FACTORES RELACIONADOS CON EL MANEJO SOBRE EL COMPORTAMIENTO}

\section{Introducción}

Durante décadas, los investigadores han buscado los causales de las diferencias en la conducta de los animales. La especie estudiada en este trabajo, y más aún, la categoría, hembras reproductoras en lactancia, ha sido ampliamente analizada.

Se han reportado diferencias individuales en el comportamiento de las cerdas, ya sea si aplastan o no lechones, si reaccionan a crías extrañas y cuando sus lechones son manipulados (Hernandez-Gonzalez, 2014). Estas evidencias en la diferencia de la actitud de la hembra hacia sus crías fueron reportadas por Hellbrügge (2007) y las experiencias se han llevado a cabo en diferentes niveles de análisis. Algers y Uvnäs-Moberg (2007) estudiaron la conducta de construcción del nido a través de vías hormonales, como las de prolactina, progesterona, somatostatina y oxitocina. Otros autores (Barnet y col, 2001; Den Hartog y col, 1993; Rodezno Arita, 2007; Hernandez-Gonzalez, 2014; Fajardo-Castillo, 2009; Spinka, 1995; 2011; Algers, 1993; Wechler y Hegglin, 1997; Chidgey, 2016; Nacipucha, 2014; Arey y Sancha, 1996; Weary, 1996; Hohenshell, 1997; Cronin, 2001; Goenaga, 2010) han abordado el comportamiento de 
las cerdas durante la crianza de sus lechones, buscando explicación en distintos factores externos. Este será el objetivo del presente capítulo, estudiar la asociación entre diferentes factores, propios de los sistemas confinados de cría intensiva en producción porcina, y la conducta de las reproductoras.

Otro factor de producción del que se ha estudiado su interacción con el temperamento de las hembras porcinas es el estado corporal de las reproductoras al inicio y al final de la lactancia. Este es de suma importancia, ya que hembras con pocas reservas corporales tenderán a hacer mayor uso de conductas para limitar los amamantamientos y de esta forma preservar su futuro reproductivo, por ejemplo realizar amamantamientos no nutritivos, con los cuales la hembra disminuye la frecuencia de eyección de leche (Spinka y col, 2011). Otra forma de limitar los amamantamientos según Drake y col (2008) en jaulas, donde no puede alejarse de las crías a partir de las 48 hs posparto, es parándose, sentándose y/o echándose ventralmente.

El estado corporal, ya sea medido en condición corporal (CC), o en espesor de grasa dorsal (EGD), se analizó, evaluó y contrastó en muchos estudios, (Fajardo-Castillo, 2009; Seguín y col, 2006; Hellbrügge, 2007, entre otros). Murillo Galán y col (2007) resaltaron que la medición del EGD al momento del parto y del destete provee información que puede ser empleada como guía de los cambios corporales de las hembras, y es de fácil obtención. 
El número de partos es un parámetro que refleja la edad productiva de la hembra, y el desarrollo ontogénico de la misma. García Gonzalez y col (2011) analizaron el número de partos de la hembra como uno de los factores que afectan la mortalidad del lechón, y encontraron que no la afectaba. También estudiaron su impacto en diferentes parámetros productivos de la cerda, encontraron que la mortalidad de los lechones es dependiente del tamaño de camada, y no del número de partos de la hembra. Wechler y Hegglin (1997) contrastaron el número de partos con la mortalidad por aplastamiento en lechones, y no hallaron diferencias significativas entre estas variables. García Mungía y col (2014) consideraron de tal importancia la cantidad de partos, que lo utilizaron para clasificar a las hembras participantes de su estudio, al igual que Gomez Medina y col (1999).

La estación o época del parto es un factor más a analizar, si bien, en una explotación intensiva confinada, el ambiente es "controlado", ya que las diferentes etapas productivas se llevan a cabo dentro de galpones, con diferentes métodos para monitorizar y manejar la temperatura, humedad y gases ambientales. Es un dato a registrar y analizar su efecto sobre la conducta materna. Gomez y col (2009) y Gomez Medina y col (1999) consideraron este efecto sobre parámetros productivos y reproductivos de las porcinas y hallaron diferencias respecto al año de parto sobre diferentes parámetros productivos.

Otro factor es la ubicación de la plaza paridera en la que transcurrió la lactancia cada cerda. Weary y col (1996) (1998); Arey y Sancha (1996); 
Marotta y col (2008); Seguin y col (2006); Manteca y col (2005); Barnett y col (2001); Bates y col (2003); Arroyo y col (2016); La den Hartog y col (1993); Stalder y col (2004) y Chidgey y col (2016) estudiaron la influencia de las instalaciones parideras en diferentes parámetros productivos de las cerdas. Algunos de los autores aquí citados hallaron diferencias en la conducta de hembras alojadas en distintos tipos de instalaciones, otros hallaron diferencias en la productividad de las reproductoras, y otros no encontraron diferencias.

Los distintos días de lactancia, o días posparto, son importantes de considerar en la productividad de las reproductoras y en el estudio de la conducta de los animales, ya que al ir creciendo los lechones, estos van variando tanto sus necesidades nutricionales y de cuidado. Del mismo modo pueden observarse cambios en la conducta de la hembra. En el presente estudio se fragmentó la lactancia en 4 bloques, presentados y descriptos en el capitulo anterior. Numerosos autores han estudiado la conducta en función de los días de lactancia transcurridos. Algunos ejemplos de estos análisis son:

- Hernandez-Gonzalez (2014) quien comparó el primer y el séptimo dia postparto, midió los minutos por hora promedio de las pautas en 3 observaciones diarias, y halló mínimas diferencias en algunas de las pautas.

- Spinka y Algers (1995) que estudiaron el porcentaje de finalización del amamantamiento por parte de la hembra en la primer y cuarta 
semana de lactancia, la primera semana la cerda finaliza el 30-50\% de los actos de lactancia y en la cuarta el $90-100 \%$ de ellos.

- Wechler y Hegglin (1997) analizaron el porcentaje de tiempo que trascurre echada o rotando, por día, los primeros 10 días de lactancia, y no encontraron asociación con estas conductas y la respuesta al chillido de alarma de los lechones, y concluyeron que esta última es independiente de la experiencia.

- Spinka y col (2011) y Algers (1993) estudiaron los cambios en las interacciones de amamantado de los lechones a medida que transcurren las semanas de lactancia, y concluyeron que a medida que aumenta la etapa de lactancia, o la edad de los lechones, aumentan los intervalos entre los amamantamientos y/o aumentan los amamantamientos no nutritivos.

- Drake (2008) trabajó sobre la mortalidad en relación a la edad de los lechones, y la disminución de la frecuencia de los amamantamientos luego de las primeras 48 hs posparto.

- Chidgey y col (2016) observó la conducta de las primeras 72 hs posparto, ya que enfatizó la importancia de los cuidados maternos en los primeros días de lactancia.

- Nacipucha (2014) enfatizó su análisis en las primeras 12 hs posparto, debido a que en esta primera etapa la hembra se 
caracteriza por la predisposición total a permitir el amamantamiento.

- Arey y Sancha (1996) estudiaron la conducta materna en distintos momentos de las 4 semanas de lactancia. $Y$ observaron las variaciones en las respuestas frente a la reproducción del sonido de un lechón, siendo manipulado por un operario, entre los días 1, $4,7,10$ y 13 .

Estos trabajos ponen en evidencia la importancia de estudiar la lactancia fragmentada en diferentes momentos, ya que en conjunto, lo que se ha encontrado es que la conducta de la cerda varía de acuerdo a la etapa de lactancia, los primeros días permanece más receptiva a las interacciones con los lechones y a medida que avanza la lactancia, y los lechones crecen esta receptividad va disminuyendo.

\section{Materiales y métodos}

Se trabajó en una granja de 300 madres, intensiva confinada ubicada en la localidad de Pergamino, Buenos Aires (-33.933833, -60.778806). La granja se constituyó de 2 galpones de gestación, uno exclusivo de padrillos, y 2 galpones de maternidad. Un galpón de recría de lechones, y la planta de alimento balanceado en este predio (Esquema $\left.n^{\circ} 4\right)$. 
Esquema $n^{\circ} 4$ : Plano de la granja porcina

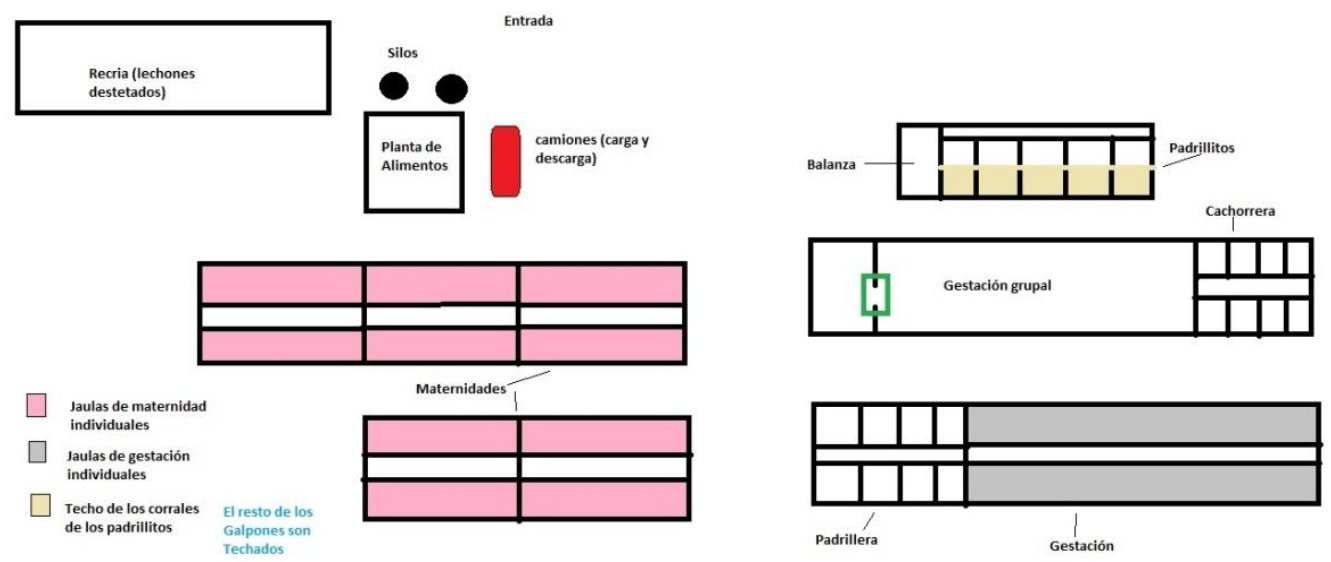

Las cerdas explotadas en esta granja pertenecieron a distintas líneas genéticas, razas e híbridas. Se trabajó con 103 hembras de razas Landrance y Yorkshire. De diferentes números de partos ("parity") los cuales para su análisis se categorizaron en tres grupos: el grupo 1 comprendió a las hembras de primer y segundo parto, ya que estás son las reproductoras que además de gestar están creciendo (García Mungía y col, 2014); el segundo grupo, o grupo 2 se constituyó de hembras del tercer al sexto parto (considerando que a partir del sexto parto la productividad de la hembra comienza a decaer), y el grupo 3 englobó a las cerdas de 7 partos o más, que según los criterios usuales deberían haberse descartado.

Al momento de ingreso a la sala de maternidad, los días lunes, se midió el estado corporal de las hembras mediante la toma de la condición corporal $\left(C_{0}\right)$ y el espesor de grasa dorsal $\left(E G D_{0}\right)$. La condición corporal se agrupó en tres categorías: 
Grupo 1: Condición corporal baja

CC 1 = Columna prominente

CC 2 = Pelvis y columna visibles y palpables

Grupo 2: Condición corporal óptima

CC 3 = Pelvis y columna no visibles y poco palpables

Grupo 3: Condición corporal alta

CC 4= Contorno en forma de tubo

CC 5 = No es posible detectar por palpación los huesos de pelvis y columna. (Agrupado de Fajardo Castillo 2009)

Esquema ${ }^{\circ} 5$ : Condición corporal en cerdas

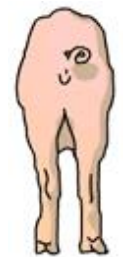

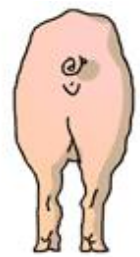

2

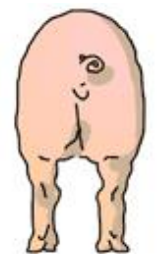

3

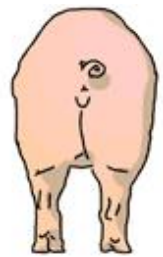

4

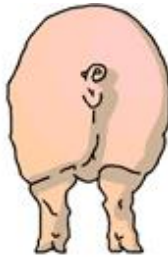

5

Fuente: https://www.3tres3.com/print/30922

La medición del espesor de la grasa dorsal se realizó utilizando un medidor de grasa dorsal para suinos S-100 Suoer ${ }^{R}$ el cual se colocó en el punto $\mathrm{P} 2$, localizado a la altura de la última costilla, a unos $6-7 \mathrm{~cm}$ de la columna hacía lateral. Considerando que las hembras de primer y segundo parto deben poseer programas diferenciales de manejo (Murillo 
Galán y col 2007) las categorías del espesor de grasa dorsal al ingreso a la lactancia fueron:

Grupo 1: $\mathrm{EGD}_{0}$ bajo $=$ Menos a $24,5 \mathrm{~mm}$ en multíparas y menor a $17 \mathrm{~mm}$ en hembras de primer y segundo parto

Grupo 2: $E G D_{0}$ óptimo $=24,5 \mathrm{~mm}$ en multíparas y entre $17 \mathrm{~mm}$ y $22 \mathrm{~mm}$ en cerdas de primer y segundo parto (Close 2003)

Grupo 3: $\mathrm{EGD}_{0}$ alto = Mayor a $24,5 \mathrm{~mm}$ en multíparas y mayor a $22 \mathrm{~mm}$ en hembras de 1 y 2 partos.

Las cerdas ingresaron a la sala de maternidad correspondiente, constituida por 14 parideras cada una, con un pasillo central ubicado en caudal de las plazas parideras. Las parideras fueron categorizadas en cuatro ubicaciones, representadas en el esquema $n^{\circ} 5$. A las parideras ubicadas en la entrada de los galpones se les asignó la ubicación A. La ubicación B para aquellas orientadas hacia el pasillo entre galpones, la C para jaulas dirigidas hacia el campo abierto, y la $\mathrm{D}$, para las plazas enfrentadas hacía la planta de alimentos. 
Esquema $n^{\circ} 6$ : Planos de salas de maternidad (las flechas indican el sentido creciente de la numeración de las jaulas dentro de cada sala)

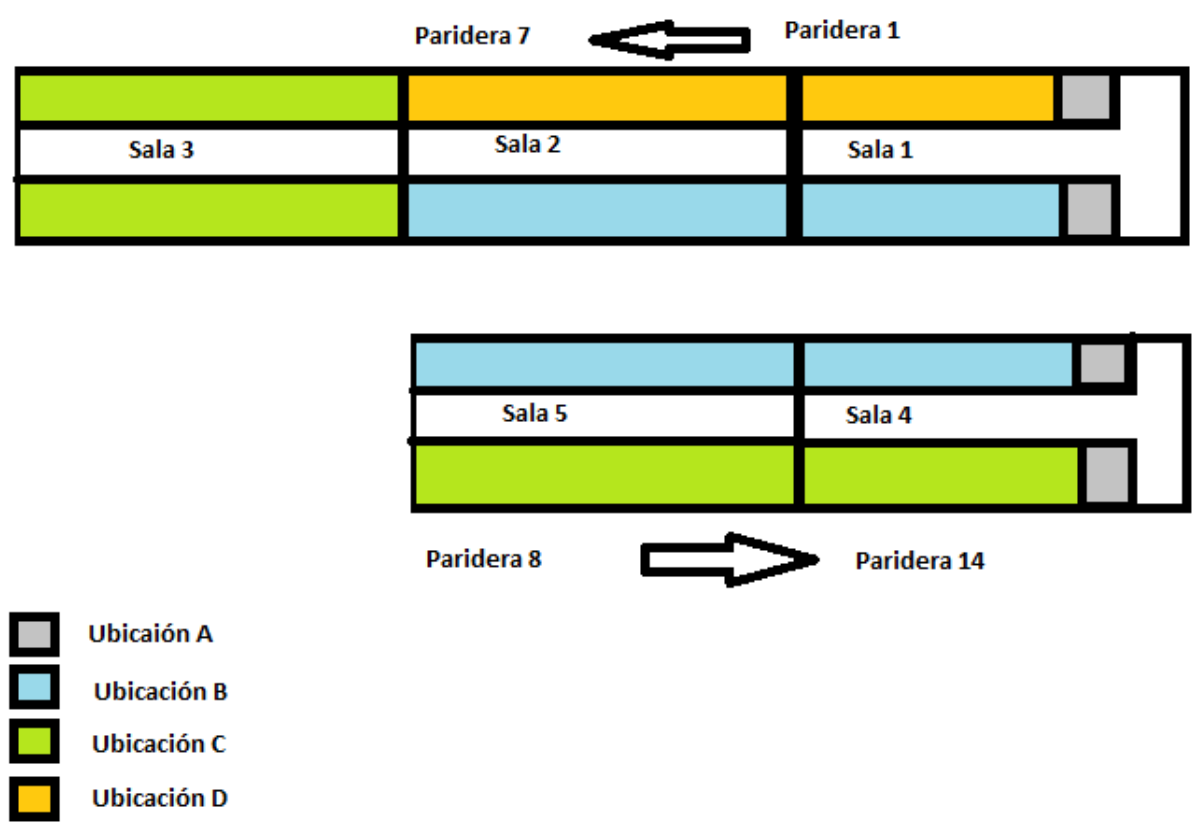

Las hembras dispusieron de agua ad libitum y fueron alimentadas cuatro veces por día, a las $7: 30,11: 00,13: 00$ y 15:30 con alimento balanceado (maíz, soja y núcleo vitamínico-mineral comercial). Se indujo el parto (excepto en hembras de primer parto), mediante la aplicación de $\mathrm{PGF}_{2} \alpha$ 24 hs previas a la fecha probable de parto, y la mayoría de los partos ocurrió entre miércoles y viernes.

El día del parto se descolmilló a los lechones, y se aseguró el calostrado de toda la camada.

Al tercer día posparto se aplicó hierro intramuscular y se suministró un coccidiostato vía oral. A los 7 días posparto se realizó la castración de los machos de líneas híbridas, se identificaron mediante señalización del 
sistema australiano a todos los lechones y se vacunó a las reproductoras contra Parvovirus porcino, Leptospira interrogans y Erysipelothrix rhusiopathiae.

El destete se realizó los días viernes por la mañana. Al día 28 de lactancia aproximadamente. En este momento se volvió a medir la condición corporal de la cerda y su espesor de grasa dorsal.

Para el análisis se consideró la variación de estos 2 parámetros $\left(\mathrm{CC}_{1}\right.$ y $E G D_{1}$ ), desde el comienzo al final de la lactancia. Las categorías consistieron en:

Grupo 1: Bajó la condición corporal

Grupo 2: Mantuvo la condición corporal

Grupo 3: Subió la condición corporal

Categoría 1: Perdió más de $3 \mathrm{~mm}$ de espesor de grasa dorsal (Hesse y Hesse 2006)

Categoría 2: Perdió entre $2 \mathrm{~mm}$ y $3 \mathrm{~mm}$ de espesor de grasa dorsal

Categoría 3: Perdió menos de 2 mm, mantuvo o aumentó el espesor de grasa dorsal.

Durante las sesiones de observación del comportamiento se registraron en filmaciones continuas de 5 minutos por día por hembra. El método de observación fue Animal Focal (observaciones individuales por animal), (Altman op. Cit). Para la medición de la frecuencia de las pautas se 
consideró en cuántas de las sesiones de observación apareció la pauta medida, método 1-0 (Altman op cit.). Y para la duración se registró el tiempo total de duración de la pauta respecto al tiempo total de observación. El análisis se realizó para el tiempo total de lactancia y para cada bloque por separado.

Esquema $n^{\circ} 7$ : Rutina durante la lactancia

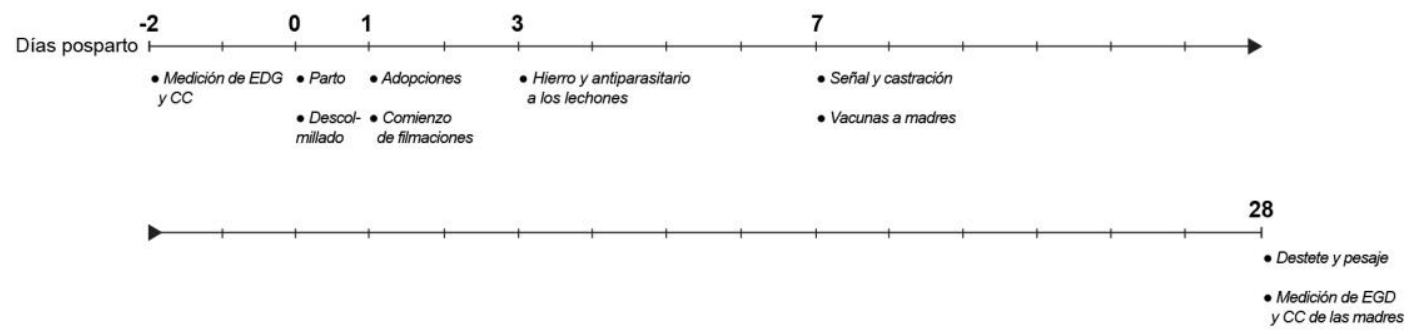

Para el análisis estadístico de los datos se utilizó el método de regresión binomial negativa (Dohoo y col, 2003) para el tiempo relativo de cada pauta respecto al bloque de lactancia considerado, la ubicación de la jaula donde la hembra parió y realizó su lactancia, y la categoría del número de parto en el cual la reproductora se encontraba criando. Estos análisis fueron realizados en el programa Stata II IC (JICA Provetsur)

$$
\operatorname{Ln}(\lambda)=B_{i}+U_{j}+P_{k}+R_{l}+D_{m}+R e_{n}
$$

B: Bloque de lactancia

U: Ubicación de la jaula paridera

P: Número de partos

R: Raza

D: Donó lechones 
Re: Recibió lechones ${ }^{2}$

Para la CC corporal y el EGD se realizó un análisis de varianza, debido a la distribución de los datos, para el tiempo relativo de la duración de las pautas y la frecuencia de aparición de las mismas, respecto a la CC y EGD inicial y las variaciones de estos parámetros durante la lactancia. Las variables dependientes fueron transformadas según la raíz cuadrada del dato más uno $(\sqrt{ }(x+1))$

$$
Y_{\mathrm{ijk} l}=\mu+C C_{0 \mathrm{i}}+C C_{1 \mathrm{j}}+E G D_{0 \mathrm{k}}+E G D_{11}+\epsilon_{\mathrm{ijkl}}
$$

$\mathbf{C C}_{0:}$ Condición Corporal al inicio de la lactancia

$\mathbf{C C}_{1:}$ Variación de la $\mathrm{CC}$ entre el inicio y el final de la lactancia

$E \mathrm{GD}_{0}$ : Espesor de grasa dorsal al comienzo de la lactancia

EGD $_{1}$ : Variación del EGD en la lactancia

Luego, se procedió al análisis de varianza multifactorial para tiempo relativo y frecuencia de aparición (transformadas según el cálculo $\sqrt{ }(X+1)$ ) utilizando como factores de variación la categoría del número de partos, la ubicación de la jaula, el bloque de lactancia, la estación del año y el año.

$$
Y_{i j k l m}=\mu+P_{i}+U_{j}+B_{k}+S_{l}+A_{m}+\varepsilon_{i j k l m}
$$

P: Número de partos

U: Ubicación de la jaula paridera

B: Bloque de la lactancia

S: Estación del año

A: Año

R: Raza. (Ver capítulo 4) D: Donó lechones. Re: Recibió lechones. (Ver capítulo 2.2) 
Estos últimos 2 ensayos fueron analizados mediante el software Statgraphics Centurion $^{R}$

El valor de significación estadística utilizado fue $p<0,05$ para todos los análisis.

\section{Resultados}

Se observó una mayor variación en el tiempo de duración de las pautas $(p<0.05)$ según el momento de la lactancia (bloque).

La pauta "beber" presentó una menor duración de la misma en los bloques 2, 3 y 4 respecto del 1. Al igual que "caminar", "arrodillada", "comer", "de pie", "echada ventral”, "hociquear", "olfatear lechón” y "sentada".

"Descender tren posterior" tuvo menor duración en el bloque 3 respecto del 1

"Echada lateral" presentó una menor duración en el bloque 3 respecto del 1 y una mayor duración en el bloque 4 respecto del 1

"Levantar barra antiaplaste" tuvo una menor duración en el bloque 4 respecto del 1

"Morder barra o comedero" presentó menor duración en el bloque 4 respecto del 1

Las hembras a su vez dedicaron menor tiempo a "orinar" en los bloques 2 y 3 que en el 1. 
Y por último estuvieron menor tiempo en la pauta "vulva contra jaula" en todos los bloques respecto del 1 . Bloque 2, 3 y 4 .

Las cerdas pasaron menos tiempo en el acto de "beber" aquellas que se alojaron en jaulas orientadas hacia la planta de alimentos respecto de aquellas ubicadas en las entradas de los galpones.

Para la pauta "caminar" también hubo diferencias entre las ubicaciones. Las hembras que criaron en jaulas orientadas al pasillo entre galpones dedicaron menor tiempo a esta conducta, y por el contrario las que se encontraban orientadas hacia la planta de alimentos estuvieron más tiempo realizando esta pauta.

Teniendo en cuenta la duración de la pauta "morder barra o comedero" las reproductoras encerradas en parideras orientadas hacía el pasillo entre galpones y hacia el campo abierto le dedicaron menos tiempo.

Para la pauta "vulva contra jaula" presentaron menor duración de la misma las hembras ubicadas en las jaulas orientadas al campo.

Las hembras de 7 partos o más dedicaron mayor tiempo que las de 1 o 2 partos a la posición "arrodillada", y a "comer"

Las cerdas de 3 a 6 partos pasaron menos tiempo en "vulva contra jaula" respecto al grupo de 1 o 2 partos. En cambio dedicaron mayor tiempo a estar en la postura "sentada".

Las cerdas de baja condición corporal (CC) al inicio de la lactancia dedicaron más tiempo a "hociquear lechón" que las hembras de CC 
óptima. Por el contrario, las reproductoras de CC óptima pasaron más tiempo en "levantar barra anti aplaste" que las porcinas de baja condición corporal. Y por último las hembras de CC óptima estuvieron más tiempo realizando la pauta "rotar" que las de baja y alta CC.

Tabla n9: Tiempo de duración de las pautas según la $\mathrm{CC}_{0}$ al ingreso a maternidad

\begin{tabular}{|cc|c|c|}
\hline $\begin{array}{l}\text { Categoría de } \\
\mathrm{CC}_{0}\end{array}$ & $\begin{array}{c}\text { Hociquear } \\
\text { lechón }\end{array}$ & $\begin{array}{c}\text { Levantar barra } \\
\text { anti aplaste }\end{array}$ & Rotar \\
\hline 1 & $0,001 \mathrm{~b}$ & $0,001 \mathrm{a}$ & $0,001 \mathrm{a}$ \\
2 & $0,0002 \mathrm{a}$ & $0,004 \mathrm{~b}$ & $0,002 \mathrm{~b}$ \\
3 & $0,002 \mathrm{ab}$ & $0,001 \mathrm{ab}$ & $0,0003 \mathrm{a}$ \\
\hline
\end{tabular}

Referencias: Letras diferentes representan diferencias significativas

Respecto a la pauta "levantar barra anti aplaste", las cerdas realizaron menos esta pauta cuando su CC era baja. Y para "rotar", las hembras de CC óptima realizaron más veces la conducta que aquellas de baja CC. 
Tabla n¹0: Frecuencia de aparición de las conductas según la CC al ingreso a maternidad

\begin{tabular}{|c|c|c|}
\hline Categoría de $\mathrm{CC}_{0}$ & $\begin{array}{c}\text { Levantar barra anti } \\
\text { aplaste }\end{array}$ & Rotar \\
\hline 1 & $0,013 \mathrm{a}$ & $0,12 \mathrm{a}$ \\
2 & $0,05 \mathrm{~b}$ & $0,2 \mathrm{~b}$ \\
3 & $0,04 \mathrm{ab}$ & $0,05 \mathrm{ab}$ \\
\hline
\end{tabular}

$\underline{\text { Referencias: Letras diferentes representan diferencias significativas }}$

Para "Caminar" tuvieron una mayor duración las cerdas que aumentaron su CC respecto de los otros dos grupos.

En el caso de la pauta "Hociquear lechón" tuvieron mayor tiempo dedicado a esta pauta, aquellas que disminuyeron su CC respecto de las que mantuvieron su CC durante toda la lactancia.

Para la conducta "Lamer" las hembras que aumentaron su CC durante la lactancia destinaron mayor tiempo a la misma, respecto de los otros dos grupos.

En el caso de "Levantar barra anti aplaste" las cerdas que disminuyeron su CC durante la crianza de sus lechones, dedicaron menor tiempo a esta conducta que las otras dos categorías.

Las cerdas que estuvieron mayor tiempo con la pauta "Meter pata en comedero" fueron aquellas que aumentaron su CC a lo largo del mes alojadas en maternidad. 
Las reproductoras que mantuvieron su CC dedicaron menor tiempo a "Olfatear lechón" que el resto de las cerdas.

Tabla $n^{\circ}$ 11: Duración de las pautas según la variación entre la CC al ingreso y egreso de maternidad

\begin{tabular}{|c|c|c|c|c|c|c|}
\hline $\begin{array}{c}\text { Categoría } \\
\text { de } \\
\text { variación } \\
\text { de CC }\end{array}$ & Caminar & $\begin{array}{c}\text { Hociquear } \\
\text { lechón }\end{array}$ & Lamer & $\begin{array}{c}\text { Levantar } \\
\text { barra } \\
\text { anti } \\
\text { aplaste }\end{array}$ & $\begin{array}{c}\text { Meter } \\
\text { pata en } \\
\text { comedero }\end{array}$ & $\begin{array}{c}\text { Olfatear } \\
\text { lechón }\end{array}$ \\
\hline 1 & $0,01 \mathrm{a}$ & $0,003 \mathrm{a}$ & $0,002 \mathrm{a}$ & $0,0005 \mathrm{a}$ & $0 \mathrm{a}$ & $0,016 \mathrm{~b}$ \\
2 & $0,01 \mathrm{a}$ & $0,0001 \mathrm{~b}$ & $0,002 \mathrm{a}$ & $0,002 \mathrm{~b}$ & $0,0002 \mathrm{a}$ & $0,006 \mathrm{a}$ \\
3 & $0,05 \mathrm{~b}$ & 0 ab & $0,03 \mathrm{~b}$ & $0,007 \mathrm{~b}$ & $0,009 \mathrm{~b}$ & $0,04 \mathrm{~b}$ \\
\hline
\end{tabular}

$\underline{\text { Referencias: Letras diferentes representan diferencias significativas }}$

Las madres que aumentaron su CC en la lactancia, fueron las mismas que presentaron mayor frecuencia de "Hociquear" respecto de las otras. Así como también realizaron más veces la conducta de "Meter pata en comedero". Lo mismo sucedió con la pauta "Morder barra o comedero".

Las hembras que aumentaron su CC presentaron mayor número de veces la pauta "Lamer" que aquellas que la mantuvieron.

Para la conducta "Masticar" la frecuencia de presentación fue en orden descendente, hembras que aumentaron su CC, luego las que la mantuvieron y por último, fue menos frecuente en aquellas que la disminuyeron. 
Tabla n¹2: Frecuencia de aparición de pautas según la variación en la $\mathrm{CC}$ al inicio y final de la lactancia

\begin{tabular}{|c|c|c|c|c|c|}
\hline $\begin{array}{c}\text { Categoría } \\
\text { de } \\
\text { variación } \\
\text { de la CC }\end{array}$ & Hociquear & $\begin{array}{c}\text { Meter } \\
\text { pata en } \\
\text { comedero }\end{array}$ & $\begin{array}{c}\text { Morder } \\
\text { barra o } \\
\text { comedero }\end{array}$ & Lamer & Masticar \\
\hline 1 & $0,09 \mathrm{a}$ & $0 \mathrm{a}$ & $0,06 \mathrm{a}$ & $0,01 \mathrm{a}$ & $0,02 \mathrm{a}$ \\
2 & $0,08 \mathrm{a}$ & $0,02 \mathrm{a}$ & $0,06 \mathrm{a}$ & $0,01 \mathrm{a}$ & $0,05 \mathrm{~b}$ \\
3 & $0,35 \mathrm{~b}$ & $0,27 \mathrm{~b}$ & $0,27 \mathrm{~b}$ & $0,125 \mathrm{~b}$ & $0,21 \mathrm{c}$ \\
\hline
\end{tabular}

Referencias: Letras diferentes representan diferencias significativas

Las cerdas que tuvieron más de $24,5 \mathrm{~mm}$ (multíparas) o de $22 \mathrm{~mm}$ (nulíparas) de EGD al momento de ingresar a la sala de maternidad dedicaron menor tiempo a la posición "de pie".

Tabla $n^{\circ}$ 13: Duración de las pautas según el EGD en el ingreso a maternidad

\begin{tabular}{|c|c|}
\hline Categoría de $\mathrm{EGD}_{0}$ & De pie \\
\hline 1 & $0,1 \mathrm{a}$ \\
2 & $0,1 \mathrm{a}$ \\
3 & $0,04 \mathrm{~b}$ \\
\hline
\end{tabular}

Referencias: Letras diferentes representan diferencias significativas

Las hembras que tuvieron $24,5 \mathrm{~mm}$ (multíparas) o entre 17-22 (nulíparas) realizaron mayor cantidad de veces la conducta "hociquear lechón" que aquellas que ingresaron con mayor cantidad de grasa dorsal. 
Las cerdas que al momento del parto presentaban más de $24,5 \mathrm{~mm}$ (multíparas) o de $22 \mathrm{~mm}$ (nulíparas) realizaron menos veces la pauta “olfatear lechón" que el resto.

Tabla $n^{\circ}$ 14: Frecuencia de pautas según el EGD al inicio de la lactancia

\begin{tabular}{|c|c|c|}
\hline Categoría de $\mathrm{EGD}_{0}$ & Hociquear lechón & Olfatear lechón \\
\hline 1 & $0,02 \mathrm{ab}$ & $0,12 \mathrm{a}$ \\
2 & $0,04 \mathrm{a}$ & $0,14 \mathrm{a}$ \\
3 & $0,01 \mathrm{~b}$ & $0,07 \mathrm{~b}$ \\
\hline
\end{tabular}

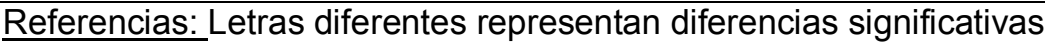

Dedicaron mayor tiempo a "caminar" y a "hociquear" las madres que perdieron menos de $2 \mathrm{~mm}$, mantuvieron o aumentaron su EGD durante la lactancia, respecto a los otros dos grupos.

Las porcinas que perdieron más de $3 \mathrm{~mm}$ de EGD durante la crianza de los lechones estuvieron más tiempo realizando la pauta "defecar" que las que perdieron entre 2 y $3 \mathrm{~mm}$. 
Tabla $n^{\circ}$ 15: Duración de las conductas según las variaciones en el EGD entre el inicio y finalización de la lactancia

\begin{tabular}{|c|c|c|c|}
\hline $\begin{array}{c}\text { Categoría de } \\
\text { variación en el } \\
\text { EGD }\end{array}$ & Caminar & Hociquear & Defecar \\
\hline 1 & $0,009 \mathrm{a}$ & $0,008 \mathrm{a}$ & $0,003 \mathrm{a}$ \\
2 & $0,007 \mathrm{a}$ & $0,005 \mathrm{a}$ & $0,0006 \mathrm{~b}$ \\
3 & $0,02 \mathrm{~b}$ & $0,02 \mathrm{~b}$ & $0,004 \mathrm{ab}$ \\
\hline
\end{tabular}

Referencias: Letras diferentes representan diferencias significativas

Las reproductoras que disminuyeron menos de $2 \mathrm{~mm}$, mantuvieron o aumentaron su EGD durante este periodo presentaron mayor cantidad de veces la pauta "vulva contra jaula" que el resto.

Tabla n¹6: Frecuencia de conductas según la variación en el EGD entre el ingreso y egreso de maternidad

\begin{tabular}{|c|c|}
\hline Categoría de la variación de EGD & Vulva contra jaula \\
\hline 1 & $0,07 \mathrm{a}$ \\
2 & $0,05 \mathrm{a}$ \\
3 & $0,12 \mathrm{~b}$ \\
\hline
\end{tabular}

Referencias: Letras diferentes representan diferencias significativas

Las cerdas de entre 3 y 6 partos dedicaron mayor tiempo a las pautas pertenecientes a la categoría "Generales", que el resto. 
Tabla n¹7: Duración de las pautas según la categoría de número de partos de las cerdas

\begin{tabular}{|c|c|}
\hline Categoría de parity & Conductas "generales" \\
\hline 1 & $0,008 \mathrm{a}$ \\
2 & $0,01 \mathrm{~b}$ \\
3 & $0,007 \mathrm{a}$ \\
\hline
\end{tabular}

Referencias: Letras diferentes representan diferencias significativas

Las cerdas de 1 o 2 partos realizaron más frecuentemente las pautas de categoría "posturales" y "hacia el lechón" que las de 3 a 6 partos.

Tabla n¹8: Frecuencia del comportamiento según la categoría de número de partos de las cerdas

\begin{tabular}{|c|c|c|}
\hline $\begin{array}{c}\text { Categoría de número } \\
\text { de partos }\end{array}$ & $\begin{array}{c}\text { Conductas } \\
\text { "posturales" }\end{array}$ & $\begin{array}{c}\text { Conductas "hacia el } \\
\text { lechón" }\end{array}$ \\
\hline 1 & $0,31 \mathrm{a}$ & $0,08 \mathrm{a}$ \\
2 & $0,27 \mathrm{~b}$ & $0,06 \mathrm{~b}$ \\
3 & $0,29 \mathrm{ab}$ & $0,06 \mathrm{ab}$ \\
\hline
\end{tabular}

$\underline{\text { Referencias: Letras diferentes representan diferencias significativas }}$

Las madres alojadas en jaulas orientadas hacia el pasillo entre galpones estuvieron mayor tiempo realizando pautas de la categoría "posturales" que las alojadas en parideras orientadas a la planta de alimentos o al campo abierto. 
Tabla n¹9: Duración de las conductas según la ubicación de la jaula paridera

\begin{tabular}{|c|c|}
\hline Ubicación de la jaula & Conductas "posturales" \\
\hline A & $0,17 \mathrm{ab}$ \\
B & $0,17 \mathrm{~b}$ \\
C & $0,16 \mathrm{ab}$ \\
D & $0,15 \mathrm{a}$ \\
\hline
\end{tabular}

Referencias: Letras diferentes representan diferencias significativas

Para las pautas de la categoría "posturales" dedicaron mayor tiempo las hembras de los bloques de lactancia 3 y 4 respecto del primer bloque.

Las conductas incluidas en las "generales" tomaron mayor parte del tiempo de las cerdas en el bloque 4, luego en el 2 y 3 por igual, y menos tiempo en el primer bloque

En el caso de las conductas "de contacto con las instalaciones" fueron más duraderas en el último bloque respecto del primero.

Y por último para aquellas pautas clasificadas como dirigidas "hacia el lechón" llevaron mayor tiempo en el primer bloque de lactancia respecto de los otros tres 
Tabla n²0: Duración de las categorías de pautas según el bloque de lactancia.

\begin{tabular}{|c|c|c|c|c|}
\hline $\begin{array}{c}\text { Bloque de } \\
\text { lactancia }\end{array}$ & Posturas & $\begin{array}{c}\text { Pautas } \\
\text { generales }\end{array}$ & $\begin{array}{c}\text { Pautas de } \\
\text { contacto con } \\
\text { el hábitat }\end{array}$ & $\begin{array}{c}\text { Pautas hacia } \\
\text { el lechón }\end{array}$ \\
\hline 1 & $0,16 \mathrm{a}$ & $0,004 \mathrm{a}$ & $0,002 \mathrm{a}$ & $0,02 \mathrm{a}$ \\
2 & $0,17 \mathrm{ab}$ & $0,008 \mathrm{~b}$ & $0,003 \mathrm{ab}$ & $0,011 \mathrm{~b}$ \\
3 & $0,17 \mathrm{~b}$ & $0,008 \mathrm{~b}$ & $0,003 \mathrm{ab}$ & $0,009 \mathrm{~b}$ \\
4 & $0,17 \mathrm{~b}$ & $0,13 \mathrm{c}$ & $0,004 \mathrm{~b}$ & $0,01 \mathrm{~b}$ \\
\hline
\end{tabular}

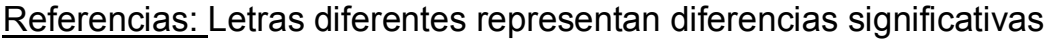

Las pautas "posturales", "generales" y "de contacto con las instalaciones" aparecieron más en el bloque de lactancia 4, luego en el 2 y 3 por igual, y fueron menos frecuentes en el bloque 1.

Tabla n²1: Frecuencia de las categorías de pautas según el bloque de lactancia

\begin{tabular}{|c|c|c|c|}
\hline $\begin{array}{c}\text { Bloque de } \\
\text { lactancia }\end{array}$ & Posturas & $\begin{array}{c}\text { Pautas } \\
\text { generales }\end{array}$ & $\begin{array}{c}\text { Pautas de } \\
\text { contacto con las } \\
\text { instalaciones }\end{array}$ \\
\hline 1 & $0,25 \mathrm{a}$ & $0,04 \mathrm{a}$ & $0,02 \mathrm{a}$ \\
2 & $0,3 \mathrm{~b}$ & $0,08 \mathrm{~b}$ & $0,04 \mathrm{~b}$ \\
3 & $0,3 \mathrm{~b}$ & $0,08 \mathrm{~b}$ & $0,04 \mathrm{~b}$ \\
4 & $0,33 \mathrm{c}$ & $0,11 \mathrm{c}$ & $0,06 \mathrm{c}$ \\
\hline
\end{tabular}

Referencias: Letras diferentes representan diferencias significativas

Para las pautas agrupadas en la categoría de "posturales" se hallaron diferencias significativas para la época y el año. Las cerdas dedicaron 
mayor tiempo a este tipo de pautas en invierno y primavera, y a su vez la duración de estas pautas fue aumentando a lo largo de los años.

Para las pautas "generales" se hallaron diferencias significativas según la época del año. Estas conductas ocuparon mayor tiempo de las reproductoras en verano.

Las pautas dirigidas "hacia el lechón" fueron significativamente menos duraderas en el año 2017

Las conductas "posturales" fueron significativamente menos frecuentes en 2015 y más frecuentes en primavera respecto a verano y otoño, y más frecuentes en invierno respecto a otoño

Tabla n²2: Duración de las pautas según la estación del año

\begin{tabular}{|c|c|c|}
\hline Época del año & Posturas & Pautas generales \\
\hline Primavera & $0,16 \mathrm{~b}$ & $0,008 \mathrm{a}$ \\
Verano & $0,17 \mathrm{a}$ & $0,011 \mathrm{~b}$ \\
Otoño & $0,16 \mathrm{a}$ & $0,007 \mathrm{a}$ \\
Invierno & $0,18 \mathrm{~b}$ & $0,004 \mathrm{a}$ \\
\hline
\end{tabular}

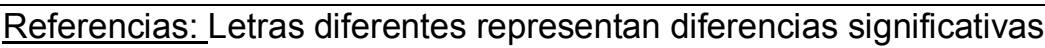

Tabla n²3: Frecuencia de las pautas según la época del año

\begin{tabular}{|c|c|}
\hline Época del año & Posturas \\
\hline Primavera & $0,3 \mathrm{c}$ \\
Verano & $0,3 \mathrm{ab}$ \\
Otoño & $0,29 \mathrm{a}$ \\
\hline
\end{tabular}


Invierno

$0,34 \mathrm{bc}$

$\underline{\text { Referencias: Letras diferentes representan diferencias significativas }}$

Tabla $n^{\circ} 24:$ Duración de las conductas según el año de estudio

\begin{tabular}{|c|c|c|}
\hline Año & Posturas & $\begin{array}{c}\text { Conductas hacia el } \\
\text { lechón }\end{array}$ \\
\hline 2015 & $0,16 \mathrm{a}$ & $0,012 \mathrm{a}$ \\
2016 & $0,16 \mathrm{~b}$ & $0,012 \mathrm{a}$ \\
2017 & $0,17 \mathrm{c}$ & $0,011 \mathrm{~b}$ \\
\hline
\end{tabular}

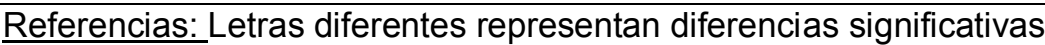

Tabla $n^{\circ} 25$ : Frecuencia de las pautas según el año

\begin{tabular}{|c|c|}
\hline Año & Posturas \\
\hline 2015 & $0,28 \mathrm{a}$ \\
2016 & $0,31 \mathrm{~b}$ \\
2017 & $0,29 \mathrm{~b}$ \\
\hline
\end{tabular}

$\underline{\text { Referencias: }}$ Letras diferentes representan diferencias significativas

\section{Discusión}

Algunos autores reportaron diferencias en la conducta de las cerdas en las distintas semanas de lactancia, Hernandez-Gonzalez (2014) por ejemplo halló un aumento en el intervalo entre amamantamientos en la cuarta semana de lactancia, y Cronin (2001) enunció que existía una diferencia en los intervalos entre amamantamientos dependiendo de la etapa de lactancia. Si bien, al analizar las pautas aquí descriptas, por separado la conducta de "Llamar a mamar" o "Amamantando" no resultó variar significativamente tanto en tiempo como en frecuencia de aparición, 
sí hubo diferencias en la conducta de las reproductoras según la etapa o bloque de lactancia. Analizando las pautas englobadas en su categoría todas ellas, salvo la categoría de pautas "dirigidas hacia el lechón" fueron más frecuentes y duraderas en el último bloque o semana de lactancia. Esta última categoría fue más duradera en el primer bloque, hecho coincidente con que es en estos primeros 5 días que la hembra realizará la mayor cantidad de cuidados e interacciones con sus crías. Dentro de las pautas que variaron de acuerdo al bloque se encuentran 17 de las 38 descriptas, difiriendo en duración en las diferentes etapas. Se han analizado descriptivamente las variaciones según el bloque de lactancia en el capítulo 1 y las conclusiones son coincidentes, las hembras modifican su comportamiento dependiendo de la etapa de lactancia o edad del lechón, lo que es importante para realizar manejos diferenciales y poder disminuir las restricciones de movimiento de las hembras en alguna/s de estas etapas. Un ejemplo de esto es que la pauta "hociquear" duró más en los primeros cinco días de lactancia, consistente con las teorías cobre construcción del nido, estudiada por Jensen $(1986,1993)$.

Estudiando las instalaciones, más allá de las consideraciones éticas y morales de este tipo de alojamientos que tanto restringe la movilidad de los animales (Marie, 2006; Rushen y col, 2008; Bernard, 2007; Hodges, 2006; Vassier, 2008), al considerar los aspectos científicos Weary y col (1996) encontraron diferencias en los cambios de postura dependiendo del tipo de paridera, y ya que los cambios de postura se asocian con los lechones aplastados, las instalaciones tienen una gran influencia en la 
productividad y bienestar de los animales. Por otro lado, García-Gonzalez y col en 2011 no encontraron diferencias en los parámetros estudiados de acuerdo a la sala de maternidad. En esta tesis, se hallaron diferencias significativas siendo las pautas "posturales" más duraderas en las hembras alojadas en jaulas parideras orientadas hacia el pasillo entre ambos galpones de maternidad. Una posible explicación para el hecho de que estas hembras estuvieran mayor tiempo en este tipo de posturas, y no realizando actos de movimiento podría ser el poco o casi nulo tránsito de personal por esta área entre galpones. En cambio al analizar cada pauta por separado se halló relación entre la pauta "caminar" y las jaulas orientadas hacia la planta de alimentos, y entre las pautas "beber", "morder barra o comederos" y "vulva contra jaula" y las cerdas alojadas en jaulas ubicadas al ingreso de los galpones, todas estas pautas comportamentales duraron mayor tiempo en este tipo de parideras, en las cuales el tránsito de personal y los sonidos fueron mayores.

Otros de los factores estudiados fueron la época del año o estación, que según autores como Hernandez-Gonzalez (2014) no tuvieron influencia en los amamantamientos. En este caso, las conductas posturales fueron más duraderas en invierno y primavera y más frecuentes en primavera, en cambio las pautas generales ocuparon mayor parte del tiempo de las cerdas en verano. Si bien ninguna de estas categorías incluye las conductas de amamantamiento que menciona este autor, sí hubo diferencias en el comportamiento de la hembra de acuerdo a la estación o época del año. Una posible explicación a la mayor duración de posturas 
en invierno puede ser la disminución de los movimientos por las temperaturas, si bien la misma dentro de la sala se encontraba regulada artificialmente, los animales llegaron a captar algo de estas variaciones, coincidente con lo estudiado por Finlay y col (2011) y Thorpe (1982) respecto al mundo perceptual propio de cada especie. $\mathrm{Y}$, respecto a las diferencias halladas para la estación de verano, puede deberse a la mayor duración de las horas luz externas, o quizás todo esto sea captado indirectamente, si bien las rutinas y los trabajadores no cambiaron, por las modificaciones en la conducta del personal de la granja, un aspecto no considerado en este trabajo.

Analizando la influencia del año en la conducta, es importante señalar que las pautas posturales ocuparon más tiempo en 2017 , y las pautas de contacto con las instalaciones más en 2015 y 2016. Las pautas posturales fueron más frecuentes en 2016 y 2017. Durante estos años de trabajo no hubo modificaciones en esta etapa tanto así en cuanto al manejo o las instalaciones. Diferentes autores han estudiado los cambios en el comportamiento productivo de los animales, algunos de ellos fueron Gomez Medina y col (1999) y Gomez (2009) quienes no hallaron diferencias. Estos resultados manifiestan que quedaron algunas variables sin considerar, la humedad de cada año puede ser una posible variable a considerar en futuros análisis.

Wechler y Hegglin (1997) estudiaron la asociación entre el número de parto de las reproductoras y la mortalidad de los lechones y al no hallar diferencias concluyeron que el aplastamiento es una conducta innata en 
las cerdas y que por lo tanto no se ve afectado por la experiencia. Estos autores reportaron que la conducta materna no se ve afectada por la experiencia de la cerda, (analizando la respuesta al chillido de alarma del lechón). Es por ello que el riesgo de aplastar a las crías es constante para cada hembra, ya que si responde o no al chillido del lechón será constante a lo largo de su vida. Por lo que observando el primer parto de una cerda se podría predecir su conducta en los siguientes. En este estudio se busca la relación entre el número de partos y la conducta, que puede o no llevar a la muerte por aplastamiento de los lechones, eventos analizados en el siguiente capítulo. Garcia Gonzalez y col (2011) no encontraron diferencias según el número de parto de las hembras y diferentes parámetros productivos de las mismas. En este trabajo, en cambio, se hallaron diferencias para el número de partos y diferentes conductas, las hembras de 3 a 6 partos dedicaron mayor tiempo a pautas de conductas generales, mientras que las cerdas de 1 o 2 partos presentaron mayor frecuencia de comportamientos posturales y dirigidos hacía el lechón. Estas diferencias en la conducta, tanto en duración de las mismas, como en frecuencia de aparición evidencian un cambio en la conducta a lo largo de la vida de la cerda. Las hembras de poca experiencia dirigen más conductas a los lechones y a su vez realizan más cambios posturales, lo que las vuelve un factor de riesgo para las crías. En esta categoría de cerdas se halló relación con la mayor duración de pautas como "vulva contra jaula" pauta asociada con el estado de alerta de la reproductora. Las hembras de 7 partos o más dedicaron mayor 
tiempo a "comer", por citar algunos ejemplos. Estas diferencias en la conducta muestran como la misma va mutando a lo largo de la vida del animal. Estos resultados, coinciden con García-Mungía y col (2014), que han sugerido que las hembras de primer y segundo parto están aún en crecimiento por lo que su producción y reproducción no es igual que el de las hembras adultas, esperándose entonces diferencias conductuales en esta categoría de reproductoras. De la misma manera, Fraser (1999) resaltó la importancia de las experiencias previas, demostrando que la conducta de las reproductoras fue diferente de acuerdo al número de lactancias que estas vivieron, coincidiendo con otros estudios (AlbiachSerrano y col, 2012) donde se reflejan diferencias en la conducta explicadas desde la ontogenia.

El estudio de la asociación entre el estado corporal de las cerdas y su conducta ha sido considerada por Drake y col en 2008 quienes describen la relación entre el descenso de la condición corporal y la disminución en la frecuencia de amamantamiento y los cambios de conducta para alejarse de la cría. En el estudio que aquí se presenta muchas conductas variaron tanto en frecuencia como en duración respecto al estado corporal al momento del comienzo de la lactancia, representado en condición corporal y espesor de grasa dorsal, y en la variación de estos parámetros, ya sea menor, mayor o la variación esperada luego de un mes de lactancia. Algunos comportamientos fueron más duraderos en hembras que disminuyeron por debajo de lo esperado su condición corporal, como por ejemplo "hociquear lechón". Por el contrario "caminar", "lamer" 
“levantar barra anti aplaste" y "meter pata en comedero", entre otras, fueron más duraderas en hembras que aumentaron sus reservas corporales, así como también fueron más frecuentes en estas cerdas "hociquear", "meter pata en comedero" y "morder barra o comedero", una posible explicación es la inquietud asociada con la ingesta de alimento. Relacionado con lo anteriormente mencionado, y utilizando la medición del dato objetivo de Espesor de Grasa Dorsal (Murillo Galan y col, 2007) las hembras que disminuyeron mucho su espesor de grasa dorsal fueron las que dedicaron mayor tiempo a "defecar". En estos casos, las conductas modificadas no parecen estar directamente relacionadas con alejarse de la cría, pero aquellas pautas de contacto con las instalaciones o algunas de las pertenecientes a la categoría de generales, podrían estar indicando alguna asociación, si bien el análisis de la motivación de la conducta requiere la profundización en otros factores, puede estarse reflejando en estas variaciones.

\subsection{EFECTO DE LAS ADOPCIONES SOBRE LA EXPRESIÓN DE LA} CONDUCTA

\section{Introducción}

Una práctica frecuente en los sistemas de producción son las adopciones cruzadas, con el fin de estandarizar las camadas en número y tamaño de lechones. Las adopciones cruzadas en función del potencial de las hembras son recomendables en producción comercial (García-Mungía y 
col, 2014). Es por eso que se ha estudiado el análisis de esta práctica y su impacto en la conducta de la hembra. Las adopciones se realizan en las primeras 24 hs postparto porque es en este momento, en este "periodo ventana" que se produce el troquelado, mencionado anteriormente. Con el fin de disminuir o eliminar el reconocimiento del lechón extraño, previo a introducirlo en la nueva camada se llevan a cabo diferentes estrategias, como envolver al lechón en placentas de la camada que lo recibe, ponerlo en contacto y frotarlo con los lechones propios de la hembra, enmascarar el olor del lechón con alguna sustancia esparcida cercana a los ollares de la cerda, entre otras. En el cerdo el olfato es uno de los sentidos más destacados, y este tiene una gran influencia en la conducta. Por ejemplo si se colocan gotas opacas en los ojos los animales no cambian su conducta social, pero se observan cambios cuando se produce anosmia (Jensen 2004). Cumbe Nacipucha (2014) estudió las diferencias conductuales en hembras que criaban lechones nacidos de otras cerdas, encontró que hembras con lechones adoptados disminuyen el tiempo entre amamantamientos y aumentan los amamantamientos no nutritivos, disminuyendo de esta manera la inversión de recursos en la crianza de lechones no propios.

Por otro lado, las experiencias tempranas pueden tener efectos a largo plazo sobre el futuro comportamiento. Estas experiencias están influenciadas por la interacción madre-cría a través de varios mecanismos (Champagne, 2008). El comportamiento de una hembra puede ser influenciado por la calidad o cantidad de cuidados maternos recibidos. 
(Champagne, 2011) Las crías aprenden cómo comportarse imitando a sus madres (Chidgey y col, 2016).

\section{Materiales y métodos}

Durante las primeras 24 horas posparto se realizaron las adopciones, estandarizaciones en peso y cantidad de lechones por camada (tanto machos como hembras), enmascarando el olor de los lechones que se introducían en otras camadas, debido a la importancia del sentido del olfato (Jensen, 2004). Se realizó un registro detallado de dichos cambios de camadas de las crías. Se los marcó temporalmente en la cola hasta los siete días de edad, momento en que se señalaron y registraron con la identificación individual y correspondiente a su camada de nacimiento. En las 166 lactancias hubo en total 61 hembras receptoras y 43 cerdas donadoras de lechones.

Para el análisis estadístico de los datos se utilizó una regresión binomial negativa (Dohoo y col, 2003) para el tiempo relativo de cada pauta respecto si había donado lechones a otra hembra y si había recibido crías de otra cerda. Estos análisis fueron realizados en el programa Stata II IC (JICA Provetsur).

$$
\operatorname{Ln}(\lambda)=B_{i}+U_{j}+P_{k}+R_{l}+D_{m}+R_{n}{ }^{3}
$$

\footnotetext{
$3 \quad$ Ver modelo referencias: Materiales y métodos, capítulo 2.
} 
Y por último se analizó mediante el estudio de $\mathbf{X}^{2}$ (Ji cuadrado) la asociación entre la condición de crianza de las lechones, adoptadas o no, y su comportamiento reproductivo.

\section{$\underline{\text { Resultados }}$}

La pauta "Caminar" presentó una menor duración en las hembras que donaron lechones respecto de las que no donaron lechones $(p<0,05)$.

La conducta "Echada lateral" presentó una mayor duración en las hembras que recibieron lechones respecto de las que no recibieron $(p<0,05)$.

Diferencias en el comportamiento reproductivo de hembras nulíparas no criadas por sus madres biológicas.

Tabla $\mathrm{n}^{\circ} 26$ : Seguimiento de las futuras reproductoras hermanas enteras

\begin{tabular}{|c|c|c|c|c|}
\hline & Destetadas $^{(1)}$ & Seleccionadas $^{(2)}$ & $\begin{array}{c}\text { Repiten } \\
\text { celo }^{(3)}\end{array}$ & Paren $^{(4)}$ \\
Adoptadas & 41 & 21 & 2 & 1 \\
No & 109 & 109 & 2 & 19 \\
adoptadas & & & & \\
$X^{2}$ & 61,06 & 1,06 & 5,79 \\
\end{tabular}

(1): Hembras de 1 mes de edad, pesadas y registradas. (2): Cerdas que cumplían los criterios fenotípicos para pasar al alojamiento de futuras reproductoras. (3): Nulíparas servidas que a los 21 
días evidenciaron celo nuevamente. (4): Hembras que gestaron e ingresaron a la etapa de maternidad a parir y criar.

De las 150 cerdas estudiadas, entre las cuales se encontraban hermanas enteras representadas en ambos grupos, de las 109 que no fueron adoptadas (criadas por su propia madre) 109 fueron seleccionadas para pasar al alojamiento y manejo de futuras reproductoras, mientras que de las 41 hembras que fueron adoptadas solo 21 fueron seleccionadas para el plantel de hembras de reposición. Existiría asociación entre la condición de crianza (adoptada-no adoptada) y ser seleccionada o no para la reposición, entre hermanas enteras $(p<0,001)$.

De las 109 hembras criadas al pie de su propia madre 19 tuvieron cría, mientras que de las hembras que fueron donadas y adoptadas por otra hembra solamente 1 tuvo cría. Existiría asociación entre la condición de crianza (adoptada o no) y parir $(p<0,05)$.

\section{Discusión}

Algunos autores encontraron que hembras que recibían otros lechones tenían intervalos más largos entre amamantamientos y aumentan los amamantamientos no nutritivos. Según Algers (1993), hembras con lechones adoptados tienen mayores frecuencias de amamantamientos no nutritivos y disminuyen el tiempo de amamantamiento (Nacipucha, 2014). Según Hernandez-Gonzalez (2014) las cerdas varían su conducta frente a crías extrañas y la manipulación de sus lechones. En esta tesis se vieron modificadas las conductas de las hembras, tanto de aquellas que 
recibieron o donaron lechones, como de las lechonas futuras reproductoras que fueron donadas.

Por un lado, las cerdas que recibieron lechones pasaron mayor tiempo "echadas lateral" y las que donaron lechones, dedicaron mayor tiempo a "caminar", estas diferencias en la conducta evidencian que más allá de controlar y enmascarar todos los aspectos del reconocimiento entre la hembra y sus crías, ambas categorías perciben estas manipulaciones y modifican su conducta en consecuencia.

En el caso de las lechonas que fueron donadas y criadas por otras hembras se encontraron las consecuencias de la adopción en los cambios respecto a la conducta reproductiva de las mismas, ya que es una posible explicación a que no hayan sido inseminadas, una vez que fueron seleccionadas para pasar de la etapa de recría al alojamiento y manejo de futuras reproductoras, (en esta etapa productiva se selecciona a las hembras al evidenciar las conductas de celo). $\mathrm{Y}$ de acuerdo a los resultados existió una asociación entre ser adoptadas y la selección o servicio durante esta etapa, y a su vez en la parición luego de haber sido inseminadas. Estos resultados coinciden con Chidgey y col (2016) al mencionar que el comportamiento futuro de las crías puede ser influenciado por el ambiente postnatal, y que el comportamiento de una hembra puede ser condicionado por la calidad o cantidad de cuidados maternos recibidos; con Champagne (2011), que establece un nexo entre las experiencias tempranas y el comportamiento, y concluye que en crías separadas de sus madres se observan modificaciones del 
comportamiento y con Williams (2004), quien demostró que el contexto social pre destete influye en la performance reproductiva. 


\section{CAPÍTULO 3: RELACIÓN ENTRE COMPORTAMIENTO Y PRODUCTIVIDAD}

\section{Introducción}

Una de las formas de estimar el estado de bienestar de los animales es inferirlo a través, junto con otros factores, de la productividad (LA den Hartog y col, 1993) (Broom, 1986). Una de las estimaciones más usadas, productivamente, del buen estado biológico, es el éxito reproductivo. Cuando un animal falla en sus intentos por acoplar con el ambiente, se evidencia, entre otras cosas, con muerte, disminución del crecimiento o fallas reproductivas (Broom, 1991). Este autor también mencionó que dos grupos de cerdas en diferentes alojamientos a las que se le dan las mismas oportunidades para reproducirse pueden diferenciarse en su éxito reproductivo. Este estudio estaría indicando como las condiciones ambientales, en este caso el tipo de alojamiento, pueden influenciar la productividad de las cerdas. En otro trabajo Broom (1986) mencionó como el descenso de los parámetros productivos es un indicador de pobre bienestar animal.

Otro trabajo sobre comportamiento y productividad de cerdas es el de Lawrence (2008) el cual describe cómo la frustración de la hembra, al no poder realizar la construcción del nido en el parto, es reflejada en la correlación de comportamiento y respuesta psicológica con potenciales efectos adversos en el comportamiento materno y la supervivencia de los lechones. La cantidad de lechones destetados es uno de los principales parámetros productivos de estas explotaciones y de ahí su importancia en 
el estudio de asociaciones con diferentes patrones conductuales. Varios autores han estudiado el tema, tal como Barnet y col (2001) quienes encontraron evidencias de que el comportamiento de la hembra es importante para la supervivencia del lechón, ya que estos son aplastados cuando la hembra come, se echa o rueda.

La relación de distintos aspectos fisiológicos de la hembra y parámetros productivos de la cerda se estudió desde diferentes perspectivas. Algers (1993) explicó cómo la hembra puede ajustar su metabolismo de acuerdo al tamaño de camada. Lechones más pesados realizarán un masaje de las mamas más vigoroso, más masajes estimularán la liberación de prolactina, glucagón y péptido vasoactivo intestinal y disminuirán la de somatostatina. De esta manera, el autor explicó la modificación de una ruta metabólica, asociada con un parámetro productivo, mediado y evidenciado por la conducta de los animales.

Otro ejemplo de la relación entre la conducta y la producción lo proponen Cronin y col (2001) al estudiar la conducta de amamantamiento, cuyos intervalos se dan entre 45-50 minutos. Estos se van modificando según el tamaño de la camada, y de acuerdo a la etapa de lactancia. De esta manera la edad de los lechones, y la cantidad de nacidos vivos modificaron la conducta de la reproductora.

Weary y col (1996) estudiaron la relación entre los cambios de postura de las hembras y las muertes por aplastamiento y encontraron una asociación positiva entre ambos eventos. 
En la actualidad las cerdas producen un alto número de crías por parto, los lechones a su vez nacen con el $0,5 \%$ del peso de la madre y bajas reservas corporales. Estos factores predisponen a aumentar la mortalidad pre-destete (Drake y col, 2008) y esta es importante para el bienestar animal y la producción (Arey y Sancha, 1996).

Grandin (2001) encontró que cerdas que estaban dispuestas a acercarse a la gente eran más productivas y tenían más crías. Hemsworth, Brand y Willenis reportaron que la performance reproductiva de los cerdos disminuye cuanto menor es su cercanía con los humanos (Hemsworth y col, 2004)

En este capítulo se estudiará la relación entre el comportamiento de las reproductoras y los parámetros productivos y reproductivos más utilizados para evaluar la eficiencia de las cerdas reproductoras explotadas en los sistemas intensivos confinados actuales.

\section{Materiales y métodos}

Se registró para cada hembra la cantidad de nacidos totales (NT), nacidos vivos (NV), nacidos muertos (NM), y nacidos muertos momificados (mo). El día del parto se descolmilló a los lechones, y se aseguró el calostrado de toda la camada. Se pesó a la totalidad de los lechones nacidos (1694, 785 hembras y 909 machos), con una balanza digital de 1 a $3000 \mathrm{gr}$. DI 8252 Daewoo $^{R}$. 
Se registró sexo, fecha y causa de muerte de los lechones muertos durante la lactancia. Se consideró “muertos" los lechones que murieron aplastados o por emaciación. Se realizó la necropsia (Segales y Domingo, 2004) de los lechones muertos pre-destete. Las crías que murieron debido a enfermedades, mal formaciones, problemas de instalaciones como por ejemplo rupturas del suelo y ahogamientos en la fosa de desechos, no fueron considerados en el análisis.

El destete se realizó los días viernes por la mañana. Al día 28 de lactancia aproximadamente. Y se realizó el pesaje individual de los lechones en una báscula portátil.

Se consideró la fecha de servicio posterior al destete de las hembras, para construir el dato productivo de Intervalo destete-servicio (IDS)

Se procedió al análisis estadístico de los datos mediante el análisis de regresión simple para el peso al nacimiento (PN) y el peso al destete (PD), este último ajustado por la edad al momento del destete y por el tamaño de la camada al momento del destete: $\mathbf{Y}_{\mathrm{ij}}=\boldsymbol{\alpha}+\boldsymbol{\beta} \mathbf{X}_{\mathrm{i}}+\boldsymbol{\varepsilon}_{\mathrm{ij}}$; y para el tratamiento de los datos de nacidos totales, nacidos vivos, nacidos muertos, momificados, destetados y el intervalo destete servicio se utilizó el análisis de regresión binomial negativa: $\mathbf{E}(\mathbf{Y i} \mid \mathbf{x i})=\exp ^{(\mathbf{x i})}$.

$$
Y_{i j}=\alpha+\beta P N_{i}+\varepsilon_{i j}
$$

PN: Peso promedio al nacimiento

$\boldsymbol{\varepsilon}$ : Error 


$$
Y_{i j}=\alpha+\beta P D_{i}+\varepsilon_{i j}
$$

PD: Peso promedio al destete (ajustado por tamaño de camada y edad al destete)

$$
E(Y i \mid x i)=\exp ^{(N V i \beta)}
$$

NV: Nacidos vivos

$$
E(Y i \mid x i)=\exp ^{(D t i \beta)}
$$

Dt: Lechones destetados

$$
E(Y i \mid x i)=\exp ^{(I D S i \beta)}
$$

IDS: Intervalo destete-servicio

Se utilizó el programa Statgraphic Centurion $^{\mathrm{R}}$ para el cálculo de $\mathbf{X}^{\mathbf{2}}$ para el análisis de la mortalidad en asociación con la duración y la frecuencia de las pautas, para lo cual se categorizó la frecuencia y la duración en 2 grupos, cada una, "0" para los valores menores a la mediana y "1" para los valores mayores a la mediana.

\section{$\underline{\text { Resultados }}$}

Se halló una relación inversa entre la frecuencia de aparición de las pautas dirigidas hacia el hábitat y $N V(p=0,028)$. A su vez se encontró una relación inversa entre la frecuencia de aparición de las pautas generales y el IDS $(p=0,033)$. Se evidenció una relación directa entre el tiempo que las cerdas dedicaron a las pautas dirigidas hacia el hábitat y el peso al destete $(p=0,025)$. 
Ecuaciones de resultados para la frecuencia de aparición de las categorías de pautas y duración de las mismas:

- $\mathrm{NV}=\exp \left(2,34166-0,412741^{*} \mathrm{FPc} 3\right)$

NV: Nacidos Vivos

FPc3: Frecuencia de pautas "de contacto con las instalaciones"

- IDS $=\exp \left(1,80805-0,72828^{*} \mathrm{FPc} 2\right)$

IDS: Intervalo destete-servicio

FPc2: Frecuencia de pautas "Generales"

- $\mathrm{PD}=8,84644+0,127591^{*}$ LOG $(\mathrm{TPc} 3)$

PD: Peso al destete

TPc3: Tiempo de pautas "de contacto con las instalaciones"

En el análisis de regresión del parámetro NV se hallaron relaciones inversas significativas con la frecuencia de aparición de "morder barra o comedero" $(p=0,008)$ y "hociquear" $(p=0,02)$, y con el tiempo de duración de "arrodillada" $(p=0,027)$, "caminar" $(p=0,04)$ y "descender tren posterior" $(p=0,007)$.

Ecuaciones de resultados para NV en relación con la frecuencia de aparición y el tiempo de duración de las pautas

- $\mathrm{NV}=\exp \left(2,3399-0,182651^{*} \mathrm{Fmb}\right)$

Fmb: Frecuencia de "morder barra o comedero" 
- $\mathrm{NV}=\exp \left(2,34032-0,158453^{*} \mathrm{Fh}\right)$

Fh: Frecuencia de "hociquear"

- $\mathrm{NV}=\exp \left(2,00811-0,0638849^{*} \mathrm{Tcf}\right)$

Tcf: Tiempo de "arrodillada"

- $\mathrm{NV}=\exp \left(2,17242-0,0300031^{*} \mathrm{Tc}\right)$

Tc: Tiempo de "caminar"

- $\mathrm{NV}=\exp \left(1,79788-0,0841793^{*} \mathrm{Tdtp}\right)$

Tdtp: Tiempo de "descender tren posterior"

Respecto al IDS, se halló una relación directa con la duración de la pauta "morder barra o comedero" $(p=0,01)$, y relaciones inversas con el tiempo de duración de "beber" $(p=0,0001)$ y "pararse" $(p=0,003)$, y con la frecuencia de aparición de "de pie" $(p=0,028)$, "sentada" $(p=0,022)$, "caminar" $(p=0,02)$, "comer" $(p=0,03)$ y "orinar" $(p=0,02)$.

Ecuaciones de resultados para IDS en relación con la duración y la aparición de las pautas

- IDS $=\exp \left(1,30345-0,120827^{\star} \mathrm{Tb}\right)$

Tb: Tiempo de "beber"

- IDS $=\exp \left(2,13264+0,0902857^{\star} \mathrm{Tmb}\right)$

Tmb: Tiempo de "morder barra o comedero"

- IDS $=\exp \left(0,347007-0,206276^{*} T p\right)$ 
Tp: Tiempo de "pararse"

- $\operatorname{IDS}=\exp \left(1,79299-0,200999^{*} \mathrm{Fdp}\right)$

Fdp: Frecuencia de "de pie"

- $\quad$ IDS $=\exp \left(1,79467-0,206758^{*} \mathrm{Fs}\right)$

Fs: Frecuencia de "sentada"

- $\mathrm{IDS}=\exp \left(1,79129-0,228215^{\star} \mathrm{Fc}\right)$

Fc: Frecuencia de "caminar"

- $\mathrm{IDS}=\exp \left(1,79064-0,202382^{*} \mathrm{Fco}\right)$

Fco: Frecuencia de "comer"

- $\quad$ IDS $=\exp \left(1,76722-0,705747^{*} \mathrm{Fo}\right)$

Fo: Frecuencia de "orinar"

Al estudiar el peso al nacimiento, se hallaron relaciones directas con el tiempo de "echada ventral" $(p=0,008)$, la frecuencia de "olfatear lechón" $(p=0,027)$, y con la frecuencia de aparición de "echada ventral" $(0,002)$.

Ecuaciones de resultados para Peso al nacimiento y la frecuencia de aparición y tiempo de duración de las pautas

- $\mathrm{PN}=1,37902+0,020278 *$ LOG $(\mathrm{Tev})$

Tev: Tiempo de "echada ventral"

- $\mathrm{PN}=1,10673+0,195947^{*} \sqrt{ }(\mathrm{Fev}+1)$

Fev: Frecuencia de "echada ventral" 
- $\mathrm{PN}=1,11932+0,208052^{*} \sqrt{ }(\mathrm{Fol}+1)$

Fol: Frecuencia de "olfatear lechón"

El Peso al Destete tuvo una relación directa con el tiempo de duración de "hociquear" $(p=0,005)$ y una relación inversa con el tiempo de duración de "de pie" $(p=0,0496)$.

Ecuaciones de resultados para Peso al Destete y el tiempo de duración y frecuencia de aparición de las pautas

- $\mathrm{PD}=9,0335+0,192718^{*} \mathrm{LOG}(\mathrm{Th})$

Th: Tiempo de "hociquear"

- $\mathrm{PD}=7,86461-0,0875184^{*} \mathrm{LOG}(\mathrm{Tdp})$

Tdp: Tiempo de "de pie"

Se halló asociación entre la duración de la pauta "echada lateral" y la cantidad de muertos en la lactancia $(p=0,0091)$.

Gráfico n¹: Asociación entre muertos y la duración de "echada lateral"

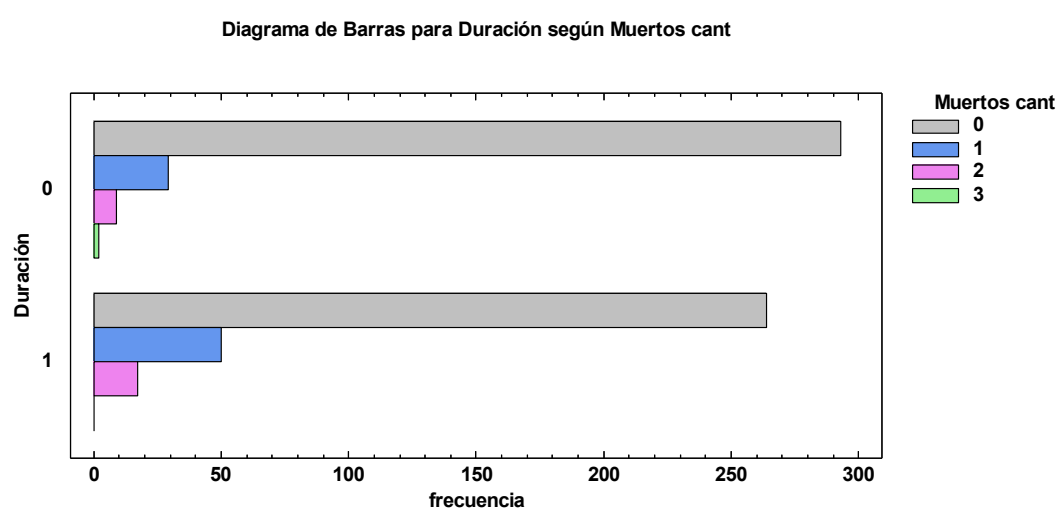


Se hallaron asociaciones entre la mortalidad pre destete y la duración de la pauta "de pie" $(p=0,02)$ y la frecuencia de la misma $(p=0,03)$.

Gráfico n²: Asociación entre mortalidad y duración de "de pie"

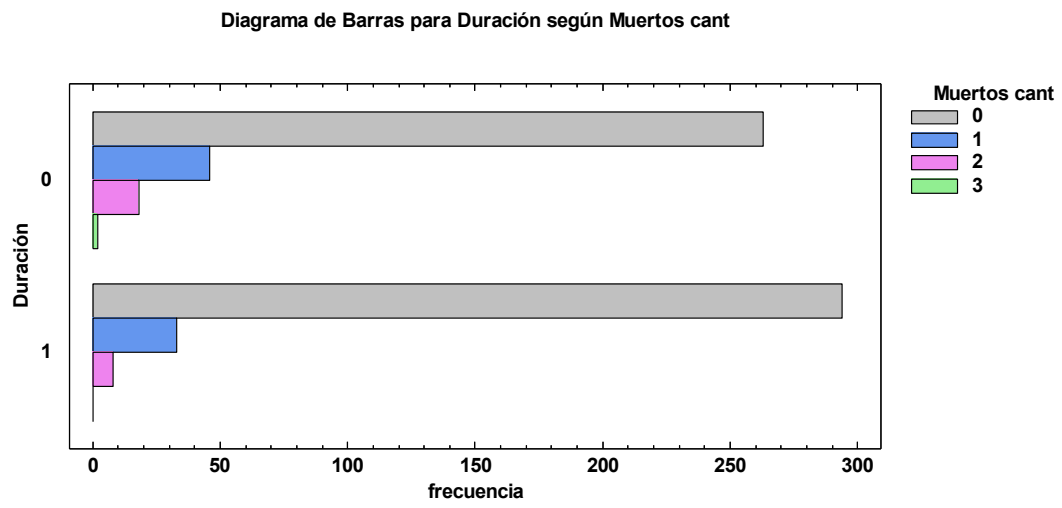

Se hallaron asociaciones entre la mortalidad pre destete para duración y frecuencia de aparición de "caminar" $(p=0,0159)$ y "comer" $(p=0,0427)$.

Gráfico n³: Asociación mortalidad y frecuencia de "caminar"

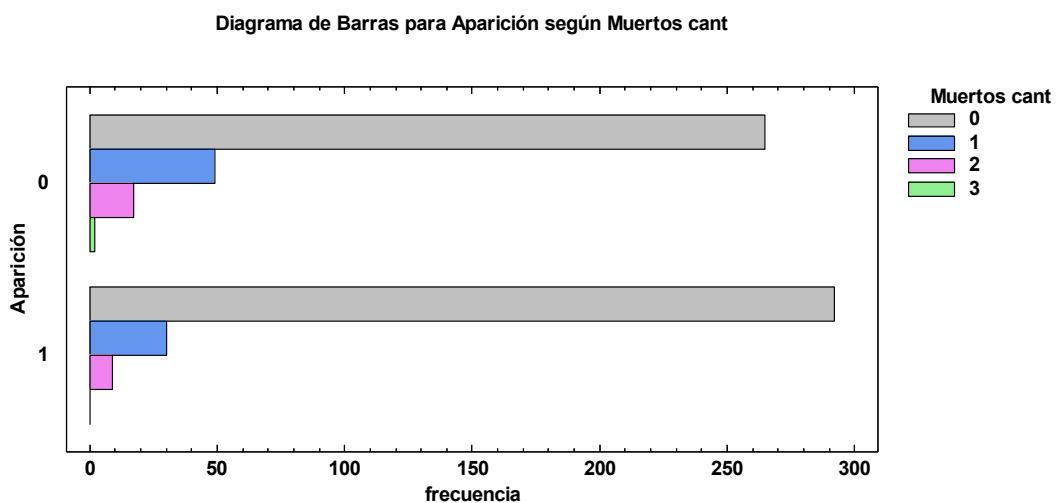


Gráfico n4: Asociación entre mortalidad y duración de "comer"

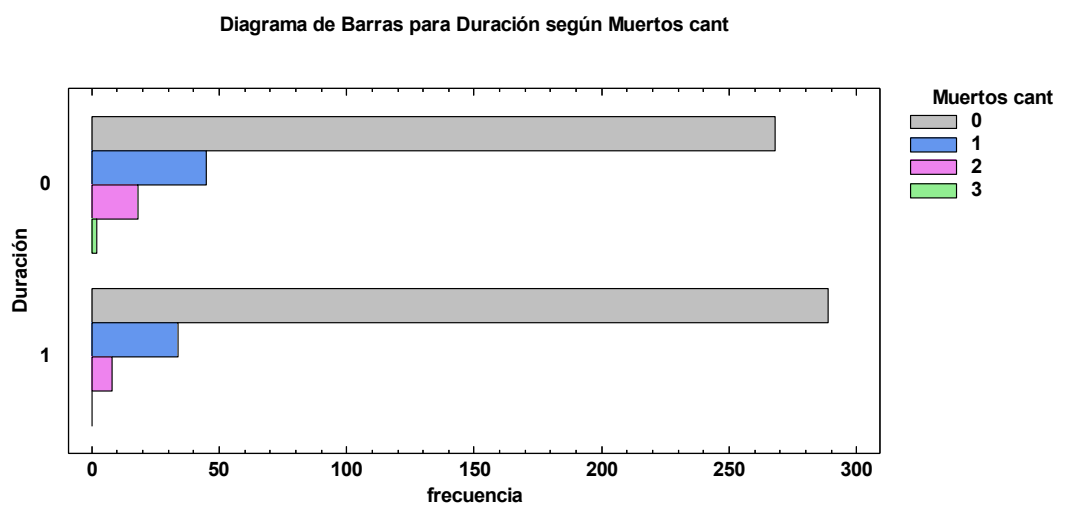

\section{Discusión}

Respecto al tamaño de camada, representada en este trabajo por NV, Cronin (2001) mencionó que el intervalo entre amamantamientos se ve afectado por este parámetro. En cambio, en este estudio no se halló relación entre la pauta "amamantando" o "llamar a mamar" respecto a tiempo ni frecuencia, en relación con los NV.

Grandin (2001) escribió sobre la relación entre hembras más tranquilas que tuvieron un mayor número de NV. Hellbrügge (2007) encontró una correlación negativa entre la reacción de las hembras frente a la separación de las crías en las primeras 24 horas posparto. En ambos casos la metodología por la cual se estudió la conducta no coincidió con la utilizada en esta tesis, por lo que el término "tranquilas" o la reacción frente a modificaciones propias de un experimento no poseen un equivalente en este estudio, pero si se encontraron relaciones de este parámetro con distintas conductas. 
En este trabajo los NV presentaron una relación inversa respecto a la categoría de pautas "de contacto con las instalaciones" con lo que a menor tamaño de camada, mayor tiempo dedica la hembra a interactuar con su alojamiento, esto podría indicar que la hembra invierte tiempo en la cría que podría dedicar a otro tipo de conductas que persigan otro objetivo, pero a mayor número de crías disminuye sus interacciones con las instalaciones.

EI IDS, por otro lado presentó una relación inversa con las pautas "generales", en estas categoría se encuentran las pautas que son independientes del momento fisiológico de la reproductora, como "comer", "orinar", "caminar", "beber", entre otras, por ende a mayor actividad en estas categorías, más rápido retornará la cerda su ciclicidad y en consecuencia productividad.

Al analizar cada pauta individualmente, ambos parámetros tuvieron relación con varias de ellas, ya sea en el tiempo y/o la frecuencia de las mismas. A mayor cantidad de lechones NV menor tiempo dedicado a pautas de locomoción como "caminar", "descender tren posterior" pauta considerada empíricamente de alto riesgo para los lechones, y estar en la posición "arrodillada". Esto podría indicar que las cerdas con un alto número de lechones limitan aún más sus movimientos o cambios entre estas posiciones, lo que significaría una disminución en el riesgo de aplastamiento, contrariamente a lo planteado por Weary y col (1998) quienes sostuvieron que los muertos tienen una relación positiva con los NV, o por García-Gonzalez y col (2011) quienes mencionaron la relación 
entre la mortalidad y el tamaño de camada. A su vez, los NV presentaron una relación inversa con "morder barra o comedero" y "hociquear" ambas pautas "de contacto con las instalaciones" coincidente con los resultados hallados al analizar las pautas por categoría. Al estudiar el IDS, y su relación con las pautas, se halló una relación inversa con "beber" y "pararse", "caminar", "comer" y "orinar" consistente con el análisis de categorías de pautas. Y una relación positiva con "morder barra o comedero" por lo que hembras con mayor tiempo dedicado a esta conducta, que en algunos casos puede considerarse un tipo de estereotipia, tardarán más en volver a ser productivas. Lo cual coincide con la asociación citada en la bibliografía respecto a la productividad y el bienestar animal.

Hansson (2005) resaltó la correlación negativa entre el tiempo de huida y el peso de los cerdos, y Del Campo (2011) mencionó que los animales más tranquilos tienen mayor ganancia diaria de peso, en bovinos. Weary y col (1998) resaltaron la importancia del peso al nacimiento, ya que concluyeron que posee una relación negativa con la tasa de mortalidad. El peso al nacimiento tuvo relación positiva con el tiempo de duración y la frecuencia de aparición de la pauta "echada ventral", lo que estaría indicando que mientras más pesados nacen los lechones la hembra permanece más tiempo en dicha posición, o visto desde otra perspectiva cuando los lechones nacen con bajo peso la hembra limita posturas que eviten el contacto de estos últimos con las mamas, como es el caso de "echada ventral". Este parámetro productivo tuvo también una relación 
positiva con la frecuencia de aparición de la pauta "olfatear lechón", con lo cual al nacer lechones más pesados, y activos, la hembra interactúa más con ellos, esto podría indicar que mientras más vitales son las crías la madre invierte más cuidados por las posibilidades de supervivencia.

Respecto al peso al destete, se halló una relación directa con el tiempo de las pautas "de contacto con las instalaciones", una relación inversa con el tiempo que la hembra permaneció "de pie" y una directa con el tiempo de "hociquear" pauta de contacto con las instalaciones, por lo que los resultados fueron consistentes. Cerdas que dedicaron menos tiempo en permanecer "de pie" debieron invertir más tiempo en pautas directamente asociadas al crecimiento o alimentación de los lechones y por ende al momento del destete estos fueron más pesados.

García-Gonzalez (2011) encontró una relación de la mortalidad con el tamaño de camada, Wechler y Hegglin (1997) estudiaron el impacto del número de partos de las cerdas con la mortalidad por aplastamiento, Hellbrügge (2007) no encontró correlación entre los aplastamientos y los cambios posturales de las cerdas, pero sí encontró una asociación respecto a hembras más reactivas con baja pérdida de lechones. En este estudio al considerar la mortalidad pre destete, variable que afecta tanto la productividad como el bienestar animal (Arey y Sancha 1996), relacionada con factores maternos (los aplastamientos y las muertes por inanición debida a la mala interacción madre-cría-) hubo asociación de la mortalidad de lechones con la conducta de la madre. Mientras menos tiempo la hembra estuvo "echada lateral" mayor fue la mortalidad, ya que 
esta postura permite el acceso de los lechones a las mamas, con lo cual lechones mejor alimentados serán más activos y vivaces, y por otro lado, al estar la hembra en esta posición realiza menos movimientos de riesgo para los lechones en cuanto a aplastamiento. En cambio, lo contrario ocurrió en cuanto a las pautas "caminar" y "comer" ambas conductas que implican a la hembra en posiciones como "de pie" y/o "sentada", estas dos posturas se asociaron empíricamente con el riesgo de aplastamiento, y en este trabajo "de pie" tuvo asociación positiva con la mortalidad, además de ser posturas y actos que no permiten el amamantamiento, por lo que la muerte por inanición es también posible.

Los resultados manifiestan la relación existente entre los parámetros productivos y la conducta, resaltando la importancia de considerar ambas medidas para estudiar el estado de bienestar de los animales, coincidiendo con lo planteado por Broom (1991) quien especifica que una medida puede estar alterada y la otra no. Se resalta la importancia de estudiar el comportamiento como indicador del bienestar animal. (Smulders, 2006) 


\section{CAPÍTULO 4: ASPECTOS GENÉTICOS DEL COMPORTAMIENTO}

\section{Introducción}

Más allá que las particularidades de la conducta puedan ser modificadas por el ambiente, estas están fijadas genéticamente (Fajardo-Castillo, 2009). Un animal que no puede vivir en la forma en la que ha evolucionado no está en buen bienestar animal (Fraser, 1999). Respecto a eso, lo codificado genéticamente incluye el conjunto de adaptaciones como resultado de la evolución y domesticación (Fraser, 1999).

El impacto de los factores genéticos en la conducta se ha estudiado y de tal forma, que ya se conoce que algunas líneas genéticas específicas pueden diferir en su habilidad para adaptarse a un tipo de alojamiento (Salak-Johnson y col, 2010).

La regulación genética del comportamiento ha sido objeto de estudio durante décadas, en diferente grado de profundidad, altamente asociado a los avances tecnológicos. Autores como Vaca (2010) han estudiado el temperamento animal y su heredabilidad. En dicho trabajo, este autor enuncia que los procesos de miedo y ansiedad son controlados en parte por factores genéticos, que el temperamento bovino es heredable y sus diferencias persisten en el tiempo, que la raza es un factor importante en la reactividad, y menciona la existencia de marcadores genéticos (QTL) asociados al miedo. Del Campo (2011) coincide en que en los bovinos existen diferencias de temperamento entre razas. 
Las investigaciones respecto del efecto de la constitución genética sobre el comportamiento, son tan antiguas, como el estudio de la conducta. A comienzos del siglo XX Lorenz, Tinbergen y Withman, entre otros estudiaron la importancia de los factores genéticos en la conducta animal. Pero estas asociaciones no se realizaron solamente en animales, en humanos, por ejemplo, la timidez, entendida como la tendencia a evitar interacciones sociales (Pilkonis, 1977), es el rasgo más heredable (Grandin, 1998).

Al hablar de heredabilidad se hace referencia al parámetro que refleja cuanto de las variaciones observadas en los fenotipos de una población se deben a las variaciones genéticas de la misma. Es muy útil para estimar el progreso genético que se logrará con la selección (Dube, 2012).

A su vez, dentro de los trabajos realizados sobre este tema, existe una gran variedad de aspectos comportamentales utilizados, por ejemplo Koolhass (1999) concluye que el genotipo es uno de los factores que afectan la capacidad de "coping" del individuo.

El factor raza es una de las formas más accesibles de realizar estudios sobre poblaciones genéticamente diferentes. Hohenshell (1997) estudió las diferencias en la conducta de hembras de raza Meishan respecto de híbridas de Yorkshire y Landrace. García Mungía (2014) estudió las diferencias entre líneas genéticas de reproductoras basándose en parámetros productivos y reproductivos de las cerdas. Piedrafita y 
Manteca (2002) mencionaron las diferencias respecto a reactividad social entre cerdos de razas chinas respecto de cerdos de razas europeas. Estos autores encontraron diferencias en el comportamiento entre los grupos estudiados.

Diferentes autores han calculado la heredabilidad para diferentes razas de cerdos respecto a diferentes caracteres. Galindez (2004) estudió la heredabilidad para la supervivencia de los lechones. D`eath (2009) calculó la heredabilidad para la agresión. Hansson (2005) trabajó sobre la heredabilidad del tiempo de huida y la correlación existente entre este parámetro y el peso de los animales, este autor a su vez propone utilizar como criterio de selección "Pruebas de Reacción" con el fin de mejorar el temperamento. En bovinos y porcinos la selección para aumentar la ganancia diaria de peso y el porcentaje de magro dio como resultados animales con caracteres más excitables, esto último se debe a los síndromes de rasgos, mencionados con anterioridad.

Uno de los cambios más significativos es que para mejorar el bienestar animal, puede ser apropiado, además de las variaciones en el manejo, contemplar alternativas que consideren componentes genéticos (Lawrence, 2008).

Dado que el concepto de "normas de reacción" hace referencia al rango de fenotipos que pueden ser producidos con un genotipo dado (Stamps, 2010) se vuelve necesario estudiar el mayor o menor impacto de distintos factores. Albores Gallo (2003) enuncia que los genes se activan y 
desactivan en diferentes etapas del desarrollo modificando el temperamento. Estos resultados están muy asociados al trabajo de Koolhass (1997) quien considera que los estilos comportamentales tienen un origen genético y epigenético en la vida temprana.

El efecto de los genotipos de los progenitores tiene un impacto profundo en el desarrollo de la "personalidad" de los animales (Stamps, 2010). El comportamiento materno tiene efectos a largo plazo en la conducta de la cría y sus descendientes, según Champagne (2009) este efecto se produce como consecuencia de procesos de metilación del ADN. Estos cambios en los cuidados maternos se transmiten de madres a hijas (Champagne, 2008). Para Jensen (2014) las crías reprodujeron una conducta utilizada por los progenitores para adaptarse a un ambiente determinado, independientemente del contexto en el cual estas crías se encontraban.

\section{Materiales y métodos}

Se trabajó con dos generaciones de hembras de razas Landrace y Yorkshire (103 cerdas en total) pertenecientes a una granja intensiva confinada ubicada en la localidad de Pergamino, Buenos Aires ($33.933833,-60.778806)$.

Para el análisis estadístico de los datos se utilizó regresión binomial negativa: $\operatorname{Ln}(\boldsymbol{\lambda})=\mathbf{B}_{\mathrm{i}}+\mathbf{U}_{\mathrm{j}}+\mathbf{P}_{\mathrm{k}}+\mathbf{R}_{\mathrm{l}}+\mathbf{D}_{\mathrm{m}}+\mathbf{R e}_{\mathbf{n}}{ }^{4}$ (Dohoo y col 2003) para el 
tiempo relativo de cada pauta respecto a la raza. Este análisis fue realizado en el programa Stata II IC (JICA Provetsur). Para el análisis de varianza de las categorías de las pautas según la raza: $\mathbf{Y}=\boldsymbol{\mu}+\mathbf{R}+\boldsymbol{\varepsilon}$ se utilizó el programa Statgraphics Centurion ${ }^{R}$

Se procedió al análisis de varianza multifactorial considerando la raza y el progenitor macho. Para $\sqrt{ }(X+1)$ en el caso de la frecuencia de aparición y para el $\log (X)$ en el caso del tiempo de duración de cada pauta.

$$
Y_{i j}=\mu+R_{i}+P M_{j}+\varepsilon_{i j}
$$

R: Raza

PM: Padre

Se realizó el análisis de los componentes de la varianza para el orden de anidamiento: Raza-Padre-Madre, para $\sqrt{ }(X+1)$ en el caso de la frecuencia de aparición y para el $\log (X)$ en el caso del tiempo de duración de cada una de las pautas que presentaron diferencias significativas $(p<0,05)$ respecto al factor "padre" del análisis multifactorial de la varianza. Se consideró $\alpha=0,05$

$$
Y_{i j k}=\mu+R_{i}+P M_{i j j} M_{i j k}+\varepsilon_{i j k}
$$

R: Raza

PM: Padre

M: Madre 
Se analizaron los componentes de la varianza para los parámetros productivos respecto al modelo de anidamiento: Raza-Padre-Madre. $(\alpha=$ $0,05)$

Se estimó la heredabilidad realizada mediante el método de regresión, y el análisis de los componentes de la varianza, para $\sqrt{ }(x+1)$ en el caso de la frecuencia de aparición, y para LOG (x) en el caso del tiempo de duración de la pauta. $(\alpha=0,05)$

Estos últimos análisis se realizaron en el programa Statgraphic Centurion $^{\mathrm{R}}$.

\section{$\underline{\text { Resultados }}$}

Las hembras Landrace dedicaron mayor tiempo a las pautas "de contacto con las instalaciones" que las Yorkshire $(p=0,03)$.

Tabla n²7: Duración de las conductas según la raza

\begin{tabular}{|c|c|}
\hline Raza & $\begin{array}{c}\text { Pautas de contacto con las } \\
\text { instalaciones }\end{array}$ \\
\hline Landrace & $0,004 \mathrm{a}$ \\
\hline Yorkshire & $0,003 \mathrm{~b}$ \\
\hline
\end{tabular}

Referencias: Letras diferentes representan diferencias significativas

Las cerdas de la raza Landrace dedicaron mayor tiempo a las conductas "amamantando" $(p=0,001)$, "llamar a mamar" $(p<0,001)$, "arrodillada" $(p=0,02)$, y "echada lateral" $(p=0,003)$ que las Yorkshire. Estas últimas en cambio estuvieron mayor tiempo realizando las conductas de "morder barra o comedero" $(p=0,01)$ y "olfatear lechón" $(p=0,003)$. 
Se observaron diferencias significativas entre las hijas de los diferentes padres (33 machos en total) para la frecuencia de las siguientes pautas: "sentada" ( $p=0,0022)$, "echada ventral" $(p=0,001)$, "masticar" $(p<0,0001)$, "mirar lateral" $(p<0,0001)$, "meter pata en comedero" $(p<0,0001)$, "morder barra o comedero" $(p=0,025)$, “orinar" $(p=0,006)$, "sentarse (estando echada)" ( $p=0,024)$, "sentarse (estando de pie) $(p=0,022)$, "toser" $(p<0,0001)$, "hociquear" $(p=0,001)$, "lamer" $(p=0,001)$, "vulva contra jaula" $(p=0,01)$.

Se hallaron diferencias significativas entre las hijas de los diferentes machos para el tiempo de duración de las pautas: "de pie" $(p<0,0001)$, "echada ventral" $(p<0,0001)$, "caminar" $(p<0,0001)$, "morder barra o comedero" ( $p=0,0023)$, "empujar lechón" $(p=0,0039)$, “olfatear lechón" $(p=0,0003)$.

En el caso de la pauta "Sentada" las hijas del Y1480 tuvieron mayor frecuencia que las hijas del Y1134, para la pauta "echada ventral" las hijas del Y342 tuvieron mayor frecuencia que las hijas del Y1568, y respecto a la duración las hijas del Y1141 estuvieron más tiempo en esta posición que las hijas de los cerdos Y1568 y Y995. En el caso de "masticar" las hijas de los machos Y1258 y Y1480 tuvieron mayor frecuencia de esta pauta. Para "mirar lateral" presentaron mayor frecuencia de la pauta las hijas de los verracos Y762, Y1141 y Y1480. Las reproductoras descendientes de los padrillos Y1515 y Y1258 realizaron con mayor frecuencia la pauta "meter pata en comedero". Las hijas del Y137 “orinaron" con más frecuencia, las del L1779 tuvieron mayor frecuencia de 
"sentarse", y las de los padrillos Y1515 y Y1258 realizaron con mayor frecuencia la pauta "lamer". Las hijas del Y 762 dedicaron mayor tiempo a “empujar lechón”.

Tabla $n^{\circ} 28$ : Componentes de la varianza para los parámetros productivos

\begin{tabular}{|c|c|c|}
\hline Parámetro productivo & Varianza Genética (\%) & Varianza Ambiental (\%) \\
\hline NT & 6,15 & 93,85 \\
NV & 2,35 & 97,65 \\
NM & 9,79 & 90,21 \\
Dt & 6,01 & 93,99 \\
PN & 26,29 & 73,71 \\
PD & 23,33 & 76,67 \\
IDS & 29,60 & 70,40 \\
\hline
\end{tabular}

En la tabla $n^{\circ} 29$ se observan los valores de heredabilidad en los cuales $h^{2} \neq 0$

Tabla $n^{\circ} 29$ : Estimación de heredabilidades para el tiempo de duración de las conductas

\begin{tabular}{|c|c|c|}
\hline Categoría & Pauta & Heredabilidad \\
\hline Posturas & De pie & 0,31 \\
& Sentada & 0,07 \\
& Echada lateral & 0,51 \\
& Echada ventral & 0,14 \\
& Carpos flexionados & 0,13
\end{tabular}




\begin{tabular}{|ccc|} 
Generales & Caminar & 0,26 \\
& Defecar & 0,42 \\
$\begin{array}{c}\text { De contacto con las } \\
\text { instalaciones }\end{array}$ & Descender tren posterior & 0,16 \\
& Hociquear & 0,1 \\
& $\begin{array}{c}\text { Morder barra o } \\
\text { comedero }\end{array}$ & 0,25 \\
Hacía el lechón & Rascarse contra objeto & 0,62 \\
& Empujar lechón & 0,61 \\
& Olfatear lechón & 0,19 \\
& Hociquear lechón & 0,42 \\
\hline
\end{tabular}

\section{Discusión}

Debido a sus diferentes orígenes y métodos de expansión de este ganado, podemos observar distintos tipos de temperamento en las razas puras, pero a su vez reconocemos la alta frecuencia de cruzamientos interraciales y similitudes en el comportamiento de las principales razas de explotación en nuestro país, gracias a que sus orígenes se han ido entrelazando a lo largo de la historia de domesticación y cría.

Entonces, la conducta que debemos contemplar a la hora de producir ha sido originada por el pasado remoto como silvestres, el pasado próximo como domesticados y la situación actual como cruza entre las distintas razas. Las situaciones de bienestar animal con impacto en la producción son producidas por las diferencias entre el ambiente actual (plasmado en las instalaciones) y el ambiente ancestral de selección; las conductas de las razas responden más al segundo que al primero. 
A pesar que ambas razas de animales tienen el mismo origen o centro de domesticación, como se menciona en los trabajos de Larson y col (2005) y Redivatti (2009), presentaron diferencias entre ellas por categorías de las pautas, las cerdas Landrance dedicaron mayor tiempo a las conductas "de contacto con las instalaciones" que las Yorkshire, pero al examinar conducta por conducta fueron las hembras Yorkshire quienes dedicaron mayor tiempo a "morder barra o comedero", pauta englobada en la categoría antes mencionada.

Las pautas que presentaron diferencias en base a las razas, ponen de manifiesto las distintas formas de acoplar con el ambiente. Una posible interpretación es que difieren en su "estilo" de disminuir el impacto del estrés mediante el comportamiento (coping) (Rayment, 2015), haciendo uso de "coping pasivo" y "coping activo". Esto coincide con lo planteado por Koolhaas y col., (1997) quienes dicen que en la selección de líneas genéticas se evidencia la fuerte base genética del coping. Las diferencias halladas en las conductas entre razas coinciden con lo estudiado por Hohenshell y col (1996) quienes hallaron discrepancias en posturas como arrodillada o sentada entre las líneas genéticas que utilizaron para su análisis y Piedrafita (2002) quien encontró menor reactividad social en cerdos chinos, respecto de razas europeas, coincidiendo que en distintas razas se observarán distintos patrones de conducta. Vaca (2010) y Del Campo (2011) hallaron diferencias en el temperamento entre razas en bovinos. No solo deberá conocerse el comportamiento específico de especie, en las producciones como plantean Salak-Johnson y col (2010) 
sino también el comportamiento de cada raza o línea genética y sus posibles variaciones dentro de cada una de ellas (Stamps y Groothuis, 2010)

Las diferencias halladas en los tiempos y frecuencias de algunas de las pautas de las hijas de diferentes reproductores machos ponen en evidencia, no sólo el control genético de la pauta sino también la importancia de evaluar estas características en los machos seleccionados.

Los resultados manifiestan el impacto del genotipo de los animales en la conducta en contraposición a las corrientes conductivistas del estudio del comportamiento, cuyos referentes principales son Skinner, Watson, y Breland (Grandin, 1998).

Los resultados del análisis de los componentes de la varianza para los parámetros productivos son consistentes con la poca variación que se encuentra en el estudio de líneas puras.

Existen numerosos trabajos realizados estimando heredabilidades para caracteres productivos como peso al nacimiento y al destete, nacidos vivos, etc. (Dude y col, 2012; Galindez y col, 2004; Holl y Robison, 2003). Sin embargo, sólo se encuentran algunos estudios sobre heredabilidades estimadas en distintos tipos de conductas. Goenaga (2010) estimó la heredabilidad para la habilidad materna en cerdas, determinada a partir de la conducta de elaboración del nido, inquietud y otras medidas, en reproductoras alojadas en parideras a campo. Cuyo resultado final fue 0,15 , lo que puede considerarse un valor relativamente bajo, ya que de 
toda la variabilidad observada en las conductas de las hijas de las cerdas, el $15 \%$ es debido a la variación genética de esa población.

Algunos autores (Albores Gallo, 2003; Koolhass, 1997; Stamps, 2010; Champagne, 2009; 2008; y Jensen, 2014) proponen que los genes tienen un alto impacto en la conducta. D’Eath y col (2009) y Hellbrügge (2007) estimaron la heredabilidad para agresión, y ésta fue alta en ambos casos, Hansson (2005) trabajó sobre la heredabilidad del tiempo de huida y lo propuso como un criterio de selección. Esto concuerda con los valores de heredabilidad estimados en las pautas analizadas que permitirían explicar las variaciones observadas dentro de las poblaciones entre las diferentes líneas o razas 


\section{Conclusión}

El etograma permitió la descripción de muchas y variadas pautas de conducta. De su utilización como método para el abordaje del estudio del comportamiento surgen las siguientes conclusiones:

Ha quedado en evidencia la relevancia de la descripción de las 2 etapas del amamantamiento, más allá que no hayan demostrado diferir en cuanto a sus relaciones con factores y/o parámetros productivos, ya que si difirieron en la frecuencia y duración que presentaron. No todos las veces que aparecía la conducta "llamar a mamar" era acompañada de la pauta "amamantando" y es en esta última en la que la eyección de leche ocurría.

Se ha demostrado que las cerdas modifican su conducta dependiendo de la etapa de lactancia, o de la edad de los lechones; de esta manera, se podrán realizar modificaciones en las instalaciones y manejos de los sistemas intensivos confinados que tanto limitan la movilidad de las hembras y llevan a que estas vivan con muy pobre bienestar animal. La disminución en las restricciones de movimiento de las reproductoras comenzó hace unos años, si bien por directivas legales solamente en gestación, es de esperarse que se extiendan a la etapa de lactancia. Dado que transcurridos los primeros diez días de lactancia la hembra comienza a dedicar mayor tiempo a las conductas de contacto con las instalaciones, puede concluirse que a partir de este momento podría permitirse una modificación del espacio destinado a la hembra, con el fin de mejorar su bienestar. Estudios como éste, permiten profundizar el 
conocimiento respecto al comportamiento de las cerdas, y de esta manera poder mejorar el alojamiento de las mismas, sin aumentar el riesgo para sus crías.

Así como se manifestó el efecto de factores internos de los galpones, también, se resalta la importancia de contemplar los factores externos, como tránsito de personal, vehículos de carga y descarga de alimentos, y ubicación de la planta de procesamiento de los mismos. Debe tenerse en cuenta al momento del manejo de los animales, como así también en el diseño de ensayos que se lleven a cabo en las explotaciones el concepto del mundo perceptual y propio de cada especie. Son innumerables los estímulos que el humano no percibe, y en consecuencia no incluye en el análisis de cualquier tipo de evaluación (rendimiento productivo, respuesta a diseños experimentales, etc).

Hecho conocido empíricamente es el que las hembras de primeros partos constituyen un factor de riesgo en sí mismas para los lechones. Durante las rutinas de manejo diarias son observadas quizás más cuidadosamente en las granjas estándar. Los resultados demostraron las diferencias en los patrones de conducta de las cerdas de primeros partos respecto de las multíparas, en concordancia con las teorías sobre cómo la experiencia moldea los comportamientos, relacionándose de esta manera con la explicación de la conducta desde la ontogenia (segunda pregunta de Tinbergen). 
La clasificación de las pautas en las categorías con las que se trabajó en este estudio, permitió resaltar las relaciones de distintos parámetros productivos con las conductas que la hembra realizó hacia las instalaciones. Estas últimas podrían verse modificadas al disminuir las restricciones de movimiento de las reproductoras.

De la observación de las diferencias en el comportamiento entre hermanas biológicas criadas por sus propias madres y las que fueron separadas al nacer de sus progenitoras y sus hermanas de camada, se puede concluir el alto impacto sobre la expresión de las conductas de celo y la gestación de las crías. Esto permite asumir que descendientes de madres que serán tenidas en cuenta para la reposición deberían ser criadas por sus propias madres. De esta manera se abordaron los factores ambientales, principalmente, los correspondientes a la crianza, enmarcados en el aprendizaje, entendiendo a éste como toda interacción con el ambiente que tenga como consecuencia la modificación de la conducta.

Con el fin de desglosar los factores no ambientales, o genéticos, se sometieron al contraste las razas de los animales, los padres y las madres de las cerdas estudiadas en los diferentes ensayos realizados.

Al hallar diferencias en las categorías de las conductas y las mismas estudiadas por separado, respecto a las razas, quedó en evidencia la importancia de la realización de ambos análisis. Las diferencias entre razas muestran la base genética del coping, lo que demarca las distintas 
formas que tienen las líneas genéticas de acoplar con el ambiente. Por esta razón debería considerarse un manejo diferencial según raza y/o línea.

Las diferencias halladas en las conductas de las hijas de diferentes cerdos resalta la importancia de considerar la influencia del padre al momento de realizar los cruzamientos. Pruebas de progenie que incluyan el estudio de factores comportamentales en las hijas permitirán mejorar la productividad en la descendencia.

Si bien la heredabilidad varía para cada población, se asume que un carácter tan relacionado con la interacción con el medio tuviera bajas heredabilidades. Sin embargo algunas de las pautas mostraron valores de variancia genética que permiten esperar una respuesta a la selección a partir de planes de mejora.

Para finalizar, si bien mejorar el bienestar animal de las cerdas ya es en sí mismo una motivación para permitir la expresión de las conductas específicas de especie, las relaciones halladas con los parámetros utilizados para evaluar la productividad de los animales, y en consecuencia, la eficiencia global de las explotaciones, destacan la importancia del estudio del comportamiento de los animales como potencial indicador de rendimiento del sistema. Un ejemplo de esta relación es que a menor cantidad de nacidos vivos mayor será la inversión de tiempo en interactuar con las instalaciones, lo que conduce al deterioro de las mismas. Se establecieron también relaciones con el 
retorno al celo, parámetro directamente asociado con los días no productivos de un animal.

Esta última variable estudiada estuvo relacionada positivamente con la presentación de una pauta asociada en otros casos con un pobre bienestar, hecho que remarca nuevamente la asociación del bienestar animal con la eficacia productiva de los animales.

Y por último, pero no menos importante, se hallaron asociaciones de las conductas con la mortalidad de los lechones, uno de los principales motivos de pérdidas económicas, y de los fundamentos para las restricciones de movimiento de las cerdas. En este estudio, a mayor dedicación de conductas de interacción con lechones, y ciertas posturas corporales, menor mortalidad de la cría. A su vez, no solo se concluyó sobre la mortalidad por aplastamiento, sino también por inanición, causa de muerte relacionada con el acoplamiento o interacción entre los lechones y su madre. De esta forma se enfatiza en la importancia del conocimiento del comportamiento de las cerdas con el fin de prevenir esta importante pérdida por mortalidad. Deben proponerse modificaciones en las instalaciones teniendo en cuenta cuales son las conductas de más alto riesgo en las poblaciones de estudio. 


\section{Bibliografía}

1. Abeledo C.M, Guerra D, González D, GutiérrezM, Santana I, Diéguez F.J., Hernández S, Camino Y, Ramírez M y Brache F. Aplicación en cerdos de la modelación matemática de caracteres con influencia materna. Revista Computadorizada de Producción Porcina 2010. Volumen 17 (número 1) 44-47

2. Albiach-Serrano A, Bräuer J, Cacchione $T$, Zickert N, Amici F. The effect of domestication and ontogeny in swine cognition (Sus scrofa scrofaand S. s. domestica). Applied Animal Behavior Science. 2012. 141:25-35. doi: 10.1016/j.applanim.2012.07.005

3. Albores-Gallo L, Marquez-Caraveo M.A, Español B. ¿Qué es el temperamento? El retorno de un concepto ancentral. Salud Mental, Vol. 26, No. 3. 16-26.

4. Alcock J. Proximate and ultimate causes of behavior: how and why birds sing. En: Animal behavior. An evolutionary approach. (7a ed). 2001. Massachusetts. Sinauer Associates, Inc., pp. 2349.

5. Algers B. Nursing in pigs: communicating needs and distributing resources. J Anim Sci. 1993;71(10):2826-31.

6. Algers B, Uvnäs-Moberg K. Maternal behavior in pigs. Horm Behav. 2007;52(1):78-85.

7. Altmann J. Observational study of behavior: sampling methods. Behavior 1974; vol 49, parts 3-4, pp 227-267 
8. Arey DS, Sancha ES. Behaviour and productivity of sows and piglets in a family system and in farrowing crates. Appl Anim Behav Sci. 1996;50(2):135-45.

9. Arroyo P, Ferrari H.R, Antonini A.G. Bienestar Animal de hembras reproductoras porcinas. Veterinaria Argentina. 2016. $33(333): 1-11$

10. Arroyo P, Ferrari H.R, Antonini A.G. Estudio del comportamiento porcino: Una mirada etológica sobre la producción porcina. ANALECTA VET 2018; 38(1): 23-32

11. Barnard C. Ethical regulation and animal science: why animal behaviour is special. Anim Behav. 2007;74(1):5-13.

12. Barnett JL, Hemsworth PH, Cronin GM, Jongman EC, Hutson GD. A review of the welfare issues for sows and piglets in relation to housing. Aust J Agric Res. 2001;52(1):1-28.

13. Bates RO, Edwards DB, Korthals RL. Sow performance when housed either in groups with electronic sow feeders or stalls. Livest Prod Sci. 2003;79(1):29-35.

14. Baxter MR. Ethology in environmental design for animal production. Applied Animal Ethology. 1983. 9:20720. doi: 10.1016/03043762(83)900019

15. Benson G, Rollin, B. Theoretical framework. En: The well being of farm animal, challenges and solutions. First edition. 2004. Blackwell Publishing. EE.UU, pp. 3179. 
16. Broom DM. 3. 142, 524 Indicators of Poor Welfare D. M. Broom*. 1986;1986.

17. Broom DM. Animal welfare: concepts and measurement . D M Broom J ANIM SCI 1991, 69: 4167-4175. The online version of this article, along with updated information and services, is located on the World Wide Web at: ANIMAL WELFARE: CONCEPTS AND MEASUREMENT' ' 3. 1991;4167-75.

18. Broom DM. A History of Animal Welfare Science. Acta Biotheor. 2011;59(2):121-37.

19. Capitelli GM, Ferrari HR, López H. Introducción a la medicina veterinaria Darwiniana. Aplicaciones de la teoría de la evolución en la práctica veterinaria. Vaccinología, zoonosis y bienestar animal como ejemplos de aplicación. Revista de Medicina Veterinaria (Buenos Aires). 2010. 91:(5/6)715.

20. Cardellino R, Rivera J. Capítulo 13: Cruzamientos. En: Mejoramiento genético animal. Editorial Agropecuaria Hemisferio Sur S.R.L. 1987. Montevideo. Uruguay.

21. Champagne FA. Maternal imprints and the origins of variation. Horm Behav [Internet]. 2011;60(1):4-11. Available from: http://dx.doi.org/10.1016/j.yhbeh.2011.02.016

22. Champagne FA. Epigenetic mechanisms and the transgenerational effects of maternal care. Front Neuroendocrinol. 2008;29(3):386-97. 
23. Champagne FA, Curley JP. Epigenetic mechanisms mediating the long-term effects of maternal care on development. Neurosci Biobehav Rev. 2009;33(4):593-600.

24. Chidgey KL, Morel PCH, Stafford KJ, Barugh IW. The performance and behaviour of gilts and their piglets is influenced by whether they were born and reared in farrowing crates or farrowing pens. Livest Sci. 2016;193(December 2015):51-7.

25. Close, W.H.B., The role of feeding and management in enhancing sow reproductive potential. Proceeding of the London Swine Conference - Maintaining Your Competitive Edge 9 - 10 April 2003, p 25-36

26. Consejo de la Unión Europea. Directiva 2001/88/CE

27. Consejo de la Unión Europea. Directiva 2001/93/CE

28. Consejo de la Unión Europea. Directiva 91/633/CEE

29. Consejo de la Unión Europea. Directiva 2008/120/CE

30. Cronin G M, Leeson E, Cronin J G, Barnet J L . The effect of broadcasting sow suckling grunts in the lactation shed on piglet growth. Asian Australasian journal of animal science, 2001; 14 (7), 1019-1023. [Online]

31. Curio E. Causal and functional questions: how are they linked? Animal Behaviour. 1994. 47:999-1021. doi: 10.1006/anbe.1994.1139 
32. Cuthill I.C, Ethical regulation and animal science: why animal behaviour is not so special. ANIMAL BEHAVIOUR, 2007, 74, 15-22 doi:10.1016/j.anbehav.2007.04.003

33. D'Eath RB, Roehe R, Turner SP, Ison SH, Farish M, Jack MC, et al. Genetics of animal temperament: Aggressive behaviour at mixing is genetically associated with the response to handling in pigs. Animal. 2009;3(11):1544-54.

34. Del Campo M. Temperamento-Bienestar Animal- Calidad de producto. INIA. 2011; 24, 11-17.

35. Dewsbury DA. The proximate and the ultimate: past, present, and future. Behavioural Processes. 1999. 46:189-99.

36. Drake A, Fraser D, Weary DM. Parent-offspring resource allocation in domestic pigs. Behav Ecol Sociobiol. 2008;62(3):309-19.

37. Dohoo, I. R., Martin, W., \& Stryhn, H. Veterinary epidemiologic research (No. V413 DOHv). Charlottetown, Canada: AVC Incorporated. (2003).

38. Dostalkova W, Spinkaz M, Kindlmann P. Begging for milk: evolution of teat massaging in suckling pigs. Journal of Theoretical Biology. 2002. 215:321-32. doi: 10.1006/jtbi.2001.2511

39. Dube B, Mulugeta SD, Dzama K. Estimation of genetic and phenotypic parameters for sow productivity traits in south african large white pigs. South African J Anim Sci. 2012;42(4):389-97. 
40. Duncan IJ. DGM WoodGush Memorial Lecture: An applied ethologist looks at the question "Why?". Applied Animal Behaviour Science. $1995 . \quad 44(24)$ 205-17. doi: $10.1016 / 01681591(95) 00614 X$

41. Fajardo-Castillo D.S. Evaluación de dos sistemas de instalaciones y manejo para la etapa de lactancia, comparando la producción porcina tradicional vs la producción al aire libre. Tesis de grado. Universidad de La Salle Facultad de Zootecnia. Bogotá, D.C. 2009.

42. Finlay B, Hinz F, Darlington R. Mapping behavioral evolution onto brain evolution: the strategic roles of conserved organization in individuals and species. Philosophical Transactions of the Royal Society B. 2011. 366:2111-23. doi: $10.1098 /$ rstb.2010.0344

43. Francis D. Nongenomic Transmission Across Generations of Maternal Behavior and Stress Responses in the Rat. Science (80- ) [Internet]. 1999;286(5442):1155-8. Available from: http://www.sciencemag.org/cgi/doi/10.1126/science.286.5442.1 155

44. Fraser D, Krames DL, Pajor EA, Weary DM. Conflict and cooperation: sociobiological principles and the behaviour of pigs. Applied Animal Behavior Science. 1995. 44:13957. doi: 10.1016/01681591(95)006105 
45. Fraser D, Rushen J. Calostrum intake by newborn pigs. Canadian Journal of Animal Sciences. 1992. 113. doi: $10.4141 /$ cjas 92001

46. Fraser D, Thompson BK. Armed sibling rivalry among suckling piglets. Behavioral Ecology and Sociobiology. 1991. 29:915.

47. Fraser D. Animal welfare and the veterinary profession: 50 years of change. $2010 ; 7-10$.

48. Fraser D. Animal behaviour, animal welfare and the scientific study of affect. Appl Anim Behav Sci. 2009;118(3-4):108-17.

49. Fraser D. Animal ethics and animal welfare science: Bridging the two cultures. Appl Anim Behav Sci. 1999;65(3):171-89.

50. Galindez R, Verde O, Martinez G. Parámetros genéticos para sobrevivencia al nacer en porcinos. 2004. Zootecnia Tropical 22(3):191-200.

51. García-Munguía CA, Ruíz-Flores A, López-Ordaz R, GarcíaMunguía AM, Ibarra-Juárez LA. Comportamiento productivo y reproductivo al parto y al destete en cerdas de siete líneas genéticas. Rev Mex Ciencias Pecu. 2014;5(2):201-11.

52. Goenaga P. Comportamiento materno de la cerda y sus implicancias en la producción. Sitio argentino Prod Anim [Internet]. 2010;1-20. Available from: http://www.produccionanimal.com.ar/produccion_porcina/00produccion_porcina_general/154-Comportamiento_materno.pdf 
53. González JSG, Lozano MAH, Gustavo R, Gamba M. Efecto del número de parto de la cerda, la caseta de parición, el tamaño de la camada y el peso al nacer en las principales causas de mortalidad en lechones. Rev Mex Ciencias Pecu. 2011;2(4):403-14.

54. Grandin Temple y Mark J. Deesing. La genetic del comportamiento animal. Depto. de Ciencia Animal, Colorado State University, Fort Collins, Colorado 80523-1171 Publicado en: Temple Grandin (comp.), Genetics and the Behavior of Domestic Animals, San Diego, California: Academic Press, 1998 (Cap. 1) y en www.grandin.com Traducción del Dr. Marcos Giménez Zapiola

55. Grandin T. Livestock behavior as related to handling facility design. International Journal for the Study of Animal Problems. 1980. 1:33-52.

56. Grandin T. La transferencia de resultados de investigación del comportamiento al sector productivo para mejorar el bienestar animal en el campo y en la planta de faena. D.G.M. Wood-Gush Memorial Lecture, 35th International Congress of the International Society of Applied Ethology, Davis, California. Depto. de Ciencia Animal, Colorado State University, Fort Collins, Colorado, EE.UU. 2001. Traducción: Dr. Marcos Giménez-Zapiola www.produccion-animal.com.ar 
57. Gomez B, Ortega R, Becerril J. Factores que contribuyen en la variación de la camada en peso al nacimiento y el número de lechones destetados de líneas y cruces maternos porcinos. Revista Computadorizada de Producción Porcina 2009. Vol 16 (4): $239-245$

58. Hansson AC, Crump RE, Graser HU, Sokolinski R. Relationships among temperament and production traits of pigs. InProceedings of the Association for the Advancement of Animal Breeding and Genetics 2005 (Vol. 16, p. 141).

59. Hartog L a Den, Backus GB, Vermeer HM, Backus GBC. Evaluation of housing systems for sows Evaluation of Housing Systems for Sows'. 1993;1339-44.

60. Hartsock TG, Graves HB. Neonatal behavior and nutrition related mortality in domestic swine. Journal of Animal Science. 1976. 42(1):235-41.

61. Hellbrugger B. Genetic aspect of piglet losses and the maternal behaviour of sows. Dr Thesis [Internet]. 2007; Available from: http://www.tierzucht.unikiel.de/dissertationen/diss_hellbruegge.p df

62. Hemsworth P.H. Cap II: Human-Livestock Interaction. En: The well-being of farm animals. Challenge and solutions. Blackwell puplishing. 2004.

63. Hernández A. Conducta de la cerda doméstica y su camada behavior of domestic sow and her litter. Abanico Vet [Internet]. 
2014;4(1):51-60.

Available

from:

http://www.medigraphic.com/pdfs/abanico/av-2014/av141f.pdf

64. Hesse, A. and D. Hesse, Feed sows automatically to fitness. Bauförderung Agriculture, 2006. online, 1-5

65. Hodges J. Culture, values and ethics of animal scientists. Livest Sci. 2006;103(3):263-9.

66. Hogan JA. A framework for the study of behavior. Behavioral Processes. 2015. 117:10513. doi: 10.1016/j.beproc.2014.05.003

67. Hohenshell LM, Minick JA, Lay Jr DC, Ford SP. Maternal behavior potentially affecting offspring survivability: a comparison between Meishan and Yorkshire $\mathrm{X}$ Landrace $(\mathrm{YL})$ sows. Swine Research Report. IOWA State University 1996. Disponible en: http://lib.dr.iastate.edu/ swinereports [Consultado 01/01/2017].

68. Holl JW, Robison OW. Results from nine generations of selection for increased litter size in swine The online version of this article, along with updated information and services, is located on the World Wide Web at: Results from nine generations of selection for increased. 2003;624-9.

69. Hoy JM, Murray PJ, Tribe A. Thirty years later: enrichment practices for captive mammals. Zoo Biology 2010. 29:30316. doi: $10.1002 /$ zoo.20254 
70. Hughes B, Duncan I. The notion of ethological 'need', models of motivation and animal welfare. Animal Behavior. 1988. 36:1696-707. doi: 10.1016/S00033472(88)801106

71. Illman G, Pokorná Z, Spinka M. Allosuckling in domestic pigs: teat acquisition strategy and consequences. Applied Animal Behavior Science. 2007. 106:2638. doi: 10.1016/j.applanim.2006.06.012

72. Jensen P. Behaviour epigenetics - The connection between environment, stress and welfare. Appl Anim Behav Sci [Internet]. 2014;157:1-7. Available from: http://dx.doi.org/10.1016/j.applanim.2014.02.009

73. Jensen P. Observation of maternal behaviour of freeranging domestic pigs. Applied Animal Behavior Science. 1986. 16:13142. doi: $10.1016 / 01681591(86) 90105 X$

74. Jensen P. Nest building in domestic sows: the sole of external estimuli. Animal Behavior. 1993. 45(2):3518.

75. Jensen, P. Comportamiento del cerdo. Etología de los animales domésticos. Zaragoza, España. Jensen (Editor), Editorial Acribia, 2004. pp. 168-84.

76. Jensen $P$, Toates F. Who needs 'behavioural needs'? Motivational aspects of the needs of animals. Applied Animal Behavior Science. $1993 . \quad 37: 161-81$. doi: $10.1016 / 01681591(93) 901082$ 
77. Kim H. Genetic Parameters for Productive and Reproductive Traits of Sows in Multiplier Farms by. 2001;(July).

78. Koolhaas JM, Korte SM, De Boer SF, Van Der Vegt BJ, Van Reenen CG, Hopster H, et al. Coping styles in animals: Current status in behavior and stress- physiology. Neurosci Biobehav Rev. 1999;23(7):925-35.

79. Korte SM, Koolhaas JM, Wingfield JC, McEwen BS. The Darwinian concept of stress: Benefits of allostasis and costs of allostatic load and the trade-offs in health and disease. Neurosci Biobehav Rev. 2005;29(1 SPEC. ISS.):3-38.

80. Lakatos I. "La metodología de los programas de investigación científica". Madrid. Alianza Editorial. 1983.

81. Larson G. Worldwide phylogeography of wild boar reveals multiple centers of pig domestication. Science. 2005. 307:1618. doi: 10.1126/science.1106927

82. Lassen J, Sandøe P, Forkman B. Happy pigs are dirty! conflicting perspectives on animal welfare. Livest Sci. 2006;103(3):221-30.

83. Lawrence AB. Applied animal behaviour science: Past, present and future prospects. Appl Anim Behav Sci. 2008;115(1-2):124.

84. Lahitte HB, Ferrari HR, Lázaro L. Sobre el etograma, 1: del etograma como lenguaje al lenguaje de los etogramas. Revista de Etología. 2002 Dec;4(2):129-41. 
85. Lahitte, H; Ferrari, H; Lázaro, L. Etogramática. Teoría y Práctica de la descripción en ciencias del comportamiento. Editorial Nobuko. ISBN 987-584-026-2 (2005).

86. Lorenz K. The companion in the bird's world. The Auk. 1937. $54: 24573$.

87. Lorenz K. Etología comparada. El comportamiento instintivo en la filogenia. En: Biología del comportamiento. Ciudad de México; Siglo XXI Editores, 1974. pp. 718.

88. Lorenz, K. La percepción de la forma como fuente del conocimiento de causas científico, en Consideraciones sobre la conducta animal y humana, Colección Obras maestras del pensamiento contemporáneo, vol. 28, Planeta-Agostini. Barcelona, España. 1959.

89. Lorenz, K. La otra cara del espejo. Plaza \& Janes. 1995.

90. Marie M. Ethics: The new challenge for animal agriculture. Livest Sci. 2006;103(3):203-7.

91. Medina MG, Segura JCC, Rodríguez JCB. Efecto de año, bimestre y número de parto de la cerda en el tamaño y peso de la camada al nacer y al destete en una granja comercial. Rev Biomed. 1999;10(1):23-8.

92. MeunierSalaün MC, Gort F, Prunier A, Schouten WPG. Behavioral patterns and progesterone, cortisol and prolactin levels around parturition in European (Large White) and 
Chinese (Meishan) sows. Applied Animal Behavior. Science. 1991. 31:4359. doi: 10.1016/01681591(91)90152N

93. Murillo Galan C, Herradora Lozano M.A, Martinez Gamba M. Relación entre la pérdida de grasa dorsal de Cerdas Lactantes con el consumo de alimento, tamaño de la camada, peso de los Lechones al destete y días de Lactancia. Rev. Cien. Maracaíbo. 2007; 17 (4): 1-14.

94. Mysterud I. Niko Tinbergen's life and work: A new approach to biology. Soc Sci Inf. 2007;46(3):543-53.

95. Nacipucha P.K.C. Bienestar del lechón en la fase de lactanción. Tesis doctoral. Facultad de veterinaria. Universidad de Murcia. 2014.

96. Nisbett, A. Lorenz. Salvat Editores. Barcelona. España. 1993.

97. Orihuela A, Solano JJ. Managing "teat order" in suckling pigs (Sus scrofa domestica). Applied Animal Behavior Science. 1995. 46:12530. doi: 10.1016/01681591(95)006397

98. Piedrafita J, Manteca X. Mejora genética del comportamiento y del bienestar del ganado rumiante. Revista ITEA. 2002.

99. Pilkonis, P.A. Shyness, public and private, and its relationship to other measures of social behaviour. Journal of Personality, (1977). 45, 585-595.

100. Rayment DJ, De Groef B, Peters RA, Marston LC. Applied personality assessment in domestic dogs: Limitations and 
caveats. Appl Anim Behav Sci [Internet]. 2015;163:1-18. Available from: http://dx.doi.org/10.1016/j.applanim.2014.11.020 101. Revidatti M. Caracterización de cerdos criollos del nordeste argentino. Tesis doctoral, Universidad de Córdoba, España. 2009.

102. Rushen J, De Passillé A.M, von Keyserlingk M.A.G, Weary D.M. Cap 1. En: The Welfare of cattle. Vol 5. Ed. Springer. Holanda. 2008.

103. Rodezno Arita J.A. Identificación y reducción de factores asociados a la mortalidad en lechones lactantes, en granja porcina. Proyecto especial presentado como requisito parcial para optar al título de Ingeniero Agrónomo en el grado Académico de Licenciatura. Zamorano. Honduras. 2007.

104. Salak-Johnson J, Cassady J, Wheeler M.B, Johnson A. Cap. II. En: Guide for the care and use of Agricultural Animals in Research and teaching. $3^{\text {rd }}$ edition. Federation of Animal Science Societies. 2010.

105. Segales J, Domingo M. La necropsia en el ganado porcino. Diagnóstico anatomopatológico y toma de muestra. Ed. Barcelona Boehringer Ingelheim. España. 2004.

106. Séguin M, Barney D, Widowski T. group-housing system for gestating sows: Effects of space allowance and pen size on the incidence of superficial skin lesions, changes in body condition, 
and. J swine Heal Prod [Internet]. 2006;14(2):89-96. Available from: http://www.aasp.org/shap/issues/v14n2/v14n2p89.html

107. Siwerdt F, Cardellino N.A, Costa da Rosa, V. Genetics parameters of litter traits in three pig breeds in southern Brazil. Rev. Brasil. Genet. 1995. 18 (2): 199-205

108. Skinner B. Sobre el conductismo. Título del original: About behaviourism. Publicado por Alfred A Knopf, New York. USA. Traducción Fernando Barrera. Ed PlanetaDe Agostini Mexico DFD. 1974.

109. Smulders D, Verbeke G, Mormède P, Geers R. Validation of a behavioral observation tool to assess pig welfare. Physiol Behav. 2006;89(3):438-47.

110. Špinka M, Algers B. Functional view on udder massage after milk let-down in pigs. Appl Anim Behav Sci. 1995;43(3):197212.

111. Špinka M, Illmann G, Haman J, Šimeček P, Šilerová J. Milk ejection solicitations and non-nutritive nursings: An honest signaling system of need in domestic pigs? Behav Ecol Sociobiol. 2011;65(7):1447-57.

112. Stamps J. Behavioral processes affecting development: Tinbergen's fourth question comes of age. Animal Behavior. 2003. 66(1):113. doi: 10.1006/anbe.2003.218 
113. Stamps J, Groothuis TGG. The development of animal personality: Relevance, concepts and perspectives. Biol Rev. 2010;85(2):301-25.

114. Suwanasopee T, Mabry JW, Koonawootrittriron S. Estimated Genetic Parameters of Non-Productive Sow Days Related to Litter Size in Swine Raised in Thailand. 2005;38:87-93.

115. Tinbergen N. On the analysis of social organization among vertebrates, with special references to birds. The American Naturalist. 1939. 21:21034.

116. Tinbergen N. "On aims and methods of ethology." Zeitschrift für Tierpsychologie. 1963. 20:410-33.

117. Tinbergen $\mathrm{N}$. El estudio del instinto. $10^{\circ}$ edición. Ciudad de México; Siglo XXI editores. 1981.

118. Thorpe $\mathrm{WH}$. The assessmentt of pain and distress in animals. En: Report of the Technical Committee to enquire into de welfare of animals kept under intensive livestock systems (F.W.R. Brambell). HMSO, London. UK. 1965.

119. Thorpe WH. Breve historia de la etología. Vol 902. Madrid, España; Alianza Editorial. 1982.

120. Vaca RJA. Temperamento y Bienestar. Efecto sobre la producción de bovinos de carne. Analecta Veterinaria. 2010. 30 (2): $74-81$ 
121. Veissier I, Butterworth A, Bock B, Roe E. European approaches to ensure good animal welfare. Appl Anim Behav Sci. 2008;113(4):279-97.

122. Weary DM, Pajor EA, Fraser D, Honkanen AM. Sow body movements that crush piglets: A comparison between two types of farrowing accommodation. Appl Anim Behav Sci. 1996;49(2):149-58.

123. Weary DM, Phillips PA, Pajor EA, Fraser D, Thompson BK. Crushing of piglets by sows: Effects of litter features, pen features and sow behaviour. Appl Anim Behav Sci. 1998;61(2):103-11.

124. Wechsler B, Hegglin D. Individual differences in the behaviour of sows at the nest-site and the crushing of piglets. Appl Anim Behav Sci. 1997;51(1-2):39-49.

125. Wemelsfelder F, Hunter EA, Mendl MT, Lawrence AB. The spontaneous qualitative assessment of behavioural expressions in pigs: First explorations of a novel methodology for integrative animal welfare measurement. Appl Anim Behav Sci. 2000;67(3):193-215.

126. Wemelsfelder F. The scientific validity of subjective concepts in models of animal welfare. Appl Anim Behav Sci. 1997;53(12):75-88. 
127. Wemelsfelder F, Hunter TEA, Mendl MT, Lawrence AB. Assessing the "whole animal": A free choice profiling approach. Anim Behav. 2001;62(2):209-20.

128. Wiepkema PR. Behavioral aspects of stress. En: Wiepkema PR; van Adrichem PWM (Editors). Biology of stress in farm animals: an integrative approach. Martinus Nijhoff, Dordrecht. 11333. 1987.

129. Williams S. Influencia que la estructura social y el comportamiento sexual de los lechones ejercen sobre las futuras cerdas primiparas. Tesis doctoral. Facultad de Ciencias Veterinarias. Universidad Nacional de La Plata. 2004 